\author{
UNIVERSIDADE DE SÃO PAULO \\ ESCOLA DE ENFERMAGEM DE RIBEIRÃO PRETO
}

LETÍCIA PIMENTA LOPES

Staphylococcus aureus em profissionais de enfermagem e as interfaces com a adesão às precauções-padrão

Ribeirão Preto

2015 


\section{Staphylococcus aureus em profissionais de enfermagem e as interfaces com a adesão às precauções-padrão}

Tese apresentada à Escola de Enfermagem de Ribeirão Preto da Universidade de São Paulo, para obtenção do título de Doutor em Ciências, Programa de Pós-Graduação em Enfermagem Fundamental.

Linha de pesquisa: Doenças Infecciosas: problemática e estratégias de enfrentamento

Orientadora: $\operatorname{Prof}^{\mathrm{a}}{ }^{\mathrm{Dr}}{ }^{\mathrm{a}}$ Elucir Gir

Ribeirão Preto 
Autorizo a reprodução e divulgação total ou parcial deste trabalho, por qualquer meio convencional ou eletrônico, para fins de estudo e pesquisa, desde que citada a fonte.

Lopes, Letícia Pimenta

Staphylococcus aureus em profissionais de enfermagem e as interfaces com a adesão às precauções-padrão. Ribeirão Preto, 2015.

142 p.: il.; $30 \mathrm{~cm}$

Tese de Doutorado, apresentada à Escola de Enfermagem de Ribeirão Preto/USP.

Orientadora: Gir, Elucir.

1. Staphylococcus aureus. 2. Resistência à meticilina. 3. Enfermagem. 4. Precauções-Padrão. 
LOPES, Letícia Pimenta

Staphylococcus aureus em profissionais de enfermagem e as interfaces com a adesão às precauções-padrão

Tese apresentada à Escola de Enfermagem de Ribeirão Preto da Universidade de São Paulo, para obtenção do título de Doutor em Ciências, Programa de Pós-Graduação em Enfermagem Fundamental.

Aprovado em:

Comissão Julgadora

Prof. Dr.

Instituição: Assinatura:

Prof. Dr.

Instituição: Assinatura:

Prof. Dr.

Instituição: Assinatura:

Prof. Dr. Instituição: Assinatura:

Prof. Dr. Instituição: Assinatura: 


\section{DEDICATÓRIA}

Dedico este trabalho a todos os profissionais de enfermagem que se dedicam ao cuidar do próximo, com carinho, compromisso, responsabilidade e amor pela profissão. 


\section{AGRADECIMENTOS ESPECIAIS}

A Deus, por estar sempre presente em minha vida e por me proporcionar infinitas bênçãos.

Ao meu esposo Danilo, por todo amor, carinho, compreensão, dedicação e paciência. Obrigada por sempre estar ao meu lado e por me apoiar em todas as situações. A você, todo meu amor hoje e sempre.

Aos meus pais Saul (in memorian) e Claudete, por todo apoio e amor incondicional. Obrigada por me incentivarem a prosseguir na jornada, independentemente dos obstáculos no caminho. A eles, minha eterna gratidão.

Aos meus queridos irmãos, Glauco, Kírian e Marcelo, sogro, sogra e cunhados, pelo carinho, pelo apoio, pela compreensão e pelo incentivo nesta caminhada.

À Prof ${ }^{a}$ Dr $^{a}$ Elucir Gir, pela orientação, pela dedicação, pela compreensão, pela confiança e pelos conhecimentos transmitidos. Muito obrigada pelos anos de convivência e por toda confiança depositada em mim. A você, meu respeito, carinho e consideração pelo exemplo de pessoa e de profissional. 


\section{AGRADECIMENTOS}

À Prof ${ }^{a}$ Dr $^{a}$ Sílvia Rita Marin da Silva Canini e Dra Miyeko Hayashida, pelo apoio, pelo incentivo e pela contribuição com seus conhecimentos no exame de qualificação.

Ao Prof. Dr. Roberto Martinez, coordenador do Laboratório de Microbiologia do Hospital das Clínicas da Faculdade de Medicina de Ribeirão Preto-USP e a toda a equipe, em especial à Lucélia Pereira pelas contribuições e pela realização das análises laboratoriais.

A toda a equipe da $\mathrm{CCIH}$, pelo apoio, pelo envolvimento e pelo comprometimento no desenvolvimento desta pesquisa. Em especial, ao Dr. Fernando Bellíssimo, ao Dr. Gilberto Gaspar e às enfermeiras Ana Elisa Ricci, Jucélia Alves, Mayra Menegueti e Magda Silva.

À Divisão de Enfermagem do Hospital das Clínicas da Faculdade de Medicina de Ribeirão Preto-USP por autorizar a realização da pesquisa.

A todos os profissionais de enfermagem que participaram do estudo, muito obrigada pelo acolhimento, pela disponibilidade e pela colaboração em cada uma das etapas.

Aos amigos do NAIDST, pelo incentivo, pela amizade, pelos conhecimentos e pelas experiências compartilhadas. Em especial, Lilian Reinato, Daiana Pio, Fernanda Pereira, Natália Pereira, Silmara Malaguti, Rosilane Magalhães, Juliano Caliari e Maria Cristina Almeida.

À Fernanda Maria Vieira Pereira, pela amizade, pelo incentivo, pela dedicação e pela colaboração em várias etapas deste estudo, principalmente na análise e organização dos dados.

A João Paulo de Freitas, Cibele Souza, Marcella Rigobello e Vanessa Castanha pela contribuição e pelo auxílio na coleta de dados.

Aos amigos do $6^{\circ}$ andar do Hospital das Clínicas da Faculdade de Medicina de Ribeirão Preto-USP, em especial, Rosângela Bernardes, Rosa Gonçalves, Sheila Hermann, Maria Cristina Lopes, Sérgio Gomes e Rosângela Martins, com quem eu tive o prazer de trabalhar por cinco anos e de compartilhar muitas experiências e conhecimentos. Muito obrigada por todo o apoio e incentivo ao longo desses anos e pela amizade que construímos.

Aos meus amigos e colegas de trabalho do Hospital das Clínicas da Universidade Federal do Triângulo Mineiro, muito obrigada pela amizade e pelas palavras de incentivo para a conclusão desta pesquisa. 
Aos amigos que sempre me apoiaram e estiveram presentes nesta caminhada, cujos nomes prefiro não citar para não cometer injustiças. A todos, meu imenso carinho e admiração.

À Escola de Enfermagem de Ribeirão Preto - USP, aos funcionários e docentes pela contribuição em meu desenvolvimento profissional. 
"O sucesso nasce do quever, da determinação $e$ persistêncía em se chegar a um objetivo. Mesmo não atingindo o alvo, quem busca e vence obstaculos, no minimo fara coisas admiraveis" 


\section{RESUMO}

LOPES, L.P. Staphylococcus aureus em profissionais de enfermagem e as interfaces com a adesão às precauções-padrão. 2015. 142 f. Tese (Doutorado) Escola de Enfermagem de Ribeirão Preto, Universidade de São Paulo, Ribeirão Preto, 2015.

Introdução: Staphylococcus aureus é um importante patógeno responsável por diversas infecções no ambiente hospitalar com elevada morbi-mortalidade. Os profissionais de saúde, sobretudo os de enfermagem, apresentam elevado risco de colonização por meio do contato direto com indivíduos suscetíveis ou pelo contato com fômites em suas atividades laborais. Com isso, esses profissionais podem disseminar esses microrganismos tanto no ambiente hospitalar como na comunidade. Objetivo: Avaliar a colonização por Staphylococcus aureus em profissionais de enfermagem e a adesão às precauções-padrão. Metodologia: Trata-se de um estudo transversal realizado em clínica médica e em unidades especializadas em prestação de cuidados a pessoas com HIV/aids de um hospital escola do município de Ribeirão Preto. A população foi composta por 100 profissionais de enfermagem que prestam cuidados direto aos pacientes dessas unidades. Foram coletadas amostras de saliva, de secreção nasal e um swab do telefone celular dos profissionais. A coleta ocorreu no período de abril de 2014 a fevereiro de 2015, em três momentos, nos meses zero, quatro e oito. A obtenção dos dados demográficos, profissionais e individuais foi feita por meio de um questionário estruturado. Para avaliar a adesão dos profissionais às precauções-padrão, foram aplicadas dez escalas psicométricas do tipo Likert, já traduzidas e validadas para o português. As amostras coletadas foram encaminhadas e processadas pelo Laboratório de Microbiologia e Sorologia do referido hospital. Resultados: Dos 100 profissionais de enfermagem, 43,0\% estavam colonizados por Staphylococcus aureus nas amostras de saliva e/ou de secreção nasal; 36,0\% eram Staphylococcus aureus sensível à oxacilina e $7,0 \%$ resistente à oxacilina. A prevalência foi de $32,0 \%$ na secreção nasal, 1,0\%, na saliva e 11,0\%, nas amostras de saliva e de secreção nasal. Observou-se que 93,0\% dos Staphylococcus aureus apresentaram resistência à penicilina, 43,0\%, à eritromicina e 39,5\%, à clindamicina. Nenhuma das amostras coletadas da base do telefone celular dos profissionais apresentou Staphylococcus aureus. Os profissionais apresentaram escores médios altos para a Escala de Adesão às Precauções-padrão e Escala de Personalidade de Risco. Não houve diferença significante ao comparar a média dos escores das escalas entre o grupo de colonizados e não colonizados. Armazenamento da escova dental em compartimento fechado/protegido ( $R P=2,07 ; \mathrm{IC} 95 \%=1,07-3,80)$ foi um fator de risco para a colonização. Enquanto que, o conhecimento sobre as PP $(R P=0,53 ; I C 95 \%=0,44-0,64)$ e participação em treinamento sobre as $P P(R P=0,52$; IC95\%=0,43-0,64) apresentaram-se como um fator de proteção para a não colonização. Conclusão: A cavidade nasal foi um importante sítio de colonização quando comparada à cavidade oral, sendo um sítio relevante e indicado para a coleta em estudos que investigam a prevalência de colonização por Staphylococcus aureus. O conhecimento sobre precauções-padrão e a participação em treinamentos foram fatores associados à proteção para a não colonização. No entanto, um dos fatores determinantes para a adesão às precauções-padrão é a percepção de suscetibilidade do profissional de adquirir e disseminar esses microrganismos.

Palavras-chave: Staphylococcus aureus; Resistência à meticilina; Enfermagem; Precauções-Padrão. 


\begin{abstract}
LOPES, L.P. Staphylococcus aureus in nursing professionals and the interfaces with adherence to standard precautions. 2015. 142 p. Dissertation (Doctoral) University of São Paulo at Ribeirão Preto College of Nursing, Ribeirão Preto, 2015.

Introduction: Staphylococcus aureus is an important pathogen responsible for several infections in hospitals with high morbidity and mortality rates. Health professionals, especially nurses, are at increased risk of colonization through direct contact with susceptible individuals or by contact with fomites in their work activities. As a consequence, these professionals can disseminate these microorganisms both in the hospital and in the community. Objective: To assess colonization by Staphylococcus aureus in nursing professionals and the adherence to standard precautions. Methods: This cross-sectional study was carried out in an outpatient clinic and in specialized units that provide care to people with HIV/Aids, in a teaching hospital of Ribeirão Preto. The population consisted of 100 nursing professionals who provide direct care to patients of these units. Samples of saliva, nasal secretions and a swab from the mobile phone of professionals were collected. The collection took place from April 2014 to February 2015 on three occasions, in months zero, four and eight. A structured questionnaire was used to obtain demographic, occupational and personal data. To assess the adherence of professionals to standard precautions, ten Likert-type psychometric scales, translated and validated for Portuguese, were applied. The collected samples were forwarded to and processed by the Microbiology and Serology Laboratory of the hospital. Results: Of the 100 nursing professionals, $43 \%$ were colonized with Staphylococcus aureus in saliva samples and/or nasal secretions; $36 \%$ were oxacillin-sensitive Staphylococcus aureus and $7.0 \%$ oxacillin-resistant. The prevalence was $32 \%$ in nasal secretion, $1 \%$ in saliva and $11 \%$ in saliva samples and nasal discharge. It was observed that $93 \%$ of Staphylococcus aureus were penicillin-resistant strains, $43 \%$ resistant to erythromycin and $39.5 \%$ to clindamycin. None of the samples collected from the base of the mobile phone of the professionals presented Staphylococcus aureus. Professionals had high mean scores for the Compliance with Standard Precautions Scale and the Risk Personality Scale. There was no significant difference when comparing the average scores of scales between the colonized and non-colonized groups. Storing the toothbrush in a closed/protected space $(\mathrm{PR}=2.07$; $\mathrm{C} 195 \%=1.07-3.80)$ was a risk factor for colonization. Knowledge of the SP (PR=0.53, C195\%=0.44-0.64) and participation in training on SP (PR=0.52, $\quad$ C195\%=0.43-0.64) were a protective factor for noncolonization. Conclusion: The nasal cavity was an important colonization site compared to the oral cavity, the nasal site is relevant and recommended for collection in studies investigating the prevalence of colonization for Staphylococcus aureus. Knowledge of the standard precautions and participation in training on standard precautions were protective factors for non-colonization. However, one of the determining factors for adherence to standard precautions is the perceived susceptibility of professional to acquire and disseminate these microorganisms.
\end{abstract}

Keywords: Staphylococcus aureus; Methicillin Resistance; Nursing; Standard Precautions. 


\section{RESUMEN}

LOPES, L.P. Staphylococcus aureus en profesionales de enfermería y las interfaces con la adhesión a las precauciones estándar. 2015. 142 h. Tesis (Doctorado) - Escuela de Enfermería de Ribeirão Preto de la Universidad de São Paulo, Ribeirão Preto, 2015.

Introducción: Staphylococcus aureus es un patógeno importante responsable de varias infecciones en ambiente hospitalario con altas tasas de morbilidad y mortalidad. Los profesionales de la salud, especialmente los de enfermería, tienen un mayor riesgo de colonización por contacto directo con las personas susceptibles o por el contacto con fómites en su trabajo. De esta forma, estos trabajadores pueden tornarse dispersores de estos microorganismos tanto en el hospital como en la comunidad. Objetivo: Evaluar la colonización por Staphylococcus aureus en profesionales de enfermería y la adhesión a las precauciones estándar (PE). Metodología: Este estudio transversal fue realizado en una clínica médica y en unidades especializadas en la atención de las personas con VIH/Sida de un hospital escuela de la ciudad de Ribeirão Preto. La población estuvo constituida por 100 profesionales de enfermería que prestan atención directa a los pacientes de estas unidades. Muestras de saliva, secreción nasal y del teléfono celular de profesionales fueron recogidas. La recolección tuvo lugar entre abril de 2014 y febrero de 2015, en tres ocasiones en los meses cero, cuatro y ocho. La obtención de los datos demográficos, laborales y personales se realizó a través de un cuestionario estructurado. Para evaluar la adhesión de los profesionales a las PE, se aplicaron diez escalas psicométricas de tipo Likert, traducidas y validadas para el portugués. Las muestras recogidas fueron enviadas y procesadas por el Laboratorio de Microbiología y Serología del hospital. Resultados: De los 100 profesionales de enfermería, el 43\% estaba colonizado con Staphylococcus aureus en las muestras de saliva y/o de secreción nasal; el 36\% eran Staphylococcus aureus sensibles a la oxacilina y el $7 \%$ resistentes a la oxacilina. La prevalencia fue del $32 \%$ en la secreción nasal, del $1 \%$ en la saliva y del $11 \%$ en las muestras de saliva y secreciones nasales. Se observó que el 93\% de los Staphylococcus aureus presentaran resistencia a la penicilina, el $43 \%$ a la eritromicina y el 39,5\% a la clindamicina. Ninguna de las muestras recogidas de la base del teléfono celular de los profesionales presentó Staphylococcus aureus. Los profesionales tuvieron altas puntuaciones medias en la Escala de Adhesión a las PE y Escala de Personalidad de Riesgo. No hubo diferencia significativa al comparar las puntuaciones medias de las escalas entre el grupo de colonizados y no colonizados. Almacenar el cepillo de dientes en un espacio cerrado/protegido (RP=2,07; IC95\%=1,07$3,80)$ fue un factor de riesgo para la colonización. El conocimiento de las $P E(R P=0,53$; $\mathrm{IC} 95 \%=0,44-0,64)$ y la participación en la formación acerca de las PE ( $R P=0,52$; IC95\%=0,43-0,64) se presenta como un factor de protección para la no-colonización. Conclusión: La cavidad nasal como un sitio importante para la colonización en comparación con la cavidad oral, y recomendado en los estudios que investigan la prevalencia de colonización por Staphylococcus aureus. El conocimiento acerca de las PE y participación en la formación fueron factores de protección para la no-colonización. Sin embargo, factores determinantes para el cumplimiento de las PE es la percepción la susceptibilidad profesional de adquirir y difundir estos microorganismos.

Palabras clave: Staphylococcus aureus; Resistencia a la Meticilina; Enfermería; Precauciones Estándar. 


\section{LISTA DE TABELAS}

Tabela 1 - Distribuição dos profissionais de enfermagem ( $N=100)$, segundo a caracterização demográfica e profissional referida. Ribeirão PretoSP, 2014-2015

Tabela 2 - Distribuição dos profissionais de enfermagem ( $N=100)$, segundo a colonização por Staphylococcus aureus na saliva e/ou na secreção nasal. Ribeirão Preto-SP, 2014-2015

Tabela 3 - Distribuição dos profissionais de enfermagem $(\mathrm{N}=100)$ colonizados por Staphylococcus aureus sensível ou resistente à oxacilina na saliva e/ou na secreção nasal, nos três períodos da coleta. Ribeirão Preto-SP, 2014-2015.

Tabela 4 - Distribuição dos profissionais de enfermagem não colonizados $(n=57)$ e colonizados $(n=43)$ por Staphylococcus aureus, segundo a caracterização demográfica e profissional referida. Ribeirão PretoSP, 2014-2015

Tabela 5 - Distribuição dos profissionais de enfermagem colonizados $(n=43)$ por Staphylococcus aureus, segundo os sítios de colonização e o estado de carreador. Ribeirão Preto-SP, 2014-2015

Tabela 6 - Distribuição dos profissionais de enfermagem $(n=43)$, segundo o total de amostras e a colonização por Staphylococcus aureus em amostras de saliva e/ou de secreção nasal, nos três períodos de coleta. Ribeirão Preto-SP, 2014-2015

Tabela 7 - Distribuição dos profissionais de enfermagem, segundo respostas atribuídas aos itens que compõem a Escala de Adesão às Precauções-Padrão e à condição de colonizado ou não colonizado por Staphylococcus aureus. Ribeirão Preto-SP, 2014-2015

Tabela 8 - Distribuição dos profissionais de enfermagem, segundo respostas atribuídas aos itens que compõem a Escala de Personalidade de Risco e à condição de colonizado ou não colonizado por Staphylococcus aureus. Ribeirão Preto-SP, 2014-2015

Tabela 9 - Distribuição dos profissionais de enfermagem, segundo respostas atribuídas aos itens que compõem a Escala de Eficácia da Prevenção e à condição de colonizado ou não colonizado por Staphylococcus aureus. Ribeirão Preto-SP, 2014-2015

Tabela 10 - Distribuição dos profissionais de enfermagem, segundo respostas atribuídas aos itens que compõem a Escala de Percepção de Risco e à condição de colonizado ou não colonizado por Staphylococcus aureus. Ribeirão Preto-SP, 2014-2015 
Tabela 11 - Distribuição dos profissionais de enfermagem, segundo respostas atribuídas aos itens que compõem a Escala de Conhecimento da Transmissão Ocupacional do HIV e à condição de colonizado ou não colonizado por Staphylococcus aureus. Ribeirão Preto-SP, 2014-2015 ..79

Tabela 12 - Distribuição dos profissionais de enfermagem, segundo respostas atribuídas aos itens que compõem a Escala de Obstáculos para Seguir as Precauções-Padrão e à condição de colonizado ou não colonizado por Staphylococcus aureus. Ribeirão Preto-SP, 2014-2015

Tabela 13 - Distribuição dos profissionais de enfermagem, segundo respostas atribuídas aos itens que compõem a Escala de Carga de Trabalho e à condição de colonizado ou não colonizado por Staphylococcus aureus. Ribeirão Preto-SP, 2014-2015

Tabela 14 - Distribuição dos profissionais de enfermagem, segundo respostas atribuídas aos itens que compõem a Escala de Clima de Segurança e à condição de colonizado ou não colonizado por Staphylococcus aureus. Ribeirão Preto-SP, 2014-2015

Tabela 15 - Distribuição dos profissionais de enfermagem, segundo respostas atribuídas aos itens que compõem a Escala de Disponibilidade de Equipamento de Proteção Individual e à condição de colonizado ou não colonizado por Staphylococcus aureus. Ribeirão Preto-SP, 2014-2015

Tabela 16 - Distribuição dos profissionais de enfermagem, segundo respostas atribuídas aos itens que compõem a Escala de Treinamento em Prevenção da Exposição Ocupacional ao HIV e à condição de colonizado ou não colonizado por Staphylococcus aureus. Ribeirão Preto-SP, 2014-2015.

Tabela 17 - Escore médio e desvio padrão das escalas que compõem o modelo explicativo de adesão às precauções-padrão entre o grupo de profissionais de enfermagem colonizados $(n=43)$ e não colonizados $(\mathrm{n}=57)$ por Staphylococcus aureus. Ribeirão Preto-SP, 2014-2015 .....85

Tabela 18 - Comparação das médias dos escores das dez escalas que compõem o modelo explicativo de adesão às precauções-padrão entre os grupos de profissionais de enfermagem colonizados $(n=43)$ e não colonizados $(n=57)$ por Staphylococcus aureus. Ribeirão Preto-SP, 2014-2015.

Tabela 19 - Comparação das médias dos escores da escala de adesão às precauções-padrão entre os profissionais de enfermagem colonizados por Staphylococcus aureus e as variáveis demográficas e profissionais, Ribeirão Preto-SP, 2014-2015

Tabela 20 - Medidas de associação entre características demográficas, profissionais e individuais com a colonização por Staphylococcus aureus em profissionais de enfermagem, Ribeirão Preto-SP, 20142015 


\section{LISTA DE FIGURAS}

Figura 1 - Crescimento do microrganismo Staphylococcus aureus em meio de cultura ágar sangue (Arquivo pessoal. Ribeirão Preto-SP, 2015)

Figura 2 - Média dos escores entre o grupo de profissionais colonizados por Staphylococcus aureus e as categorias de enfermagem

Figura 3 - Média dos escores entre o grupo de profissionais colonizados por Staphylococcus aureus e o tempo de função na enfermagem. 


\section{LISTA DE GRÁFICOS}

Gráfico 1 - Perfil de resistência dos Staphylococcus aureus sensíveis e resistentes à oxacilina isolados na saliva e na secreção nasal dos profissionais de enfermagem aos antimicrobianos. Ribeirão PretoSP. 2014-2015

Gráfico 2 - Perfil de sensibilidade dos Staphylococcus aureus sensíveis e resistentes à oxacilina isolados na saliva e na secreção nasal dos profissionais de enfermagem aos antimicrobianos. Ribeirão PretoSP, 2014-2015 


\section{LISTA DE ABREVIATURAS E SIGLAS}

ANVISA

BRMD

CAAE

CA-MRSA

$\mathrm{CCIH}$

CDC

CLSI

CONEP

ECDC

EPI

ESKAPE

HAART

HA-MRSA

HCFMRP-USP

HIV

$\mathrm{mL}$

MRSA

MSSA

$\mathrm{NaCl}$

NAIDST

OMS

PBP
Agência Nacional de Vigilância Sanitária

Bactérias resistentes a múltiplas drogas

Certificado de Apresentação para Apreciação Ética

Staphylococcus aureus resistente à meticilina adquirido na comunidade

Comissão de Controle de Infecção Hospitalar

Centers for Disease Control and Prevention

Clinical and Laboratory Standards Institute

Conselho Nacional de Saúde

European Centre for Disease Prevention and Control

Equipamento de Proteção Individual

Enterococcus faecium, Staphylococcus aureus, Klebsiella pneumoniae, Acinetobacter baumannii, Pseudomonas aeruginosa e Enterobacter spp.

Terapia Antirretroviral Altamente Ativa

Staphylococcus aureus resistente à meticilina adquirido no hospital

Hospital das Clínicas da Faculdade de Medicina de Ribeirão Preto da Universidade de São Paulo

Vírus da Imunodeficiência Humana

Mililitro

Staphylococcus aureus resistente à meticilina

Staphylococcus aureus sensível à meticilina

Cloreto de Sódio

Núcleo de AIDS e Doenças Sexualmente Transmissíveis

Organização Mundial da Saúde

Proteína ligadora de penicilina 
PP

Precauções-Padrão

PVL

Leucocidina Panton-Valentine

SCCmec

Staphylococcal cassette chromosome

SMX-TMP

Sulfametoxazol-trimetoprima

TCLE

Termo de Consentimento Livre e Esclarecido

VISA

Staphylococcus aureus com resistência intermediária à vancomicina

VRSA

Staphylococcus aureus resistente à vancomicina

WHO

World Health Organization 


\section{SUMÁRIO}

1 APRESENTAÇÃO

2 INTRODUÇÃO 24

2.1 Staphylococcus aureus - Identificação, caracterização, patogênese e aspectos epidemiológicos

2.2 Resistência bacteriana - Staphylococcus aureus resistente à meticilina

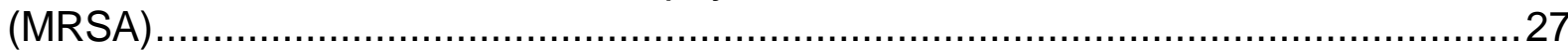

2.3 Colonização dos profissionais de enfermagem por Staphylococcus aureus........31

2.4 Contaminação microbiana de objetos inanimados ............................................33

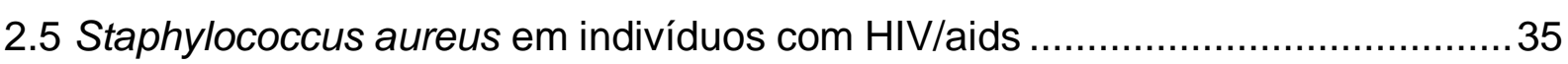

2.6 Prevenção e controle da disseminação de MRSA...............................................37

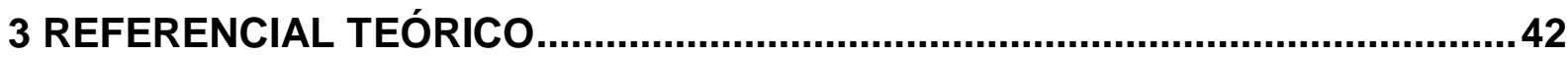

4 OBJETIVOS

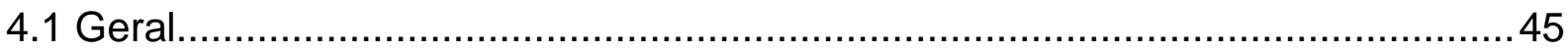

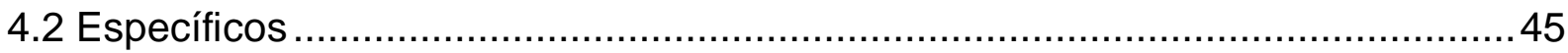

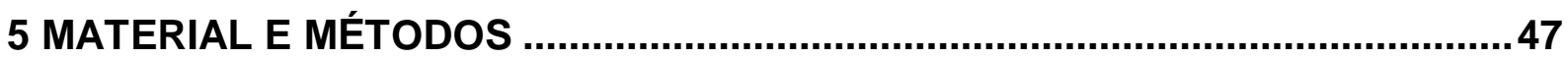

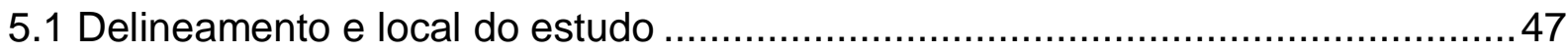

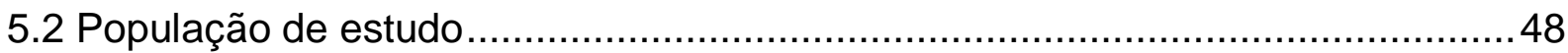

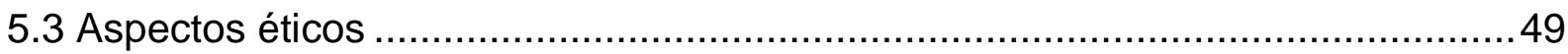

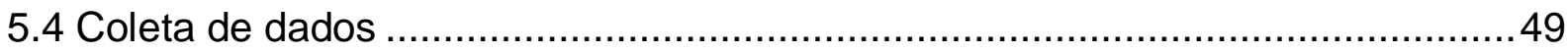

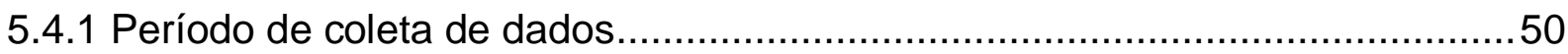

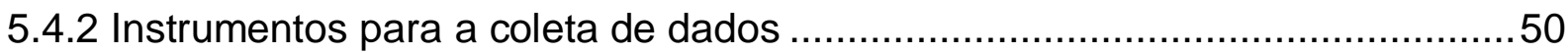

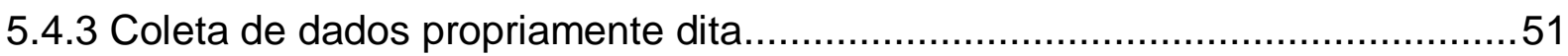

5.5 Seleção e treinamento dos auxiliares de pesquisa..........................................52

5.6 Estudo piloto

5.7 Procedimentos laboratoriais - Isolamento e identificação fenotípica dos

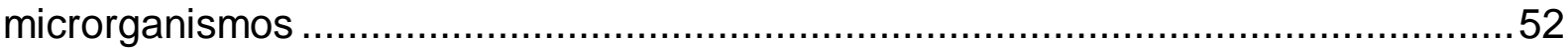

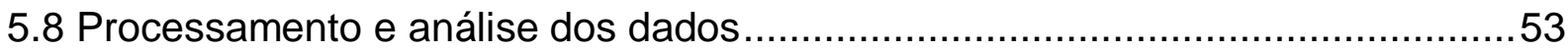

5.9 Conceito: classificação do estado de carreador .............................................55 
6.1 Caracterização demográfica e profissional dos profissionais de enfermagem ....57

6.2 Caracterização de aspectos individuais dos profissionais de enfermagem 60

6.3 Prevalência de Staphylococcus aureus em profissionais de enfermagem e em seu telefone celular

6.4 Caracterização demográfica, profissional e individual dos profissionais de enfermagem colonizados por Staphylococcus aureus

6.5 Estado de carreador dos profissionais colonizados por Staphylococcus aureus 67

6.6 Perfil de suscetibilidade dos Staphylococcus aureus aos antimicrobianos .71

6.7 Descrição dos itens que compõem as escalas do modelo explicativo de

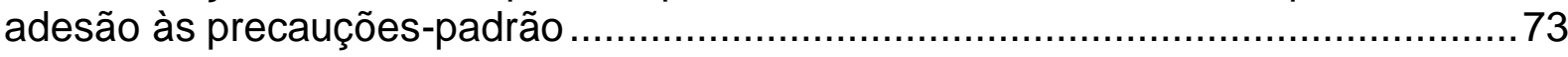

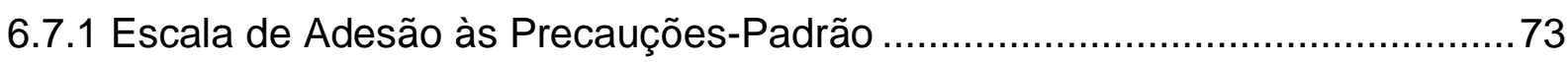

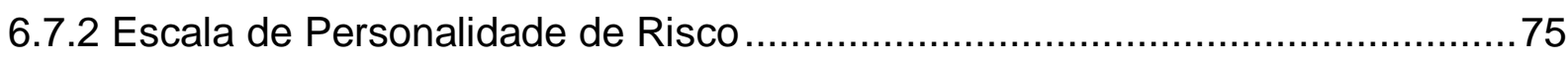

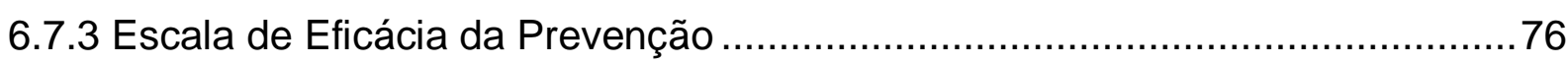

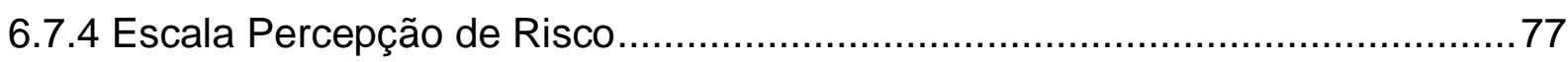

6.7.5 Escala de Conhecimento da Transmissão Ocupacional do HIV ......................78

6.7.6 Escala Obstáculos para Seguir as Precauções-Padrão ...................................79

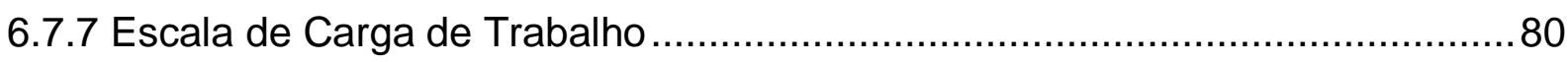

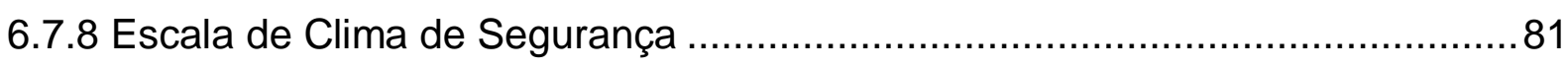

6.7.9 Escala de Disponibilidade de Equipamento de Proteção Individual ..................83

6.7.10 Escala de Treinamento em Prevenção da Exposição Ocupacional ao HIV ...83 6.8 Comparação dos escores médios das escalas do modelo explicativo de

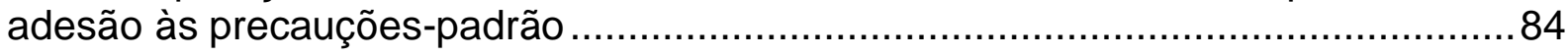

7 DISCUSSÃO

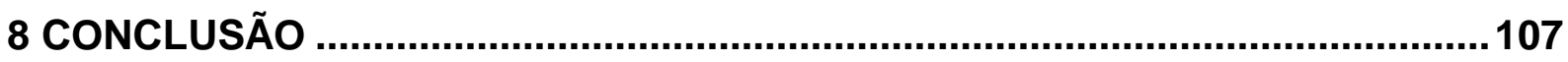

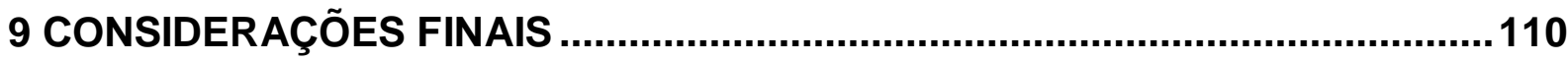

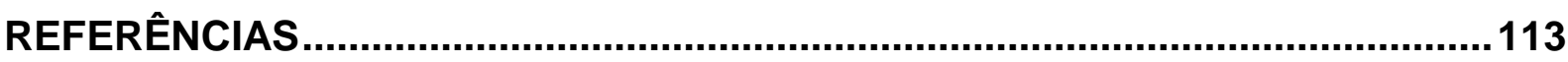

APÊNDICES

ANEXOS 


\section{APRESENTAÇÃO}

No ambiente hospitalar, os profissionais de saúde convivem diariamente com um grande número de pacientes com as mais variadas patologias e estão expostos a diversos riscos ocupacionais.

Microrganismos resistentes ${ }^{1}$ podem se disseminar rapidamente no ambiente e tornar-se endêmico na instituição. A transmissão desses microrganismos ocorre por contato direto, ou seja, são transferidos diretamente de um indivíduo colonizado ou infectado para outro suscetível; ou mesmo por contato indireto, em que a transmissão ocorre por meio de objetos contaminados.

Indivíduos com HIV/aids normalmente apresentam imunossupressão e fazem uso prolongado de antimicrobianos aliado a longos períodos de internação. Isso os torna mais suscetíveis à colonização por inúmeros microrganismos, entre eles os Staphylococcus aureus, sejam eles, sensíveis ou resistentes à meticilina (oxacilina). Sendo assim, os profissionais de enfermagem que prestam assistência direta a essa clientela também ficam suscetíveis à colonização por esses microrganismos, caso a adesão às medidas de precaução-padrão (PP) seja deficiente.

Uma vez colonizados, os profissionais de enfermagem tornam-se potenciais disseminadores de microrganismos nos serviços de saúde, podendo ocasionar surtos de infecção e comprometer o estado de saúde do cliente.

Os telefones celulares utilizados por esses profissionais, no ambiente de trabalho, podem ser potenciais fômites e importantes veículos na transmissão de microrganismos do âmbito hospitalar para a comunidade.

Infecções causadas por Staphylococcus aureus resistente à meticilina (MRSA) são preocupantes, pois, além de elevarem as taxas de morbidade e de mortalidade, podem ser de difícil controle devido à facilidade de esse microrganismo desenvolver resistência a múltiplas drogas.

A adoção às medidas de PP contribui para a diminuição do risco de aquisição de microrganismos patogênicos, e são consideradas medidas essenciais para

${ }^{1}$ Os microrganismos resistentes estão classificados em três categorias:

MDR ("Multidrug-resistant") - quando são resistentes a um ou mais antimicrobiano de três ou mais categorias testadas.

XDR ("Extensively drug-resistant") - quando são resistentes a um ou mais antimicrobiano em quase todas categorias (exceto uma ou duas).

PDR ("Pandrug-resistant") - resistente a todos os agentes antimicrobianos testados (EUROPEAN CENTRE FOR DISEASE PREVENTION AND CONTROL (ECDC), 2011). 
proteger profissionais de saúde dos riscos a que estão expostos no ambiente hospitalar.

Embora a cavidade nasal seja considerada um dos principais sítios de colonização por Staphylococcus aureus, estudos realizados previamente apontam a cavidade oral como um potencial reservatório e fonte de disseminação deste microrganismo. Sendo assim, neste estudo, consideramos relevante associar os dois sítios (nasal e saliva) com o intuito de melhorar a identificação de Staphylococcus aureus sensível à meticilina (MSSA) e MRSA entre os profissionais de enfermagem.

Diante disso, considerou-se relevante desenvolver este estudo que teve como objetivo avaliar a colonização por Staphylococcus aureus em profissionais de enfermagem e a adesão às PP, pois acredita-se que este estudo poderá identificar variáveis que consequentemente poderão fornecer importantes considerações em relação a estratégias educativas para maior adesão às medidas de controle e de prevenção de microrganismos nessa população.

As hipóteses neste estudo foram:

- A prevalência de Staphylococcus aureus pode ser influenciada por fatores relacionados às características demográficas, profissionais e individuais;

- Profissionais de enfermagem que prestam cuidados a pacientes com HIV/aids podem apresentar colonização na saliva e na narina anterior por Staphylococcus aureus em seu ambiente de trabalho;

- Objetos de uso pessoal dos profissionais como telefone celular podem estar contaminados por Staphylococcus aureus;

- Os escores médios das escalas que compõem o modelo explicativo de adesão às precauções-padrão entre os profissionais de enfermagem não colonizados são maiores com relação ao grupo de profissionais colonizados por Staphylococcus aureus.

Esta tese é parte do projeto "Prevalência de microrganismos sensíveis e resistentes em indivíduos com HIV/aids e profissionais de enfermagem". Processo CNPq 476480/2012. Chamada Pública Universal 14/2012. 


\section{INTRODUÇÃO}

\subsection{Staphylococcus aureus - Identificação, caracterização, patogênese e aspectos epidemiológicos}

Os Staphylococcus aureus são bactérias esféricas com diâmetro entre 0,5 a 1,0 micrômetro, catalase positivos, anaeróbios facultativos, imóveis e não formadores de esporos. São cocos Gram-positivos que crescem seguindo um padrão que se assemelha a cachos de uva com coloração amarelada, devido à produção de carotenoides; sendo assim conhecido como "estafilococo dourado" (Figura 1) (JORGE, 2001; MURRAY; ROSENTHAL; PFALLER, 2014).

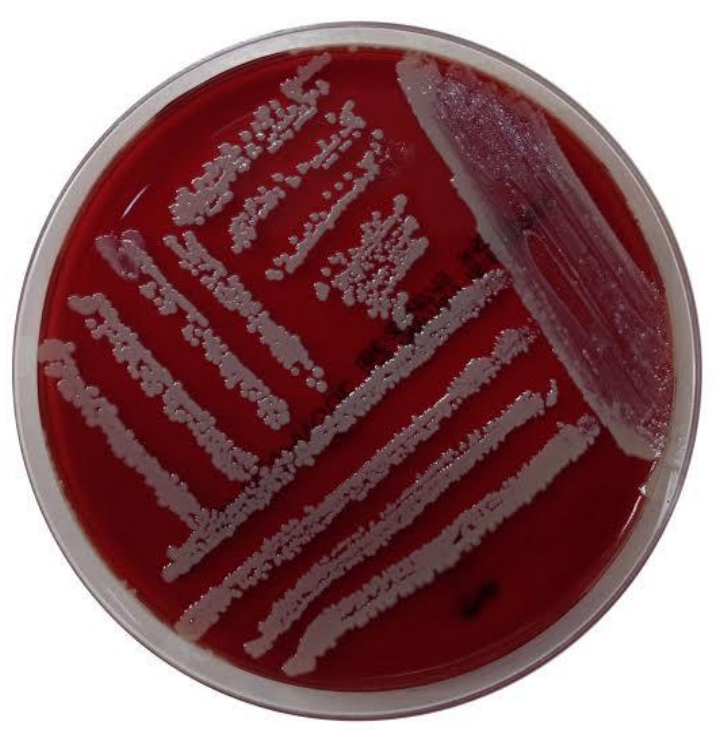

Figura 1 - Crescimento do microrganismo Staphylococcus aureus em meio de cultura ágar sangue (Arquivo pessoal. Ribeirão Preto-SP, 2015)

O gênero Staphylococcus pertencente à família Micrococcaceae é constituído por pelo menos 40 espécies; além do Staphylococcus, a família é composta também pelos gêneros Planococcus, Micrococcus e Stomatococcus. A prova de catalase consiste no principal teste para a identificação da família Micrococcaceae (BROOKS et al., 2014). 
Essas bactérias do gênero Staphylococcus, apesar de integrantes da microbiota humana, compreendem um grupo de bactérias mais estudadas pela microbiologia e detêm grande importância por se relacionarem a infecções hospitalares e alimentares (MURRAY; ROSENTHAL; PFALLER, 2014).

Microrganismos pertencentes ao gênero Staphylococcus podem ser isolados no homem e causar uma variedade de infecções que variam de doenças cutâneas superficiais a infecções sistêmicas letais. O Staphylococcus aureus é considerado o patógeno humano de maior relevância entre os estafilococos (MANDELL; BENNET; DOLIN, 2010).

A literatura mostra que o Staphylococcus foi descrito pela primeira vez em 1880, por um cirurgião escocês chamado Alexander Ogston, em pus de abscesso cirúrgico de uma articulação do joelho (LICITRA, 2013; OGSTON 1881).

Staphylococcus aureus apresentam um alto potencial infeccioso, não apenas pela facilidade de multiplicação nos tecidos, mas também pela capacidade de produzir enzimas e toxinas com elevado poder patogênico (SANTOS et al., 2007).

Dentre as enzimas, encontram-se a coagulase que age dificultando a fagocitose celular ao converter fibrinogênio em fibrina; a catalase responsável por converter o peróxido de hidrogênio em água e em oxigênio; e a hialuronidase que atua na despolimerização do ácido hialurônico, facilitando a invasão dos tecidos (MURRAY; ROSENTHAL; PFALLER, 2014).

Entre os fatores de virulência produzidos por Staphylococcus aureus, além das enzimas, podem-se citar as toxinas alfa, beta, delta, gama, a toxina leucocidina Panton-Valentine (PVL), toxinas esfoliativas $A$ e $B$, toxina-1 do choque tóxico estafilocócico (TSST-1) e as enterotoxinas (A-E, G-J, K-R, e U-V) (BROOKS et al., 2014).

Os seres humanos são considerados reservatórios naturais de diversos microrganismos, entre eles, o Staphylococcus aureus apontado como um importante patógeno humano responsável por diversas infecções. Entre elas, as infecções de pele como impetigo, piodermites, foliculites, furúnculos, abscessos, necrose epidérmica tóxica (síndrome da pele escaldada), síndrome do choque tóxico e outras infecções como pneumonias, bacteremias, endocardites, osteomielites (LOWY, 2003). Além disso, os principais sítios de colonização do Staphylococcus aureus são a pele e as membranas mucosas, as vias aéreas superiores, o trato gastrointestinal e o períneo (BROOKS et al., 2014). 
O nicho ecológico do Staphylococcus aureus é a narina anterior, pois é apontada como o reservatório primário em pessoas colonizadas por este microrganismo. Sendo assim, é o sítio mais eficiente e indicado para a coleta de espécimes com o propósito de triagem (KLUYTMANS; VAN BELKUM; VERBRUGH, 1997; WENZEL et al., 1998).

Colonização por Staphylococcus aureus é mais frequente na nasofaringe anterior comparada à orofaringe; aproximadamente 15\% dos indivíduos adultos saudáveis são portadores desse microrganismo na nasofaringe. Esse número pode ser mais elevado se considerarmos indivíduos hospitalizados, portadores de doenças crônicas e profissionais de saúde (MURRAY; ROSENTHAL; PFALLER, 2014).

$\mathrm{Na}$ população geral, as taxas de colonização nasal por Staphylococcus aureus variam de 20 a $50 \%$, porém taxas maiores são observadas nos profissionais de saúde (SANTOS, 2000).

Segundo Kluytmans, Van Belkum e Verbrugh (1997), aproximadamente 20\% dos indivíduos da população são considerados carreadores persistentes, 60\% carreadores intermitentes e os demais $20 \%$ não apresentam colonização por Staphylococcus aureus.

Em geral, Staphylococcus aureus se desenvolvem em meios de culturas comuns, como o caldo simples ou ágar simples, com pH 7, e a temperatura ótima de crescimento entre 30 a 37으 (MORETTI; PEDRO, 2009; TRABULSI; ALTERTHUM, 2008).

O ágar manitol-sal é um meio considerado importante e seletivo para a espécie, pois Staphylococcus aureus é capaz de fermentar o manitol, produzindo ácido lático em meios com elevada concentração de sal (cloreto de sódio - $\mathrm{NaCl}$ a $7,5 \%$ ). Meio que contém $\mathrm{NaCl}$ a $7,5 \%$ pode ser utilizado para cultivar amostras contaminadas por microbiotas mistas, pois o sal inibe o crescimento de grande parte da microbiota normal, porém não inibe o crescimento de Staphylococcus aureus (BROOKS et al., 2014; TRABULSI; ALTERTHUM, 2008). 


\subsection{Resistência bacteriana - Staphylococcus aureus resistente à meticilina (MRSA)}

O surgimento dos microrganismos resistentes a múltiplos agentes antimicrobianos tem sido uma ameaça global à saúde pública e tem afetado tanto os países desenvolvidos como os países em desenvolvimento (WORLD HEALTH ORGANIZATION (WHO), 2001).

A resistência aos antibióticos é compreendida como uma habilidade de adaptação da população bacteriana; é uma consequência natural da bactéria de se adaptar à exposição aos antimicrobianos. A pressão seletiva provocada pelo uso indiscriminado de antibióticos tem contribuído para a expansão da resistência antimicrobiana (SANTOS, 2004).

Nos Staphylococcus aureus, a resistência antimicrobiana pode ser tanto cromossomais, como mediada por plasmídios. A resistência à oxacilina nos Staphylococcus aureus pode ocorrer pela hiperprodução de betalactamases e por modificações no receptor betalactâmico, estimulando a produção de uma proteína ligadora de penicilina (PBP2a) que possui uma baixa afinidade pela oxacilina, como também por outros antimicrobianos betalactâmicos. Além disso, essa resistência à oxacilina requer a presença de um gene cromossômico denominado mecA, responsável pela síntese das PBP2a (LOWY, 2003; SCHITO, 2006).

O gene mecA é carreado por um elemento genético móvel, conhecido como Staphylococcal cassette chromosome ( $\mathrm{SCCmec})$. A literatura aponta que até o momento foram descritos onze tipos de SCCmec; os três primeiros estão relacionados aos Staphylococcus aureus resistentes à meticilina adquiridos no hospital (HA-MRSA), enquanto que os tipos IV e V têm sido descritos em isolados de Staphylococcus aureus resistentes à meticilina provenientes da comunidade (CAMRSA) (TURLEJ; HRYNIEWICZ; EMPEL, 2011). O SCCmec tipo IV apresenta um menor tamanho que os demais tipos e menor resistência aos antibióticos não betalactâmicos. O CA-MRSA pode possuir a toxina PVL, responsável por infecções de pele, de tecidos moles e, ocasionalmente, por pneumonia necrotizante (LOPES, 2005).

Os Staphylococcus aureus encontram-se no grupo de patógenos conhecidos como ESKAPE (Enterococcus faecium; Staphylococcus aureus; Klebsiella 
pneumoniae; Acinetobacter baumannii; Pseudomonas aeruginosa e Enterobacter spp.) (RICE, 2008). Esses patógenos estão associados à grande parte das infecções relacionadas à assistência à saúde e representam os maiores riscos em relação aos padrões de resistência antimicrobiana (BOUCHER et al., 2009).

Uma das principais características dos Staphylococcus aureus é a capacidade de aquisição de mecanismos de resistência aos antibióticos. $O$ desenvolvimento dessa resistência está diretamente relacionado ao amplo emprego de antimicrobianos (SANTOS et al., 2007).

O primeiro relato de MRSA ocorreu em 1961, aproximadamente um ano após o início do uso clínico dessa penicilina semissintética (JEVONS, 1961). Deste então, o MRSA encontra-se endêmico em diversos hospitais e essa problemática não mais se restringe aos grandes hospitais e países em desenvolvimento (SIMOR, 2001).

Com o surgimento das cepas de MRSA, a vancomicina tem sido utilizada no tratamento de infecções causadas por esses cocos Gram-positivos. No entanto, em 1997, no Japão, foi relatado o primeiro caso de isolamento de cepas de Staphylococcus aureus com resistência intermediária à vancomicina (VISA). Essa cepa foi isolada de uma infecção de ferida operatória de um bebê de quatro meses de idade submetido a uma cirúrgica cardíaca (HIRAMATSU et al., 1997).

Essas cepas de VISA, posteriormente, foram relatadas em estudos nos Estados Unidos, na França, na Coréia e no Brasil (FRIDKIN, 2001; KIM et al., 2000; OLIVEIRA et al., 2001; PLOY et al., 1998).

Em 2002, nos Estados Unidos, foi relatado o primeiro caso de Staphylococcus aureus resistente à vancomicina (VRSA), isolado em um paciente com 40 anos, diabético, hipertenso e portador de insuficiência renal crônica (CENTERS FOR DISEASE CONTROL AND PREVENTION (CDC), 2002).

Desde então, o Staphylococcus aureus tem desenvolvido resistência a praticamente todas as classes de antibióticos disponíveis para uso clínico (MANDELL; BENNET; DOLIN, 2010).

Os MRSA disseminam-se rapidamente no ambiente hospitalar e são responsáveis por elevadas taxas de infecções hospitalares. Apesar de ser um microrganismo tipicamente hospitalar, na literatura encontramos relatos de sua disseminação na comunidade (CDC, 1999). Em 2003, cepas de MRSA adquiridas na comunidade, não relacionadas às que circulavam no meio hospitalar, foram 
descritas como responsáveis por surtos de infecções cutâneas e de pneumonia grave (MURRAY; ROSENTHAL; PFALLER, 2014).

Ellis et al. (2004) apontaram que colonizações por MRSA frequentemente precedem infecções. Em seu estudo, 38\% dos participantes colonizados por cepas de CA-MRSA desenvolveram infecções de pele e de tecidos moles em um período de 8 a 10 semanas em que ocorreu a investigação.

Estudo sobre padrões de suscetibilidade antimicrobiana de patógenos Grampositivos realizado em hospitais brasileiros apontou que, dos microrganismos avaliados, o Staphylococcus aureus foi o patógeno mais frequentemente isolado nas infecções de corrente sanguínea e infecções de pele e de tecidos moles; e o MRSA correspondeu a $31 \%$ dos casos de infecções nosocomiais e comunitárias (GALES et al., 2009).

Uma das formas de o MRSA ser introduzido nas instituições hospitalares é por meio da admissão de novos pacientes colonizados ou infectados, provenientes da comunidade ou mesmo de outra instituição. Sendo assim, é essencial que esses clientes sejam identificados o mais precocemente possível para se evitar a disseminação de cepas resistentes no ambiente hospitalar.

O aumento da resistência bacteriana aos antibióticos em uma instituição está relacionado não apenas ao tamanho do hospital, mas também aos tipos de atendimento e ao grau de complexidade nos cuidados prestados (SIEGEL et al., 2007a).

Os antimicrobianos destacam-se por serem a classe farmacológica mais prescrita no mundo. O quantitativo de antimicrobianos utilizados apresenta uma relação direta com o aumento de mecanismos de resistência, e o uso indiscriminado e abusivo desses antimicrobianos tem causado sérias implicações na prática clínica (WILLEMSEN et al., 2009).

O aumento das infecções causadas por MRSA foi acompanhado pelo crescimento da resistência a uma variedade de antimicrobianos, como aminoglicosídeos, quinolonas, macrolídeos e tetraciclinas (BOUCHER et al., 2009). Contudo, a preocupação mundial concentra-se na identificação precoce de cepas de MRSA resistentes ao glicopeptídeo vancomicina, pois essa droga tem sido uma das principais opções terapêuticas para o tratamento de infecções causadas por cocos Gram-positivos multirresistentes (APPELBAUM, 2006). 
Embora já se tenham passado mais de meio século desde que o MRSA foi descrito, este microrganismo continua se disseminando por todo o mundo e sendo responsável por grande parte das infecções adquiridas no meio hospitalar e na comunidade (MOELLERING, 2012).

Estima-se que, em 2011, nos Estados Unidos, ocorreram mais de 80.000 casos de infecções por MRSA, sendo que aproximadamente 11.000 evoluíram para óbito (CDC, 2011).

Esforços para erradicar e para controlar as graves infecções causadas pelo Staphylococcus aureus têm obtido pouco sucesso e as opções terapêuticas têm se tornado cada vez mais restritas, favorecendo o uso de antibióticos de amplo espectro e, consequentemente, a resistência microbiana (APPELBAUM, 2006).

Instituições de saúde têm adotado estratégias para controlar a existência de cepas resistentes pelo uso indiscriminado de antimicrobianos. Dentre essas medidas, podem-se citar o descalonamento de antimicrobianos e a restrição de algumas drogas de amplo espectro de ação, permitindo sua liberação apenas após autorização prévia de médicos da Comissão de Controle de Infecção Hospitalar (CCIH) (MARRA et al., 2009).

A compreensão do funcionamento da patogenicidade dos Staphylococcus aureus pode orientar os profissionais de saúde na racionalização do uso de antimicrobianos, minimizando, com isso, a seleção de cepas resistentes e/ou multirresistentes (SANTOS et al., 2007).

Embora as ações para a prevenção de infecção e para o controle da disseminação de microrganismos resistentes implementadas pelas CCIHs têm sido destaque, é necessário para o sucesso dessas ações o envolvimento e a participação efetiva de todos os membros da equipe (SANTOS et al., 2010).

Para Santos (2004), as instituições ao adotarem uma política de controle de infecção hospitalar irão reduzir, com isso, a resistência bacteriana. Porém, é imprescindível que os profissionais de saúde adotem em sua prática assistencial as principais medidas básicas para a prevenção e o controle das infecções hospitalares. 


\subsection{Colonização dos profissionais de enfermagem por Staphylococcus aureus}

No ambiente de trabalho, os profissionais de saúde são suscetíveis à colonização por microrganismos, na maioria das vezes, multirresistentes. Considerando-se as características do trabalho que demanda uma aproximação física com os pacientes, associado à falta de adesão às PP, esses profissionais podem se tornar portadores e disseminadores desses microrganismos, favorecendo com isso, a ocorrência de surtos de infecção (MOURA et al., 2011).

Estudos brasileiros e internacionais apontam os profissionais de saúde e, principalmente os profissionais de enfermagem, como um grupo vulnerável à colonização pelo Staphylococcus aureus, e potenciais disseminadores desses microrganismos em suas atividades laborais (ALBRICH; HARBARTH, 2008; CARVALHO, M. et al., 2009; CRUZ et al., 2011; GEBREYESUS; GEBRESELASSIE; MIHERT, 2013; MOGHADAM; POURMAND; DAVOODABAD, 2015; MOURA et al., 2010; OTTER; FRENCH, 2011; SILVA, E. et al., 2012).

Investigação realizada com 270 profissionais de saúde de cinco hospitais universitários no Irã mostrou que a prevalência de Staphylococcus aureus nas narinas dos profissionais foi de 14,4\% (39/270), sendo que 6,3\% (17/270) eram considerados MRSA (MOGHADAM; POURMAND; DAVOODABAD, 2015).

Uma pesquisa para determinar a prevalência de portadores assintomáticos de Staphylococcus aureus entre os profissionais de saúde mostrou alta taxa de colonização nasal, pois 112 dos 256 (43,8\%) profissionais de saúde estavam colonizados por Staphylococcus aureus. Destes, 51 (45,5\%) eram enfermeiros (ELIE-TURENNE et al., 2010).

Gebreyesus, Gebre-Selassie e Mihert (2013) realizaram uma investigação para avaliar a colonização por MRSA nas narinas e nas mãos de 177 profissionais de saúde. O estudo mostrou que os profissionais de saúde apresentavam colonização mais frequente nas narinas, comparada às mãos. Além disso, enfermeiros e médicos foram os profissionais mais colonizados por MRSA, sendo a prevalência de $13,6 \%$ e 2,3\%, respectivamente.

Investigação realizada em um hospital universitário de nível terciário nos Estados Unidos apontou uma prevalência de 6,6\% de MRSA entre profissionais de saúde e 5,1\%, entre enfermeiros (ELIE-TURENNE et al., 2010). 
Estudo realizado no Paraná para determinar a prevalência de Staphylococcus aureus isolados na cavidade nasal e nas mãos de pacientes e membros da equipe de enfermagem apontou que $54,8 \%$ dos pacientes e $59,0 \%$ dos profissionais estavam colonizados pelo microrganismo (MOREIRA; SANTOS; BEDENDO, 2013).

A prevalência de profissionais de enfermagem colonizados por Staphylococcus aureus na saliva foi de $41,0 \%$, dos quais, $7,1 \%$ foram resistentes à meticilina (MOURA et al., 2011).

Pesquisa para avaliar a colonização por Staphylococcus aureus sensíveis e resistentes à oxacilina na saliva dos profissionais de enfermagem mostrou que, das 1068 culturas processadas, em 158 (14,8\%) culturas observou-se o crescimento de Staphylococcus aureus. Destes, isolados, 24 (15,2\%) foram caracterizados como MRSA (MOURA et al., 2010).

Carvalho, M. et al. (2009), ao analisar a prevalência de colonização por MRSA na saliva de 340 profissionais de saúde, verificou que, dos 162 profissionais colonizados, $54,3 \%$ eram auxiliares de enfermagem, 27,8\%, técnicos de enfermagem, 10,5\%, enfermeiros e 7,4\%, médicos. Neste estudo, a prevalência de MSSA foi de 43,5\% (148/340) e de MRSA, 4,1\% (14/340).

No Brasil, estudo epidemiológico longitudinal realizado em Curitiba-PR envolvendo 486 trabalhadores de um hospital universitário identificou que 60,9\% estavam colonizados por Staphylococcus aureus na saliva; a prevalência de MSSA foi de $48,1 \%$ e de MRSA, 12,7\% (CRUZ et al., 2011).

Estudo transversal realizado em Pernambuco com 151 membros da equipe de enfermagem identificou que 25,8\% estavam colonizados por Staphylococcus aureus e 3,3\%, por MRSA. Além disso, observou-se que, dos 39 profissionais colonizados, 25,6\% apresentaram colonização exclusivamente nas mãos, 48,8\%, apenas na cavidade nasal e 25,6\%, em ambos os sítios (SILVA, E. et al., 2012).

A prevalência de MRSA em profissionais de saúde de um hospital universitário no Recife foi de $22,5 \%$ nas amostras biológicas isoladas da cavidade nasal de enfermeiros, de técnicos de enfermagem, de médicos, de fisioterapeutas, de nutricionistas e de psicólogos (RABELO et al., 2014).

Palos (2006) realizou um estudo em Goiânia com o objetivo de determinar a prevalência de Staphylococcus aureus na saliva de 268 profissionais das equipes médicas e de enfermagem. Destes, 227 (84,7\%) profissionais estavam colonizados por Staphylococcus aureus e 9,7\% (26/268) eram portadores de MRSA. 
Profissionais de saúde, além de ser apontados como grandes reservatórios e disseminadores de microrganismos, são considerados veículos de transmissão entre pacientes e comunidade (CRUZ et al., 2011).

Pesquisas evidenciam que os profissionais de saúde, assim como seus familiares/contactantes, estão potencialmente em risco de infecção por MRSA (ALBRICH; HARBARTH, 2008; MACKENZIE et al., 2007; OTTER; FRENCH, 2011).

Carreadores assintomáticos de Staphylococcus aureus podem atuar como disseminadores do microrganismo para outros indivíduos suscetíveis à colonização. Aproximadamente $80 \%$ das infecções por Staphylococcus aureus são causadas por cepas disseminadas a partir da nasofaringe de carreadores (SIVARAMAN; VENKATARAMAN; COLE, 2009).

Cruz et al. (2011) consideram que conhecer a condição de portador de MRSA é um direito do profissional de saúde e deve ser algo considerado decorrente de sua atividade profissional, não um motivo de crítica. Ao saber que é portador, o profissional é levado a refletir e a rever suas práticas e riscos ocupacionais, o que acaba por gerar mudança de atitude e maior adesão às medidas de prevenção. Além disso, o conhecimento de sua condição possibilita a descolonização e, com isso, a redução do risco individual e de disseminação desses agentes.

\subsection{Contaminação microbiana de objetos inanimados}

Embora microrganismos sejam mais comumente transmitidos pelas mãos dos profissionais de saúde, estudos revelam que inúmeros objetos utilizados por estes profissionais podem estar contaminados por patógenos. Entre esses artigos, estão estetoscópios, jalecos, telefones celulares, termômetros, canetas, crachás (LONGTIN et al., 2014; PANDEY et al., 2010; TREAKLE et al., 2009).

Estudos demonstram que no ambiente em que o paciente se encontra objetos e superfícies podem ser facilmente contaminados por microrganismos e neste permanecerem por um longo período de tempo (BOYCE; PITTET, 2002). Além disso, o Staphylococcus aureus, inclusive o MRSA, é capaz de sobreviver por meses em superfícies secas (KRAMER; SCHWEBKE; KAMPF, 2006). 
Grande parte das infecções no ambiente hospitalar é decorrente da disseminação de microrganismo, por meio do contato direto com um indivíduo suscetível ou pelo contato com fômites (MURRAY; ROSENTHAL; PFALLER, 2014).

Estudos consideram os estetoscópios como importantes fômites na transmissão de microrganismos resistentes e recomendam que a prática da desinfecção deve ser considerada após cada utilização (LONGTIN et al., 2014; XAVIER; UENO, 2009).

Pandey et al. (2010) realizaram uma pesquisa com o objetivo de investigar a prevalência de microrganismos nos acessórios utilizados por profissionais de saúde de um hospital terciário. No total de 436 swabs coletados de canetas, de estetoscópios, de telefones celulares e de jalecos, 207 (47,5\%) estavam contaminados por microrganismos patogênicos; o Staphylococcus aureus foi encontrado em 12,3\% das culturas e o MRSA em 7,3\%.

Jalecos utilizados por profissionais de saúde são apontados como veículos potenciais para a transmissão de microrganismos não apenas no ambiente intrahospitalar como também na comunidade (MARGARIDO et al., 2014).

Do total de 149 jalecos analisados em um estudo transversal norteamericano, $34(22,8 \%)$ estavam contaminadas com Staphylococcus aureus e seis (4,0\%) eram MRSA; demonstrando que foi a bactéria prevalente nos jalecos dos profissionais de saúde (TREAKLE et al., 2009).

Em 2011, no Estado de São Paulo, foi aprovada a Lei $n^{\circ} 14.466$ que proíbe o uso, por profissionais da área da saúde, de equipamentos de proteção individual fora do ambiente de trabalho, inclusive jalecos e aventais. A lei visa impedir o risco de contaminação de pacientes e da população em geral, prevendo punições financeiras aos que descumprirem a regra (SÃO PAULO, 2011).

Vestimentas usadas pelos profissionais de saúde constituem risco para a transmissão de microrganismos não apenas para os pacientes, mas também para os familiares e contactantes desses profissionais (HIGGINSON, 2011).

Embora a finalidade do jaleco seja proteger o profissional de saúde em atividades executadas envolvendo exposição a material biológico, estudo relata que a utilização inadequada desta vestimenta, principalmente fora do ambiente de trabalho, pode ocasionar consequências graves para a saúde pública (CARVALHO, C. et al., 2009).

Os telefones celulares de profissionais de saúde que utilizam o equipamento no ambiente de trabalho podem estar contaminados por agentes patogênicos como 
- MRSA. Com isso, esses aparelhos contaminados por patógenos hospitalares podem causar contaminação cruzada entre trabalhadores, pacientes e comunidade, ocasionando infecções graves, com elevadas taxas de morbidade, de mortalidade e custos (BRADY, et al., 2009; GOLDBLATT et al., 2007).

Com o objetivo de avaliar a contaminação microbiana de telefones celulares de profissionais de saúde, estudo apontou que de 183 destes aparelhos, 179 $(97,8 \%)$ estavam contaminados por algum tipo de bactéria. O Staphylococcus aureus foi encontrado em 28 (15,6\%) e o MRSA em 17 (9,5\%) culturas microbiológicas desses telefones (USTUN; CIHANGIROGLU, 2012).

Um dos métodos adotados e recomendados para a descontaminação do telefone celular é a realização da limpeza do mesmo com álcool a 70\%. A adoção dessa medida demonstra uma redução significativa da contaminação bacteriana nesses aparelhos (BRADY et al., 2009).

A literatura aponta que a higienização das mãos, antes e após a manipulação de acessórios, tais como canetas, telefones celulares, estetoscópios e jalecos é uma medida universalmente recomendada (BRADY et al., 2009; CARVALHO, C. et al., 2009; PANDEY et al., 2010).

No entanto, apesar de a literatura relatar que os dispositivos utilizados pelos profissionais de saúde abrigam uma diversidade de microrganismos patogênicos, o uso desses equipamentos não pode ser proibido nos serviços de saúde, por serem ferramentas essenciais e necessárias para os profissionais executarem suas atividades. Portanto, é extremamente recomendável que os acessórios utilizados regularmente como, canetas, telefones celulares, estetoscópios e crachás sejam limpos regularmente com produtos à base de álcool, com o objetivo de reduzir a carga microbiana (LONGTIN et al., 2014; PANDEY et al., 2010).

\subsection{Staphylococcus aureus em indivíduos com HIV/aids}

Indivíduos com HIV/aids são considerados como uma população suscetível à colonização e infecções por Staphylococcus aureus. Pesquisa realizada com o objetivo de verificar a prevalência de infecções oportunistas em pacientes com HIV/aids mostrou que infecção por Staphylococcus aureus foi a mais frequente; a 
prevalência em indivíduos que convivem com o HIV foi de $9,8 \%$, enquanto que nos indivíduos com aids foi de 28,7\% (SAEED; FARID; JAMSHEER, 2015).

A colonização por Staphylococcus aureus na narina anterior varia de acordo com a população estudada. Indivíduos que convivem com HIV/aids apresentam uma taxa média de $35,5 \%$. Além disso, essa colonização tem sido associada a uma maior morbidade e mortalidade nesta população de indivíduos com deficiência imunológica (KLUYTMANS; VAN BELKUM; VERBRUGH, 1997).

Taxas mais elevadas de colonização em indivíduos com HIV/aids foram encontradas no estudo de Chacko, Kuruvila e Bhat (2009). Neste estudo, 76,7\% apresentaram colonização por Staphylococcus aureus, sendo 17,4\% portadores de MRSA; a permanência hospitalar por mais de 10 dias foi um fator de risco para a resistência à meticilina.

Estudo apontou uma taxa de $7,3 \%$ de MRSA em indivíduos com internação recente e os fatores de risco relacionados foram ser portador de HIV/aids, relato de internações anteriores, uso prévio de antibiótico e infecções de pele e de tecidos moles (HIDRON et al., 2005).

Pesquisa envolvendo 131 indivíduos que convivem com o HIV/aids aponta que 34 (25,9\%) apresentaram colonização nasal por Staphylococcus aureus, sendo que dois eram MRSA (OLIVA et al., 2013).

Investigação para avaliar a prevalência de colonização nasal por Staphylococcus aureus em indivíduos que convivem com HIV/aids mostrou que, dos 169 participantes, 46 (27,2\%) foram identificados como colonizados por Staphylococcus aureus. Destes, 36 (78,3\%) eram MSSA e 10 (21,7\%), MRSA (REINATO et al., 2013).

Estudo de Farley et al. (2015) apontaram que as narinas foram os principais sítios de colonização por MRSA em indivíduos com HIV; entretanto, os autores recomendam a triagem em diferentes sítios anatômicos, visto que em seu estudo $40,3 \%$ dos indivíduos colonizados por MRSA apresentaram culturas negativas nas narinas e positivas na cavidade oral, na virilha, na axila, no períneo, entre outros.

Weinke et al. (1991) apontam que cepas multirresistentes de Staphylococcus aureus ocorreram com mais frequência em indivíduos com HIV. Além disso, observou-se que esses microrganismos eram mais presentes em portadores persistentes comparados aos portadores intermitentes. 
Contagem de células T CD4 inferior a 200 células $/ \mathrm{mm}^{3}$, exposição prévia a antimicrobianos $\beta$-lactâmicos e hospitalizações anteriores foram associadas a infecções por MRSA em indivíduos com HIV/aids (RAMSETTY et al., 2010; TUMBARELLO et al., 2002).

Pesquisa realizada nos Estados Unidos para determinar a prevalência de colonização nasal por MRSA entre pacientes ambulatoriais vivendo com HIV/aids identificou que, dos 146 participantes, 15 (10,3\%) apresentaram colonização por MRSA. Além disso, a contagem média de células T CD4 nesses indivíduos era mais baixa, se comparada à dos não colonizados (CENIZAL et al., 2008).

Fatores de risco identificados para colonização ou para infecção por MRSA incluem: internação prolongada; uso prolongado $e$ ou inadequado de antimicrobianos; presença de procedimentos invasivos; e o contato com ambiente hospitalar ou com profissionais de saúde (HIDRON et al., 2005).

Estudos apontam como fator de proteção contra a colonização por MRSA o uso da terapia antirretroviral altamente ativa (HAART), por melhorar o sistema imunológico dos indivíduos com HIV/aids (HIDRON; MOANNA; RIMLAND, 2011; RAMSETTY et al., 2010).

O Staphylococcus aureus possui característica virulenta capaz de provocar sérios agravos à saúde em indivíduos imunocomprometidos que convivem com HIV/aids. Entretanto, o monitoramento da disseminação desse microrganismo, nessa população, contribuirá não apenas para a implementação de programas de prevenção e de controle das infecções, como também na sobrevida desses indivíduos com HIV/aids (REINATO et al., 2013).

\subsection{Prevenção e controle da disseminação de MRSA}

É inquestionável que os antimicrobianos revolucionaram o tratamento das infecções no século XX. No entanto, a ocorrência de surtos de infecção por Staphylococcus aureus, na década de 1960, aumentaram os custos hospitalares, e com isso, os órgãos governamentais demostraram mais interesse para medidas de controle de infecção (FONTANA, 2006). 
A higienização das mãos é considerada uma importante medida para reduzir a transmissão de microrganismos que causam infecções relacionadas à assistência à saúde; a adesão a esta prática é capaz de prevenir e de controlar a disseminação de agentes infecciosos (WHO, 2009a). Trabalhos enfatizam essa técnica de fundamental importância no combate a infecções cruzadas no ambiente hospitalar (PITTET et al., 2006; PRADO; HARTMANN; TEIXEIRA FILHO, 2013).

Embora a reconhecida eficácia e alto custo-benefício da higienização das mãos no controle de infecções, estudos nacionais e internacionais relatam a baixa adesão a esta prática pelos profissionais de saúde (BOYCE; PITTET, 2002; CRUZ et al., 2009; NEVES et al., 2006; PRIMO et al., 2010).

Estudo identificou que a maioria dos profissionais de saúde participantes da pesquisa realizaram a higienização das mãos com água e sabão em um tempo menor que o indicado para uma boa higiene ( 40 a 60 segundos); o tempo utilizado para higienização das mãos em mais de $90,0 \%$ dos profissionais foi inferior a 20 segundos (MOTA et al., 2014).

Igualmente importante para a boa prática de higienização das mãos, destacamos a presença de uma adequada estrutura física. Estudos identificam barreiras que comprometem a adesão à higienização das mãos, como dificuldade de acesso às pias, carência ou inexistência de dispensadores, falta de abastecimento dos insumos (sabão líquido, álcool gel, papel toalha) (PITTET, 2000; PRADO; HARTMANN; TEIXEIRA FILHO, 2013).

Com o objetivo de promover a higienização das mãos, a Organização Mundial da Saúde (OMS) recomenda o uso de soluções alcoólicas para facilitar o acesso e estimular o uso do produto pelos profissionais da saúde. Comparada à higienização com água e sabão, o uso de soluções alcoólicas nas mãos oferece vantagens como: rapidez na aplicação e facilidade no uso; maior eficácia antimicrobiana; menor ressecamento da pele e maior aceitabilidade pelos profissionais (PITTET, 2000; WHO, 2009a).

A equipe de $\mathrm{CClH}$ das instituições de saúde, por desempenhar um papel fundamental na motivação dos profissionais para adotarem as práticas de higienização das mãos, deve sempre buscar estratégias com objetivo de melhorar as taxas de adesão a essas práticas pelos profissionais (OLIVEIRA; PAULA, 2014).

Estratégias como colocação de dispositivos com álcool gel em locais visíveis próximos aos leitos e uma maior divulgação de informações sobre a eficácia do 
álcool gel na eliminação de microrganismos presentes nas mãos favoreceram a adesão à higienização das mãos pelos profissionais de saúde (VILARINHO et al., 2015).

Investigação realizada no Estado do Piauí mostrou que a higienização das mãos por meio da utilização de soluções alcoólicas foi eficiente em eliminar bactérias pertencentes ao gênero Staphylococcus, principalmente Staphylococcus aureus. Além disso, esses produtos apresentaram maior adesão pelos profissionais de saúde (VILARINHO et al., 2015).

Segundo o manual de Investigação e Controle de Bactérias Multirresistentes da Agência Nacional de Vigilância Sanitária (ANVISA), as principais estratégias de controle para prevenção de microrganismos multirresistentes são: identificação precoce de pacientes colonizados ou infectados, identificação do isolamento dos pacientes por meio de placas ilustrativas e adesão às precauções de contato preconizadas pelos Serviços de Controle de Infecção Hospitalar (BRASIL, 2007).

Peres et al. (2014) desenvolveram um estudo em Portugal com objetivo de implementar uma estratégia multimodal para controle de MRSA em um hospital com níveis endêmicos. O pilar básico da estratégia consistiu em: incentivo à adesão às PP pelos profissionais de saúde; realização de rastreio ativo de uma população selecionada; implementação de medidas de isolamento de contato em pacientes com suspeita ou confirmação de colonização/infecção por MRSA e descolonização de paciente internados em unidades críticas.

Protocolos adotados para a descolonização podem apresentar variações, e as terapias empregadas podem ocorrer mediante o uso de antibióticos via oral ou tópico. Os principais antibióticos de uso sistêmico relatados nos estudos foram: rifampicina; doxiciclina; ciprofloxacina; minociclina e vancomicina. No entanto, para o tratamento tópico, os mais empregados foram: mupirocina; sulfonamida; clorohexidina; iodopovidona; octenidina, entre outros (BUEHLMANN et al., 2008; SIMOR, 2011).

Após a descolonização, o monitoramento de sua eficácia é indicado, por meio de três rastreios de acompanhamento, sendo o primeiro indicado após 48 horas do término do tratamento, e os demais com intervalos semanais (PERES et al., 2014).

Para a adoção de medidas de prevenção e de controle da disseminação do MRSA em seu cotidiano, o conhecimento dos profissionais da enfermagem é elemento essencial. Estudo para avaliar o conhecimento da equipe de enfermagem 
de um hospital sobre as medidas preventivas mostrou que $92,7 \%$ dos profissionais sentem-se preocupados ao prestarem assistência a pacientes com MRSA e 78,3\% reconhecem os riscos a que estão expostos (SILVA et al., 2010).

Dessa forma, identifica-se a necessidade de estimular os profissionais em sua prática de enfermagem a adotarem com responsabilidade as medidas básicas para o controle de infecções, essenciais tanto para a segurança do paciente como para a do profissional. Sendo assim, é de fundamental importância a conscientização do profissional como um potencial disseminador de agentes patológicos em seu ambiente de trabalho (SANTOS, 2004; SILVA et al., 2010). 


\section{REFERENCLAL TEÓRICO}




\section{REFERENCIAL TEÓRICO}

Brevidelli e Cianciarullo (2009) desenvolveram um modelo explicativo de adesão às PP adaptado, traduzido e validado para o português, baseado no modelo de Dejoy, Murphy e Gershon (1995) e Gershon et al. (1995). Esse modelo proposto analisa a intersecção entre fatores individuais, relacionados ao trabalho, e organizacionais, na adesão às PP. É composto por um total de dez escalas psicométricas do tipo Likert, com cinco opções de resposta. São elas:

- Escala de Adesão às PP;

- Escala de Personalidade de Risco;

- Escala de Obstáculos para Seguir as PP;

- Escala de Eficácia da Prevenção;

- Escala de Percepção de Risco;

- Escala de Clima de Segurança;

- Escala de Treinamento em Prevenção da Exposição Ocupacional ao HIV;

- Escala de Disponibilidade do Equipamento de Proteção Individual;

- Escala de Conhecimento da Transmissão Ocupacional do HIV;

- Escala de Carga de Trabalho.

Dejoy, Murphy e Gershon (1995) desenvolveram um Modelo de Sistemas de Trabalho com a finalidade de estudar a influência de conjuntos de fatores (individuais, relativos ao trabalho, e organizacionais) na adesão às PP pelos profissionais de enfermagem de um grande centro médico. Nesse modelo, a adesão às PP ocorre por meio da interface dos três fatores.

O Modelo de Adesão às PP, desenvolvido por Gershon et al. (1995), considera os fatores individuais, psicossociais e organizacionais, sendo que os fatores psicossociais abordam questões relacionadas ao medo e ao estresse no trabalho, assim como as atitudes em relação ao HIV/aids e à percepção de risco.

Brevidelli e Cianciarullo (2009) aplicaram as escalas em profissionais da enfermagem e médicos; o objetivo foi analisar a influência de fatores psicossociais e organizacionais na adesão às PP para prevenir a exposição a material biológico em 
um hospital universitário paulista. A adesão às PP foi influenciada por fatores individuais, relativos ao trabalho e organizacionais. O modelo explicativo de adesão às PP não engloba aspectos relacionados ao estresse no trabalho.

Os fatores individuais compreendem aspectos sociodemográficos; de conhecimento da transmissão ocupacional do HIV; de percepção de risco; de personalidade de risco e de eficácia da prevenção. Os fatores relativos ao trabalho avaliam os obstáculos para seguir as PP e a carga de trabalho. Os fatores organizacionais estão relacionados à gerência e referem-se aos aspectos organizacionais definidos pelo clima de segurança, disponibilidade do equipamento de proteção, treinamento para prevenção da exposição ao HIV (BREVIDELLI; CIANCIARULLO, 2009). 


\section{OBJETIVOS}

\subsection{Geral}

Avaliar a colonização por Staphylococcus aureus em profissionais de enfermagem e a adesão às precauções-padrão.

\subsection{Específicos}

> Caracterizar aspectos profissionais, demográficos e individuais dos profissionais de enfermagem;

> Estimar a prevalência de Staphylococcus aureus sensível e resistente à oxacilina isolados na saliva, em secreção nasal e em base do telefone celular;

> Identificar o estado de carreador dos profissionais de enfermagem;

> Identificar o perfil de suscetibilidade dos Staphylococcus aureus isolados na saliva e na secreção nasal dos profissionais de enfermagem aos antimicrobianos;

$>$ Descrever e comparar a média dos escores das escalas do modelo explicativo de adesão às precauções-padrão entre os profissionais de enfermagem colonizados e não colonizados por Staphylococcus aureus;

> Comparar a média dos escores da escala de adesão às precauções-padrão entre os profissionais de enfermagem colonizados com as variáveis demográficas e profissionais;

> Identificar medidas de associação entre os profissionais de enfermagem colonizados e não colonizados por Staphylococcus aureus com as variáveis demográficas, profissionais e individuais. 


\section{MATERIAL E MÉTODOS}

\subsection{Delineamento e local do estudo}

Trata-se de um estudo de corte transversal realizado em cinco unidades de internação de um hospital escola do município de Ribeirão Preto, sendo três unidades destinadas à clínica médica e duas especializadas em prestação de cuidados a pessoas adultas com HIV/aids. Optou-se por desenvolver este estudo nesses locais por serem unidades onde são internados pacientes de alta e de média complexidade, por períodos de internação prolongados, dentre estes as pessoas que convivem com HIV/aids.

A instituição onde o estudo foi desenvolvido é um hospital público terciário de grande porte, integrado ao Sistema Único de Saúde (SUS) e reconhecido como centro de referência. O Hospital, que iniciou suas atividades em junho de 1956, oferece assistência para toda a macrorregião de Ribeirão Preto (composta de cerca de quatro milhões de habitantes), e inclusive atende pacientes referenciados de outras regiões e até mesmo de outros Estados. O complexo do Hospital das Clínicas da Faculdade de Medicina de Ribeirão Preto (HCFMRP-USP) tem como atividades principais proporcionar assistência médico-hospitalar e servir de campo de Ensino e de Pesquisa, na área da saúde. Dispõe de três prédios, dois situados no Câmpus Universitário e um, na área central da cidade, local de funcionamento da Unidade de Emergência. Em 2012, a Unidade Câmpus contava com 704 leitos e foram realizadas mais de 25.600 internações. As unidades inclusas neste estudo possuíam 123 leitos; no ano de 2012, aproximadamente 5.560 internações foram registradas (HCFMRP-USP, 2012).

Em geral, 5.768 servidores faziam parte da equipe de trabalho, sendo que $38,0 \%$ deste quadro era composto pela equipe de enfermagem (HCFMRP-USP, 2012). A jornada de trabalho dos servidores variava de 30 a 36 horas semanais, sendo a carga horária diária de seis horas no turno diurno (manhã e tarde) ou de 12 horas noturnas.

Além disso, a instituição possui uma equipe de $\mathrm{CCIH}$ atuante composta por quatro médicos e quatro enfermeiros (Unidade Câmpus), responsável por 
desenvolver ações de prevenção e de controle das infecções hospitalares, além de medidas como controle do uso de antimicrobianos, fiscalização da limpeza e desinfecção de artigos e superfícies, incentivo à correta higienização das mãos, entre outras.

\subsection{População de estudo}

A população do estudo foi composta pelos auxiliares de enfermagem, técnicos de enfermagem e enfermeiros das unidades de clínica médica e de unidades especializadas em HIV/aids da instituição. Para serem elegíveis, os profissionais atenderam aos seguintes critérios de inclusão: prestar assistência direta aos doentes; estar lotado em uma das unidades de internação do estudo; encontrar-se em exercício ativo na função no período das coletas.

Os profissionais de enfermagem que no decorrer da pesquisa foram transferidos de setores, demitidos da instituição, afastados do serviço por qualquer natureza, ou que exerciam atividades exclusivamente administrativas, assim como aqueles que não tiveram todas as amostras previstas coletadas foram excluídos do estudo.

Uma relação com 142 profissionais de enfermagem lotados nas referidas unidades foi obtida junto ao Departamento de Recursos Humanos da instituição. Destes, 14 recusaram-se a participar da pesquisa e sete encontravam-se afastados por licença saúde por prazo indeterminado. Sendo assim, um total de 121 profissionais de enfermagem foram abordados no primeiro período da coleta. Após quatro meses, no segundo período, seis profissionais foram excluídos por motivo de licença saúde, cinco por se desvincularem da instituição e dois por transferência de setor. O terceiro e último período da coleta foi concluído oito meses após o início da pesquisa, e a população foi composta por um total de 100 profissionais de enfermagem (participantes dos três períodos de coleta); pois entre os meses quatro e oito, três profissionais foram desvinculados da instituição, três estavam de licença saúde e dois se recusaram a permanecer no estudo. 


\subsection{Aspectos éticos}

Para a realização da presente pesquisa, foram consideradas as diretrizes e normas regulamentadoras de pesquisas envolvendo seres humanos, Resolução no 466 de dezembro 2012, do Conselho Nacional de Saúde (CONEP). O projeto foi submetido ao Comitê de Ética em Pesquisa da Escola de Enfermagem de Ribeirão Preto- USP e aprovado conforme o parecer n 603.228/2013, número Certificado de Apresentação para Apreciação Ética (CAAE) 20111213.3.0000.5393 que, posteriormente, foi alterado para 20111213.3.3001.5440 (Anexo A).

Foi solicitada e concedida a autorização junto à Diretoria de Enfermagem da instituição para o desenvolvimento da pesquisa (Anexo B).

Os profissionais de enfermagem foram convidados a participar da presente pesquisa e ler as informações contidas no Termo de Consentimento Livre e Esclarecido (TCLE) (Apêndice A). Os participantes foram assegurados quanto ao anonimato e ao sigilo das informações, bem como ao direito de interromper a participação, em qualquer momento, sem sofrer nenhum prejuízo.

Vale ressaltar que a coleta de dados foi iniciada somente mediante consentimento dos que aquiesceram participar da pesquisa. Os profissionais identificados como colonizados, primeiramente, foram comunicados sobre os resultados da cultura; e, mediante concordância, encaminhados à $\mathrm{CCIH}$ da referida instituição para proceder à conduta necessária, de acordo com o protocolo de descolonização vigente na instituição (ROSSINI et al., 2009).

\subsection{Coleta de dados}

A coleta de dados compreendeu a obtenção de aspectos demográficos, profissionais, individuais e referentes às PP, contendo as variáveis, como sexo, idade, categoria profissional, turno e setor de trabalho, tempo de exercício profissional, carga horária semanal de trabalho, hábitos ou características de saúde e conhecimento sobre precauções-padrão. Além disso, foram obtidas amostras de 
saliva, de secreção nasal e swab do telefone celular dos profissionais de enfermagem.

\subsubsection{Período de coleta de dados}

A coleta de dados teve início em abril de 2014 e estendeu-se até fevereiro de 2015, totalizando 10 meses, e compreendeu três momentos. O primeiro período da coleta abrangeu os meses de abril de 2014 a junho de 2014 (mês zero); o segundo de agosto de 2014 a outubro de 2014 (mês quatro) e o terceiro, de dezembro de 2014 a fevereiro de 2015 (mês oito). Nestes períodos foram coletadas amostras de saliva e de secreção da narina anterior de todos os profissionais da enfermagem participantes do estudo. Também foi realizado esfregaço, por meio de swab, na superfície externa e posterior do telefone celular de todos os profissionais que 0 possuíam. Sendo assim, o esfregaço foi realizado em 97 telefones celulares, pertencentes aos profissionais.

\subsubsection{Instrumentos para coleta de dados}

Os dados demográficos, profissionais e individuais foram obtidos por meio de um instrumento semiestruturado (Apêndice B) e aplicado no primeiro momento da coleta de dados. Esse instrumento foi submetido à validação quanto à forma e ao conteúdo por três especialistas na temática e foram sugeridas algumas alterações em determinados itens. Essas sugestões foram consideradas apropriadas para o alcance dos objetivos e prontamente acatadas.

Para a avaliação da adesão dos profissionais às PP, foram aplicadas dez escalas psicométricas do tipo Likert, desenvolvidas por Dejoy, Murphy e Gershon (1995) e Gershon et al. (1995), traduzidas e validadas para o português por Brevidelli e Cianciarullo (2009), sendo elas: "Escala de Adesão às PP" (13 itens); "Escala de Personalidade de Risco" (04 itens); "Escala de Obstáculos para Seguir as PP" (06 itens); "Escala de Eficácia da Prevenção" (03 itens); "Escala de Percepção 
de Risco" (03 itens); "Escala de Clima de Segurança" (12 itens); "Escala de Treinamento em Prevenção da Exposição Ocupacional ao HIV" (04 itens); "Escala de Disponibilidade do Equipamento de Proteção Individual (EPI)" (02 itens); "Escalas de Conhecimento da Transmissão ocupacional do HIV" (07 itens); "Escala de Carga de Trabalho" (03 itens), totalizando 57 itens, cujas opções variam segundo uma sequência progressiva de 1 a 5 pontos (Anexo C). Foi obtida autorização dos autores para a utilização das escalas (Anexo D).

\subsubsection{Coleta de dados propriamente dita}

Para a coleta de saliva, foi solicitado que o participante depositasse de três a cinco mililitro $(\mathrm{mL})$ de saliva diretamente em um tubo de ensaio graduado, seco, estéril e com tampa. A obtenção de secreção da narina anterior foi por meio de um swab seco introduzido em cada uma das narinas, e realizado três movimentos circulares, em sentido horário. O esfregaço na base do telefone celular foi por meio de um swab umedecido em solução salina estéril e realizado movimentos circulares na superfície externa e posterior do equipamento portátil, em sentido diagonal e unidirecional. Em telefones celulares que possuíam capa protetora, o esfregaço foi realizado na própria capa protetora por ser o local que mantinha contato com as mãos dos profissionais de enfermagem. Vale ressaltar que os swabs utilizados continham meio de cultura para transporte (ágar semi-sólido de Stuart).

As amostras de saliva e de secreção nasal foram coletadas em três momentos (meses zero, quatro e oito), enquanto que o swab da base do telefone celular em dois momentos (meses zero e oito).

Após a coleta, o material era encaminhado ao laboratório de Microbiologia e Sorologia da referida instituição. As normas de biossegurança recomendadas foram cumpridas em todas as etapas de coleta e de transporte do material.

A aplicação do instrumento semiestruturado e a coleta do material foram realizadas pelo pesquisador e por quatro auxiliares de pesquisa (três enfermeiros e um aluno de graduação em enfermagem), especificamente treinados para tal atividade. Os profissionais foram abordados no próprio local de trabalho, nos turnos manhã, tarde e noite. O pesquisador e auxiliares de pesquisa aguardaram o 
momento oportuno que o profissional tivesse disponibilidade para participar do estudo. A coleta de dados ocorreu em sala privativa; o tempo médio para a aplicação do instrumento e para a coleta do material biológico foi de 20 minutos.

\subsection{Seleção e treinamento dos auxiliares de pesquisa}

Os auxiliares de pesquisa selecionados para atuarem na coleta de dados da presente pesquisa receberam um treinamento específico para desenvolverem essa atividade. Além disso, receberam recomendações por escrito sobre a coleta das amostras e sobre o controle dos profissionais de saúde.

\subsection{Estudo piloto}

Foi realizado um estudo piloto com cinco profissionais da enfermagem para avaliar as estratégias propostas para a coleta, o tempo utilizado pelo pesquisador e pelos auxiliares de pesquisa na aplicação do instrumento, a verificação das condições técnicas para a realização do estudo e o processamento dos dados laboratoriais. Os participantes do estudo piloto, não foram incluídos na população estudada.

\subsection{Procedimentos laboratoriais - Isolamento e identificação fenotípica dos microrganismos}

O material foi semeado em ágar sangue e manitol. As amostras coletadas foram processadas no Laboratório de Microbiologia e Sorologia do Hospital das Clínicas da Faculdade de Medicina de Ribeirão Preto da Universidade de São Paulo.

Após, foi utilizado o sistema automatizado Vitek® 2 (BioMérieux ${ }^{\mathrm{TM}}$ ), por meio de cartões GP Test Kit Vitek® 2 para a identificação de bactérias Gram-positivas. 
Para identificar e avaliar a suscetibilidade Staphylococcus aureus aos antibióticos, foram utilizados cartões AST P585 (BioMérieux ${ }^{\mathrm{TM}}$ ).

Placas contendo Ágar Müeller-Hinton foram utilizadas para a confirmação do antibiograma. Após a semeadura e a aplicação dos discos de papel filtro impregnados com antibióticos em concentrações fixas sobre a placa, foi realizada a incubação por 24 horas a uma temperatura de $35^{\circ} \mathrm{C}$. Os diâmetros dos halos de inibição de crescimento ao redor de cada disco foram mensurados em milímetros e feita sua interpretação, conforme os critérios estabelecidos pelo Clinical and Laboratory Standards Institute (CLSI, 2014). Sendo assim, as amostras bacterianas foram categorizadas em sensíveis, resistentes ou intermediárias, medindo-se halo de inibição do crescimento ao redor do disco de antibióticos. Os fabricantes de discos de sensibilidade fornecem tabelas de halos de sensibilidade específicas para os discos empregados, os quais são baseados em recomendações do CLSI.

\subsection{Processamento e análise dos dados}

Os dados foram digitados em planilhas do Microsoft Office Excel for Windows 2013. Realizou-se a dupla digitação e validação, a fim de identificar possíveis erros de digitação. Posteriormente, a planilha foi transportada para o software IBM $^{\circledR}$ SPSS, versão 20.0, cujo banco definitivo foi formatado e foram realizadas as operações de gerenciamento, como a criação de novas variáveis, a categorização das variáveis e demais operações incluídas no estudo.

Para a análise, utilizou-se estatística descritiva e testes de associação entre as variáveis. A análise foi realizada em diversas etapas:

a) Descritiva: Medidas de tendência central (média e mediana) e de dispersão (desvio padrão);

b) Estudo de Associação: Para a comparação das médias de adesão entre os grupos colonizados e não colonizados, utilizou-se o teste t de Student e a análise de variância (ANOVA). Para a comparação entre as variâncias utilizou-se $o$ teste Levene. Valor de $p \leq 0,05$ foi considerado 
estatisticamente significante. Foi calculada a razão de prevalência (RP) para testar a associação entre os grupos de profissionais colonizados e não colonizados com as características demográficas, profissionais e individuais;

c) Confiabilidade: O coeficiente alfa de Cronbach foi utilizado para testar a confiabilidade das escalas, e deve ser interpretado no intervalo entre 0 e 1. A confiabilidade é tanto maior quanto mais perto de 1 estiver o valor da estatística.

Para analisar os níveis de adesão às PP, foi realizado o cálculo dos escores médios simples de cada item das escalas e calculado o escore médio global de cada escala para o grupo de colonizados e não colonizados. De acordo com Brevidelli (2003), os escores foram classificados como:

- Alto: escores médios iguais ou superiores a 4,5;

- Intermediário: escores médios com valores entre 3,5 e 4,49;

- Baixo: escores médios com valores abaixo de 3,5.

Os escores das escalas variaram entre 1 e 5, sendo que, quanto maior 0 escore, melhor a adesão ou percepção. Dessa forma, para o cálculo dos escores médios, foi necessária uma recodificação em determinados itens das escalas para que todas obtivessem a seguinte interpretação: quanto maior o valor, maior a percepção da intensidade. Sendo assim, após a recodificação, o número 1 passou a ser considerado número 5, 2-4, 3-3, 4-2, e, por último, o número 5 como número 1.

Para a Escala de Adesão às PP, somente o item 11 não foi invertido, pois consiste em uma questão negativa. Após a recodificação, a escala passou a ser interpretada: quanto maior o escore, maior a adesão.

A interpretação foi a mesma para a Escala de Conhecimento da Transmissão Ocupacional do HIV; Escala Eficácia da Prevenção; Escala de Carga de Trabalho; Escala de Clima de Segurança; Escala Disponibilidade de Equipamento de Proteção Individual e para a Escala de Treinamento em Prevenção da Exposição ao HIV, pois todos os itens foram invertidos para se manter a interpretação de que, quanto maior o escore, maior a intensidade percebida.

Na Escala de Percepção de Risco, apenas dois itens (03 e 13) necessitaram de inversão, enquanto que na Escala de Personalidade de Risco e na Escala de 
Obstáculos para Seguir as PP, não houve necessidade de inversão em nenhum dos itens. Porém a interpretação para a Escala de Personalidade de Risco deve ser: quanto maior o escore, menor a personalidade de risco adotada pelo profissional.

\subsection{Conceito: classificação do carreador}

O estado de carreador dos profissionais de enfermagem considerado neste estudo foi de acordo com o proposto por Nilsson e Ripa (2006).

Para esses autores, o estado de carreador é definido tendo como numerador o total de amostras positivas, e como denominador, o número total de amostras coletadas de cada indivíduo. Sendo assim, consideramos no presente estudo:

- Carreadores persistentes: indivíduos com duas ou três culturas positivas para Staphylococcus aureus;

- Carreadores transitórios: indivíduos com apenas uma cultura positiva para Staphylococcus aureus;

- Não carreadores: indivíduos com nenhuma cultura positiva para Staphylococcus aureus. 


\section{RESULTADOS}

\subsection{Caracterização demográfica e profissional dos profissionais de enfermagem}

Dos 100 profissionais de enfermagem participantes da pesquisa, 59 (59,0\%) eram auxiliares de enfermagem, 22 (22,0\%) técnicos de enfermagem e 19 (19,0\%), enfermeiros. O predomínio foi do sexo feminino com $79,0 \%$ dos indivíduos. A idade variou entre 23,5 e 61,8 anos, com mediana de 41,4 anos (DP=8,6); 39 (39,0\%) encontravam-se na faixa etária de 40 a 49 anos.

Quanto à escolaridade dos participantes, considerou-se o mais elevado nível educacional relatado pelos participantes; além disso, pós-graduação completa foi classificada tanto a modalidade lato sensu como stricto sensu. Verificou-se que 68 $(68,0 \%)$ dos profissionais relataram ensino médio completo como o mais elevado nível educacional. Esse resultado é compatível com a predominância da categoria profissional em $81,0 \%$ dos participantes.

Com relação ao turno de trabalho, 37 (37,0\%) atuavam no período diurno e 28 (28,0\%), no noturno. Um total de $35(35,0 \%)$ relatou trabalhar em regime de rodízio de turnos, ou seja, em períodos diurno e noturno.

O tempo de trabalho na área da enfermagem referido pelos profissionais variou de 08 meses a 36 anos, com média de 12,9 anos (DP=7,6), e 43,0\% dos profissionais possuíam entre 05 e 14 anos de experiência profissional.

Sobre o número de vínculos empregatícios, $86,0 \%$ dos profissionais declararam um único vínculo e 14,0\%, duplo vínculo nas atividades laborais, em diferentes instituições. Com relação à carga horária de trabalho exercida semanalmente em todos os empregos, evidenciou-se que 57,0\% dos profissionais trabalhavam acima de 36 horas semanais. A maior carga horária de trabalho semanalmente foi de 96 horas, relatada por um profissional que mantinha dois vínculos e realizava plantões extras semanalmente na instituição.

Dos $92(92,0 \%)$ profissionais de enfermagem com o conhecimento sobre as PP, $37(40,2 \%)$ referiram ter adquirido esse conhecimento no próprio hospital, por 
meio de palestras, $32(34,8 \%)$ na escola ou universidade, e $23(25,0 \%)$ alegaram as duas opções anteriores.

Quanto ao treinamento sobre as PP, 91 (91,0\%) dos profissionais informaram que em algum momento de sua formação profissional participaram de capacitação acerca deste tema. Para $84(92,3 \%)$, o treinamento foi oferecido na própria instituição de trabalho, sendo que 15 (17,9\%) o referiram nos primeiros três meses, ou seja, no período admissional. Além disso, 12 (13,2\%) dos profissionais mencionaram que a capacitação foi nos últimos 12 meses, 35 (38,5\%), entre 1 e 5 anos, 12 (13,2\%) alegaram um período superior a 5 anos e 32 (35,1\%) não souberam informar o momento.

Características demográficas e profissionais dos 100 indivíduos que constituíram a população deste estudo estão apresentadas na Tabela 1. 
Tabela 1 - Distribuição dos profissionais de enfermagem $(\mathrm{N}=100)$, segundo a caracterização demográfica e profissional referida. Ribeirão Preto-SP, 2014-2015

\begin{tabular}{|c|c|c|}
\hline Variáveis & $f$ & $\%$ \\
\hline \multicolumn{3}{|l|}{ Categoria Profissional } \\
\hline Enfermeiro & 19 & 19,0 \\
\hline Técnico de Enfermagem & 22 & 22,0 \\
\hline Auxiliar de Enfermagem & 59 & 59,0 \\
\hline \multicolumn{3}{|l|}{ Sexo } \\
\hline Feminino & 79 & 79,0 \\
\hline $\begin{array}{l}\text { Masculino } \\
\text { Idade (anos) }\end{array}$ & 21 & 21,0 \\
\hline 20 a 39 & 09 & 9,0 \\
\hline 30 a 39 & 36 & 36,0 \\
\hline 40 a 49 & 39 & 39,0 \\
\hline$\geq 50$ & 16 & 16,0 \\
\hline \multicolumn{3}{|l|}{ Escolaridade } \\
\hline Ensino médio completo & 68 & 68,0 \\
\hline Superior completo & 22 & 22,0 \\
\hline $\begin{array}{l}\text { Pós-graduação completa } \\
\text { Turno de trabalho }\end{array}$ & 10 & 10,0 \\
\hline Diurno & 37 & 37,0 \\
\hline Noturno & 28 & 28,0 \\
\hline Rodízio & 35 & 35,0 \\
\hline \multicolumn{3}{|l|}{ Tempo na função (anos) } \\
\hline$<05$ & 15 & 15,0 \\
\hline 05 a 14 & 43 & 43,0 \\
\hline$\geq 15$ & 42 & 42,0 \\
\hline \multicolumn{3}{|c|}{ Trabalha em outra instituição } \\
\hline Sim & 14 & 14,0 \\
\hline Não & 86 & 86,0 \\
\hline \multicolumn{3}{|c|}{ Carga horária semanal (horas) } \\
\hline 30 a 36 & 43 & 43,0 \\
\hline$>36$ & 57 & 57,0 \\
\hline \multicolumn{3}{|l|}{ Conhecimento sobre PP* } \\
\hline $\operatorname{Sim}$ & 92 & 92,0 \\
\hline Não & 08 & 8,0 \\
\hline \multicolumn{3}{|c|}{ Participação em treinamento sobre PP* } \\
\hline Sim & 91 & 91,0 \\
\hline Não & 09 & 9,0 \\
\hline
\end{tabular}




\subsection{Caracterização de aspectos individuais dos profissionais de enfermagem}

Foram considerados aspectos individuais, uso de antimicrobianos, consumo de tabaco, utilização de prótese dentária ou aparelho ortodôntico e hábitos pessoais.

Com relação ao uso de antimicrobianos, 08 (8,0\%) indivíduos afirmaram que estavam em uso, ou que o fizeram nos últimos trinta dias que antecederam a coleta. Os antibióticos mais utilizados foram da classe betalactâmicos, entre eles, a amoxicilina com clavulanato de potássio, benzilpenicilina benzatina e cefalexina.

Quanto ao consumo de tabaco pelos profissionais de enfermagem do estudo, $13 \%$ afirmaram ser tabagistas, e $38,5 \%$ deles relataram o uso do tabaco por um período superior a 20 anos.

A respeito da utilização de prótese dentária, 10 (10,0\%) profissionais disseram fazer uso. Destes, 08 (80,0\%) afirmaram utilizar prótese parcial e 02 $(20,0 \%)$, prótese total. Além disso, 08 (8,0\%) indivíduos relataram usar aparelho ortodôntico; destes, seis $(75,0 \%)$ referiram ser do tipo fixo e dois $(25,0 \%)$, do tipo móvel; cinco (62,5\%) mencionaram utilizar uma escova dental específica para o aparelho ortodôntico.

Sobre o local em que habitualmente guardam a escova dental no domicílio, 78 $(78,0 \%)$ dos profissionais mencionaram que armazenam no banheiro em compartimento fechado; e 22 (22,0\%) referiram mantê-la exposta na pia do banheiro, sem capa protetora. Com relação à frequência de troca da escova dental, $72(72,0 \%)$ profissionais informaram a troca regular a cada trimestre; $22(22,0 \%)$, com quatro meses ou mais e seis $(6,0 \%)$ não souberam informar a periodicidade da troca da escova.

Dos 100 participantes do estudo, 97 (97,0\%) referiram possuir telefone celular; destes, 41 (42,3\%) mencionaram ter o hábito de compartilhar o equipamento com familiares. Além disso, 70 (72,2\%) profissionais relataram fazer uso do telefone celular no ambiente de trabalho e 63 (64,9\%) informaram não ter o costume de higienizá-lo. Dos 34 (35,1\%) com o hábito de higienizar o equipamento, 5 (14,7\%) alegaram a limpeza diariamente; sete (20,6\%), semanalmente; três $(8,8 \%)$, mensalmente e 19 (55,9\%), apenas esporadicamente. Quanto ao produto utilizado para a higienização, 24 (70,6\%) utilizavam álcool a 70\%; cinco (14,7\%), pano 
umedecido com água e cinco (14,7\%), apenas um pano seco. Os profissionais, ao serem questionados, se geralmente no seu dia a dia, higienizam as mãos antes e após a utilização do telefone celular, 70 (72,2\%) mencionaram não higienizar e apenas $27(27,8 \%)$ higienizam.

\subsection{Prevalência de Staphylococcus aureus em profissionais de enfermagem e em seu telefone celular}

Dos 100 profissionais de enfermagem que participaram do estudo e atenderam aos critérios de inclusão, 97 (97,0\%) informaram possuir um telefone celular e 94 (94,0\%) estavam com o equipamento no momento da coleta de dados. Foram realizados dois esfregaços na base posterior do telefone celular desses profissionais, com intervalo de oito meses, totalizando 188 amostras. Não houve crescimento de Staphylococcus aureus em nenhuma das amostras coletadas.

Com relação às amostras de secreção nasal e de saliva dos 100 participantes, foram coletadas e processadas 600 amostras no total, sendo três de secreção nasal e três de saliva de cada trabalhador. O intervalo médio entre as coletas foi de quatro meses, variando de 120 a 140 dias.

Considerando os três períodos da coleta, 57 (57,0\%) profissionais de enfermagem não estavam colonizados por Staphylococcus aureus em nenhuma amostra; 43 (43,0\%) apresentaram pelo menos uma amostra positiva para o microrganismo, seja em saliva e/ou em secreção nasal.

Tabela 2 - Distribuição dos profissionais de enfermagem $(\mathrm{N}=100)$, segundo a colonização por Staphylococcus aureus na saliva e/ou secreção nasal. Ribeirão Preto-SP, 2014-2015

\begin{tabular}{lcc}
\hline Estado de colonização & $\mathbf{f}$ & $\%$ \\
\hline Não Colonizado & 57 & 57,0 \\
Colonizado & & \\
$\quad$ Nasal & 32 & 32,0 \\
$\quad$ Saliva & 01 & 1,0 \\
$\quad$ Nasal e Saliva & 10 & 10,0 \\
\hline
\end{tabular}


Entre os colonizados por Staphylococcus aureus, ressalta-se que 32/43 dos participantes apresentaram amostras de secreção nasal positivas, 1/43 amostra de saliva positiva e identificou-se que em 10/43 dos colonizados as amostras de saliva e secreção nasal foram positivas (Tabela 2). Esse dado demonstra a preferência do microrganismo em colonizar a cavidade nasal, pois a prevalência de Staphylococcus aureus nesse sítio foi de 42,0\% (42/100), enquanto que na cavidade oral foi apenas de $11,0 \%$ (11/100). A prevalência de colonização por MRSA nas narinas dos profissionais foi de 7,0\%, porém na saliva foi apenas de 2,0\%.

O total de profissionais colonizados por Staphylococcus aureus sensível e resistente à oxacilina foi semelhante nos três períodos da coleta, ou seja, de 27 $(27,0 \%), 26(26,0 \%)$ e $25(25,0 \%)$, respectivamente, considerando-se as amostras de saliva e/ou de secreção nasal (Tabela 3).

Tabela 3 - Distribuição dos profissionais de enfermagem $(\mathrm{N}=100)$ colonizados por Staphylococcus aureus sensível ou resistente à oxacilina na saliva e/ou em secreção nasal, nos três períodos da coleta. Ribeirão Preto-SP, 2014-2015

\begin{tabular}{|c|c|c|c|c|c|}
\hline \multicolumn{2}{|c|}{$\begin{array}{l}\text { Colonização por } \\
\text { Staphylococccus aureus }\end{array}$} & \multicolumn{2}{|c|}{ MSSA } & \multicolumn{2}{|c|}{ MRSA } \\
\hline & & $f$ & $\%$ & $f$ & $\%$ \\
\hline \multirow[t]{3}{*}{ Mês zero } & Nasal & 21 & 21,0 & 04 & 4,0 \\
\hline & Saliva & 01 & 1,0 & _ & - \\
\hline & Nasal e Saliva & 01 & 1,0 & - & - \\
\hline \multirow[t]{3}{*}{ Mês quatro } & Nasal & 17 & 17,0 & 03 & 3,0 \\
\hline & Saliva & 01 & 1,0 & 01 & 1,0 \\
\hline & Nasal e Saliva & 04 & 4,0 & - & - \\
\hline \multirow[t]{3}{*}{ Mês oito } & Nasal & 18 & 18,0 & 03 & 3,0 \\
\hline & Saliva & 01 & 1,0 & - & - \\
\hline & Nasal e Saliva & 02 & 2,0 & 01 & 1,0 \\
\hline
\end{tabular}

A prevalência de colonização por MSSA nos meses zero, quatro e oito, seja nas amostras de saliva e/ou de secreção nasal dos profissionais, foi de 23,0\%, $22,0 \%$ e 21,0\%, respectivamente. Enquanto que a prevalência de MRSA foi 4,0\% em cada um dos três períodos.

É importante ressaltar que houve profissionais de enfermagem que apresentaram colonização por Staphylococcus aureus nas amostras de saliva e/ou de secreção nasal em mais de um período da coleta. 
Dos 100 profissionais de enfermagem, a prevalência de MSSA nas amostras de saliva e/ou de secreção nasal foi de 36,0\%, enquanto que de MRSA foi de 7,0\%. Sendo que entre os colonizados, a prevalência de MSSA foi de 83,7\% (36/43), e de MRSA foi de $16,3 \%(7 / 43)$.

6.4 Caracterização demográfica, profissional e individual dos profissionais de enfermagem colonizados por Staphylococcus aureus

As características demográficas e profissionais dos grupos de profissionais de enfermagem colonizados e não colonizados por Staphylococcus aureus estão apresentadas na Tabela 4. 
Tabela 4 - Distribuição dos profissionais de enfermagem não colonizados $(n=57)$ e colonizados $(n=43)$ por Staphylococcus aureus, segundo a caracterização demográfica e profissional referida. Ribeirão Preto-SP, 2014-2015

\begin{tabular}{|c|c|c|c|c|c|c|}
\hline \multirow[t]{2}{*}{ Variáveis } & \multicolumn{2}{|c|}{$\begin{array}{c}\text { Não } \\
\text { Colonizados } \\
(n=57)\end{array}$} & \multicolumn{2}{|c|}{$\begin{array}{l}\text { Colonizados } \\
\qquad(n=43)\end{array}$} & \multicolumn{2}{|c|}{$\begin{array}{c}\text { Total } \\
(\mathrm{N}=100)\end{array}$} \\
\hline & $f$ & $\%$ & $f$ & $\%$ & $f$ & $\%$ \\
\hline \multicolumn{7}{|l|}{ Categoria Profissional } \\
\hline Enfermeiro & 10 & 52,6 & 09 & 47,4 & 19 & 100,0 \\
\hline Técnico de Enfermagem & 11 & 50,0 & 11 & 50,0 & 22 & 100,0 \\
\hline Auxiliar de Enfermagem & 36 & 61,0 & 23 & 39,0 & 59 & 100,0 \\
\hline \multicolumn{7}{|l|}{ Sexo } \\
\hline Feminino & 46 & 58,2 & 33 & 41,8 & 79 & 100,0 \\
\hline Masculino & 11 & 52,4 & 10 & 47,6 & 21 & 100,0 \\
\hline \multicolumn{7}{|l|}{ Idade (anos) } \\
\hline 20 a 29 & 01 & 11,1 & 08 & 88,9 & 09 & 100,0 \\
\hline 30 a 39 & 24 & 61,5 & 15 & 38,5 & 39 & 100,0 \\
\hline 40 a 49 & 25 & 69,4 & 11 & 30,6 & 36 & 100,0 \\
\hline$\geq 50$ & 07 & 43,8 & 09 & 56,2 & 16 & 100,0 \\
\hline \multicolumn{7}{|l|}{ Escolaridade } \\
\hline Ensino médio completo & 42 & 61,8 & 26 & 38,2 & 68 & 100,0 \\
\hline Superior completo & 10 & 45,5 & 12 & 54,5 & 22 & 100,0 \\
\hline Pós-graduação completa & 05 & 50,0 & 05 & 50,0 & 10 & 100,0 \\
\hline \multicolumn{7}{|l|}{ Turno de trabalho } \\
\hline Diurno & 16 & 43,2 & 21 & 56,8 & 37 & 100,0 \\
\hline Noturno & 22 & 78,6 & 06 & 21,4 & 28 & 100,0 \\
\hline Rodízio & 19 & 54,3 & 16 & 45,7 & 35 & 100,0 \\
\hline \multicolumn{7}{|l|}{ Tempo na função (anos) } \\
\hline$<05^{\circ}$ & 07 & 46,7 & 08 & 53,3 & 15 & 100,0 \\
\hline 05 a 14 & 27 & 62,8 & 16 & 37,2 & 43 & 100,0 \\
\hline$\geq 15$ & 23 & 54,8 & 19 & 45,2 & 42 & 100,0 \\
\hline \multicolumn{7}{|l|}{$\begin{array}{l}\text { Trabalho em outra } \\
\text { instituição }\end{array}$} \\
\hline Sim & 08 & 57,1 & 06 & 42,9 & 14 & 100,0 \\
\hline Não & 49 & 57,0 & 37 & 43,0 & 86 & 100,0 \\
\hline \multicolumn{7}{|l|}{$\begin{array}{l}\text { Carga horária semanal } \\
\text { (horas) }\end{array}$} \\
\hline 30 a 36 & 21 & 48,8 & 22 & 51,2 & 43 & 100,0 \\
\hline$>36$ & 36 & 63,1 & 21 & 36,9 & 57 & 100,0 \\
\hline \multicolumn{7}{|l|}{ Conhecimento sobre PP* } \\
\hline Sim & 49 & 53,3 & 43 & 46,7 & 92 & 100,0 \\
\hline Não & 08 & 100,0 & - & - & 08 & 100,0 \\
\hline \multicolumn{7}{|l|}{$\begin{array}{l}\text { Participação em } \\
\text { treinamento sobre PP* }\end{array}$} \\
\hline Sim & 48 & 52,7 & 43 & 47,3 & 91 & 100,0 \\
\hline Não & 09 & 100,0 & - & - & 09 & 100,0 \\
\hline
\end{tabular}


Dentre os auxiliares de enfermagem, $61,0 \%$ estavam entre os não colonizados por Staphylococcus aureus. Ao observar a colonização por Staphylococcus aureus entre as diferentes categorias profissionais, a prevalência foi maior no grupo de técnicos de enfermagem, com 50,0\%, seguida pelo grupo de enfermeiros, com $47,4 \%$.

Observou-se que 58,2\% dos indivíduos do sexo feminino estavam no grupo dos profissionais não colonizados. A prevalência de Staphylococcus aureus foi maior no sexo masculino $(47,6 \%)$.

O maior número de indivíduos não colonizados prevaleceu nos profissionais de enfermagem que se encontravam na faixa etária de 40 a 49 anos (69,4\%). A maior prevalência de Staphylococcus aureus nos colonizados concentrou-se na faixa etária de 20 a 29 anos (88,9\%).

Quanto à escolaridade, observou-se que 61,8\% dos indivíduos com ensino médio completo estavam no grupo dos profissionais não colonizados; e 54,5\% dos profissionais que possuíam ensino superior completo no grupo dos colonizados.

Com relação ao turno de trabalho, o noturno prevaleceu entre os não colonizados $(78,6 \%)$, enquanto que $56,8 \%$ dos indivíduos que realizavam o turno diurno estavam colonizados.

Sobre o tempo de exercício profissional, observou-se que 62,8\% dos indivíduos que possuíam de 05 a 14 anos estavam não colonizados; 53,3\% dos que exerciam a profissão há menos de cinco anos eram portadores de Staphylococcus aureus.

Ao considerar os profissionais com mais de um vínculo empregatício, 57,1\% estavam entre os não colonizados, enquanto que, no grupo de colonizados, a maior prevalência de Staphylococcus aureus concentrou-se em profissionais que referiram apenas um vínculo empregatício (43,0\%).

Quanto à carga horária de trabalho semanal exercida pelos profissionais de enfermagem, 63,1\% que referiram exercer uma jornada superior a 36 horas estavam não colonizados. Entre os que trabalhavam de 30 a 36 horas semanais, 51,2\% encontravam-se colonizados.

Observou-se que 49 (53,3\%) profissionais que afirmaram ter conhecimento sobre as PP estavam não colonizados. Destes, 20 (40,8\%) mencionaram que adquiriram por meio de palestras oferecidas pelo hospital; $18(36,7 \%)$, na escola ou universidade, e 11 (22,5\%) citaram as duas opções anteriores. Em relação aos 
colonizados, 17 (39,5\%) referiram que a aquisição de conhecimento resultou de palestras na própria instituição, 14 (32,6\%) na escola ou universidade e 12 (27,9\%), nas duas opções anteriores.

Quanto à participação em treinamento sobre as PP, 52,7\% e 47,3\% dos profissionais que informaram ter recebido capacitação sobre essa temática em sua formação profissional estavam não colonizados e colonizados, respectivamente. $O$ treinamento ocorreu na própria instituição de trabalho em 93,8\% dos não colonizados e em $90,7 \%$, dos colonizados. Além disso, apenas 16,7\% dos não colonizados e 9,3\% dos colonizados mencionaram que a capacitação foi nos últimos 12 meses. Dos demais profissionais não colonizados, $27,1 \%$ relataram que o treinamento foi entre 1 e 5 anos; 18,7\%, há mais de 5 anos e 37,5\% não souberam informar o momento. Entre os colonizados, 51,2\% relataram entre 1 e 5 anos; 7,0\%, em um período superior a 5 anos; e 32,5\% não souberam informar o período do treinamento sobre PP.

Com relação ao uso de antimicrobianos, 8,8\% dos indivíduos não colonizados e $7,0 \%$ dos colonizados afirmaram que estavam em uso ou haviam utilizado nos últimos trinta dias que antecederam a coleta. Entre os colonizados por MRSA, nenhum profissional referiu ter usado antibiótico nesse período.

Ao serem questionados sobre o uso do tabaco, 15,8\% dos não colonizados e $9,3 \%$ dos colonizados afirmaram ser tabagistas. A maioria dos não colonizados e colonizados relataram ser fumantes há mais de 20 anos.

Quanto à utilização de prótese dentária, seis (10,5\%) profissionais não colonizados que relataram fazer uso; cinco (83,3\%) disseram utilizar a prótese parcial e um (16,7\%), prótese total. Entre os colonizados, quatro $(9,3 \%)$ informaram possuir prótese dentária. Destes, $75,0 \%$ mencionaram ser prótese total e 25,0\%, prótese parcial.

Dos oito indivíduos que utilizavam aparelho ortodôntico, seis $(75,0 \%)$ estavam não colonizados e dois (25,0\%), colonizados. Quanto ao tipo de aparelho ortodôntico, 50,0\% dos colonizados referiram ser do tipo fixo e 50,0\%, do tipo móvel; e apenas um indivíduo colonizado afirmou utilizar uma escova dental específica para o aparelho ortodôntico.

Ao descrever o local em que têm o costume de guardar a escova dental no domicílio, $87,7 \%$ dos não colonizados e $65,1 \%$ dos colonizados mencionaram que a escova geralmente era armazenada no banheiro em compartimento 
fechado/protegido. Com relação à frequência de troca da escova dental, 15 (26,3\%) profissionais não colonizados e sete (16,3\%) dos colonizados relataram a troca regular a cada quatro meses ou mais.

\subsection{Estado de carreador dos profissionais colonizados por Staphylococcus} aureus

Os profissionais foram considerados carreadores persistentes quando apresentaram duas ou três amostras positivas para Staphylococcus aureus e os carreadores transitórios apenas uma única amostra. Os não carreadores foram aqueles que não apresentaram cultura positiva para esse microrganismo. Sendo assim, $57(57,0 \%)$ profissionais foram classificados como não carreadores de Staphylococcus aureus e $43(43,0 \%)$ apresentaram no mínimo uma cultura de saliva e/ou de secreção nasal positiva para Staphylococcus aureus, nos três períodos da coleta (Tabela 5).

Tabela 5 - Distribuição dos profissionais de enfermagem colonizados $(n=43)$ por Staphylococcus aureus, segundo os sítios de colonização e o estado de carreador. Ribeirão Preto-SP, 2014-2015

\begin{tabular}{|c|c|c|c|c|c|c|c|c|}
\hline $\begin{array}{l}\text { Sítios de } \\
\text { colonização }\end{array}$ & $\mathbf{P}_{\mathbf{N}}$ & $\mathbf{P}_{\mathbf{s}}$ & $\mathbf{T}_{\mathbf{N}}$ & $\mathbf{T}_{\mathrm{s}}$ & $\mathbf{T}_{\mathrm{N}} \mathbf{T}_{\mathrm{S}}$ & $P_{N} T_{S}$ & $\mathrm{~T}_{\mathrm{N}} \mathrm{P}_{\mathrm{S}}$ & Total \\
\hline Nasal & 16 & - & 16 & - & - & - & - & 32 \\
\hline Saliva & - & - & - & 01 & - & - & - & 01 \\
\hline Nasal e Saliva & - & - & - & - & 02 & 07 & 01 & 10 \\
\hline Total & 16 & 0 & 16 & 01 & 02 & 07 & 01 & 43 \\
\hline
\end{tabular}

Com relação aos 16 colonizados no sítio nasal classificados como persistentes, 11 (11/16) tiveram o microrganismo isolado em duas amostras e cinco trabalhadores o tiveram nas três amostras de secreção nasal.

O único profissional colonizado exclusivamente na amostra de saliva foi classificado como carreador transitório. 
Com relação aos 10 profissionais colonizados (nasal e saliva), 07 (7/10) foram considerados persistentes pela amostra de secreção nasal. Destes, em quatro (4/7) o Staphylococcus aureus foi isolado nas três amostras e, em três (3/7) profissionais, em duas amostras de secreção nasal. O único profissional carreador persistente na saliva teve o microrganismo isolado em duas amostras.

Considerando-se a colonização por MRSA, 100,0\% foram carreadores nasais de Staphylococcus aureus. Destes, 42,9\% (3/7) foram classificados como transitórios e $57,1 \%$ (4/7), persistentes. Dos quatro profissionais carreadores persistentes, em dois o Staphylococcus aureus foi detectado nas três amostras e, nos outros dois, em duas amostras. Observou-se que dois (28,6\%) profissionais, além de serem carreadores nasais, foram também carreadores transitórios na saliva.

A Tabela 6 apresenta o mapeamento individual dos 43 profissionais de enfermagem colonizados por MSSA ou MRSA na saliva e/ou em secreção nasal, nas coletas obtidas nos meses zero, quatro e oito. Esses profissionais foram agrupados em blocos representados pelas cores branco, amarelo e azul, de acordo com o total de amostras positivas ou negativas para Staphylococcus aureus. Em branco, estão os profissionais que se apresentaram colonizados nas amostras de saliva e/ou de secreção nasal em apenas um dos períodos; em amarelo, aqueles colonizados em dois períodos e, em azul, os colonizados nos três períodos (meses zero, quatro e oito). Além disso, ressalta-se que as amostras positivas para MRSA estão representadas pela cor vermelha. 
Tabela 6 - Distribuição dos profissionais de enfermagem $(n=43)$, segundo o total de amostras e a colonização por Staphylococcus aureus em amostras de saliva e/ou de secreção nasal, nos três períodos de coleta. Ribeirão Preto-SP, 2014-2015

\begin{tabular}{|c|c|c|c|c|c|c|c|c|c|c|c|c|c|}
\hline \multirow[b]{3}{*}{$\mathbf{n}$} & \multicolumn{4}{|c|}{ Mês zero } & \multicolumn{4}{|c|}{ Mês quatro } & \multicolumn{4}{|c|}{ Mês oito } & \\
\hline & \multicolumn{2}{|c|}{ Nasal } & \multicolumn{2}{|c|}{ Saliva } & \multicolumn{2}{|c|}{ Nasal } & \multicolumn{2}{|c|}{ Saliva } & \multicolumn{2}{|c|}{ Nasal } & \multicolumn{3}{|c|}{ Saliva } \\
\hline & MSSA & MRSA & MSSA & MRSA & MSSA & MRSA & MSSA & MRSA & MSSA & MRSA & MSSA & MRSA & \\
\hline 01 & - & - & - & - & - & - & - & - & + & - & - & - & \\
\hline 02 & + & - & - & - & - & - & - & - & - & - & - & - & \\
\hline 03 & + & - & - & - & - & - & - & - & - & - & - & - & \\
\hline 04 & - & - & - & - & + & - & - & - & - & - & - & - & \\
\hline 05 & + & - & - & - & - & - & - & - & - & - & - & - & \\
\hline 06 & + & - & - & - & - & - & - & - & - & - & - & - & \\
\hline 07 & - & - & - & - & - & - & - & - & + & - & - & - & \\
\hline 08 & - & - & - & - & + & - & - & - & - & - & - & - & \\
\hline 09 & + & - & - & - & - & - & - & - & - & - & - & - & \\
\hline 10 & + & - & - & - & - & - & - & - & - & - & - & - & \\
\hline 11 & - & - & - & - & - & - & - & - & + & - & - & - & \\
\hline 12 & - & - & - & - & - & - & - & - & + & - & - & - & \\
\hline 13 & - & - & + & - & - & - & - & - & - & - & - & - & \\
\hline 14 & + & - & - & - & - & - & - & - & - & - & - & - & \\
\hline 15 & - & + & - & - & - & - & - & - & - & - & - & - & \\
\hline 16 & - & - & - & - & - & + & - & - & - & - & - & - & \\
\hline 17 & + & - & - & - & - & - & - & - & - & - & - & - & \\
\hline 18 & - & - & - & - & - & - & - & - & + & - & + & - & \\
\hline 19 & + & - & - & - & - & - & - & - & + & - & - & - & \\
\hline 20 & - & + & - & - & - & - & - & - & - & + & - & - & \\
\hline 21 & + & - & - & - & + & - & - & - & - & - & - & - & \\
\hline 22 & + & - & - & - & + & - & - & - & - & - & - & - & \\
\hline 23 & + & - & - & - & + & - & - & - & - & - & - & - & \\
\hline 24 & - & - & - & - & - & - & - & + & - & + & - & - & \\
\hline 25 & - & - & - & - & + & - & - & - & + & - & - & - & \\
\hline 26 & + & - & - & - & + & - & - & - & - & - & - & - & \\
\hline 27 & - & - & - & - & + & - & - & - & + & - & - & - & \\
\hline 28 & - & - & - & - & - & + & - & - & - & + & - & - & \\
\hline 29 & - & - & - & - & + & - & - & - & + & - & - & - & \\
\hline 30 & - & - & - & - & + & - & - & - & + & - & - & - & \\
\hline 31 & + & - & - & - & + & - & + & - & - & - & - & - & \\
\hline 32 & - & - & - & - & + & - & + & - & + & - & - & - & \\
\hline 33 & - & - & - & - & + & - & - & - & + & - & + & - & \\
\hline 34 & - & + & - & - & + & - & - & - & + & - & - & - & \\
\hline 35 & + & - & - & - & + & - & - & - & + & - & - & - & \\
\hline 36 & + & - & - & - & + & - & - & - & + & - & - & - & \\
\hline 37 & + & - & - & - & + & - & - & - & + & - & - & - & \\
\hline 38 & + & - & - & - & + & - & - & - & + & - & - & - & \\
\hline 39 & + & - & - & - & - & - & + & - & - & - & + & - & \\
\hline 40 & + & - & - & - & + & - & + & - & + & - & - & - & \\
\hline 41 & + & - & + & - & + & - & - & - & + & - & - & - & \\
\hline 42 & + & - & - & - & + & - & + & - & + & - & - & - & \\
\hline 43 & - & + & - & - & - & + & - & - & - & + & - & + & \\
\hline $\begin{array}{l}\text { Total } \\
\text { amostra } \\
\text { nasal }\end{array}$ & 22 & 04 & 0 & 0 & 21 & 03 & 0 & 0 & 20 & 04 & 0 & 0 & 74 \\
\hline $\begin{array}{l}\text { Total } \\
\text { amostra } \\
\text { saliva }\end{array}$ & 0 & 0 & 02 & 0 & 0 & 0 & 05 & 01 & 0 & 0 & 03 & 01 & 12 \\
\hline
\end{tabular}


Um total de 18 (41,9\%) profissionais de enfermagem apresentaram-se colonizados nas amostras de saliva e/ou de secreção nasal em apenas um dos períodos; 15 (34,9\%), em dois períodos e 10 (23,2\%), nos três.

Considerando-se os três períodos da coleta, o Staphylococcus aureus foi isolado em 74 amostras de secreção nasal dos profissionais; sendo 26 amostras no mês zero; 24 , no mês quatro e 24, no mês oito.

O Staphylococcus aureus esteve presente em 12 amostras de saliva dos profissionais, sendo duas amostras isoladas no mês zero; seis, no mês quatro e quatro, no mês oito.

Conforme o TCLE, todos os profissionais colonizados por MRSA primeiramente foram informados pelo pesquisador responsável sobre os resultados das culturas e, mediante a concordância, esses resultados foram encaminhados para a $\mathrm{CCIH}$ para a indicação do protocolo de descolonização por microrganismos resistentes, conforme preconizado na própria instituição.

O protocolo de descolonização por MRSA adotado na instituição consiste em aplicação tópica de sulfadiazina de prata 1\% nas fossas nasais (de 12 em 12 horas), associada ao banho de clorexidina degermante $2 \%$ (uma vez a dia), por um período de cinco dias. Além disso, aos indivíduos com colonização oral por MRSA, recomenda-se também o bochecho com clorexidina $0,12 \%$ três vezes ao dia.

Os sete profissionais colonizados por MRSA tiveram indicação para realizar o protocolo de descolonização vigente na instituição do estudo. Entretanto, um deles recusou referindo receio e medo por já ter histórico de reações alérgicas a uma variedade de fármacos. Esse profissional que não aceitou o protocolo de descolonização estava colonizado por MRSA na amostra de secreção nasal no mês zero; no mês quatro, as culturas foram negativas, porém, no mês oito, tornou a apresentar cultura positiva para MRSA na secreção nasal.

Portanto, o protocolo de descolonização foi aplicado em seis profissionais; sendo que dois deles apresentaram culturas negativas para Staphylococcus aureus após a descolonização. Dos quatro profissionais que permaneceram colonizados, três foram resistentes à oxacilina e um, sensível; a $\mathrm{CClH}$ recomendou para esses profissionais que o protocolo fosse repetido por apenas uma vez. 


\subsection{Perfil de suscetibilidade dos Staphylococcus aureus aos antimicrobianos}

O antibiograma foi realizado para identificar o perfil de suscetibilidade dos Staphylococcus aureus aos antimicrobianos.

Das 74 amostras de secreção nasal isoladas com Staphylococcus aureus, a resistência à oxacilina foi identificada em 14,9\% (11/74); enquanto que a sensibilidade a este antibiótico, em 85,1\% (63/74).

Considerando-se as 12 amostras de saliva isoladas com Staphylococcus aureus, a resistência à oxacilina foi constatada em apenas duas amostras (16,7\%); as demais amostras (83,3\%) apresentaram-se sensíveis à oxacilina.

O Gráfico 1 apresenta o perfil de resistência de MRSA e MSSA isolados nas amostras de saliva e de secreção nasal dos profissionais colonizados aos antimicrobianos.

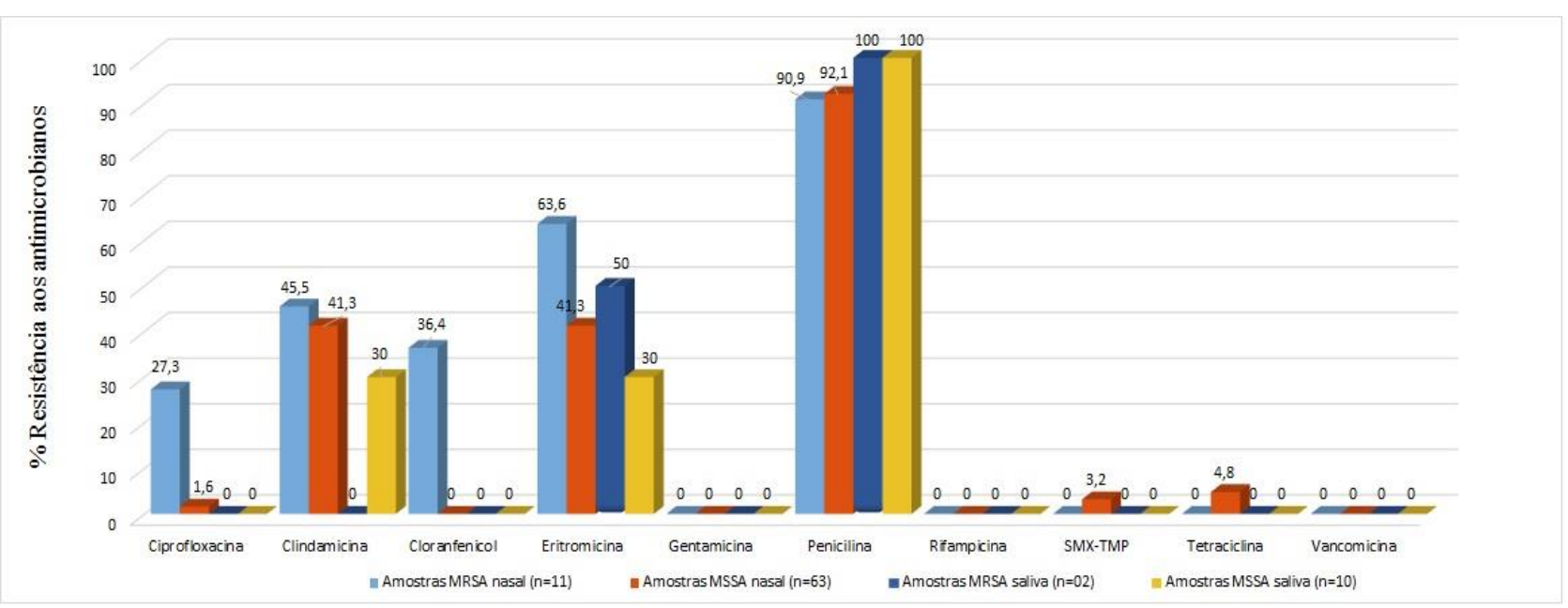

Gráfico 1 - Perfil de resistência dos Staphylococcus aureus sensíveis e resistentes à oxacilina isolados na saliva e na secreção nasal dos profissionais de enfermagem aos antimicrobianos. Ribeirão Preto-SP. 2014-2015

Das 11 amostras de MRSA isoladas na secreção nasal dos profissionais de enfermagem, 90,9\% apresentaram resistência à penicilina; 63,6\% à eritromicina; $45,5 \%$, à clindamicina; $36,4 \%$, ao cloranfenicol e $27,3 \%$, à ciprofloxacina. As duas culturas positivas para MRSA isoladas na saliva dos profissionais foram resistentes à penicilina e uma delas apresentou resistência à eritromicina. 
Com relação aos 63 isolados de MSSA na secreção nasal dos profissionais, $92,1 \%$ apresentaram resistência à penicilina; 41,3\%, à clindamicina e eritromicina; $4,8 \%$, à tetraciclina; 3,2\%, ao sulfametoxazol-trimetoprima (SMX-TMP) e 1,6\%, resistentes à ciprofloxacina. Entre as 10 amostras de MSSA isoladas na saliva dos profissionais, resistência de $100,0 \%$ foi identificada à penicilina e $30,0 \%$, à clindamicina e à eritromicina.

Evidenciou-se que os Staphylococcus aureus isolados na saliva e na secreção nasal dos profissionais apresentaram maior resistência à penicilina $(93,0 \%)$, à eritromicina (43,0\%) e à clindamicina (39,5\%).

Observa-se no Gráfico 2 o perfil de sensibilidade de MRSA e MSSA isolados nas amostras de saliva e de secreção nasal dos profissionais de enfermagem aos antimicrobianos.

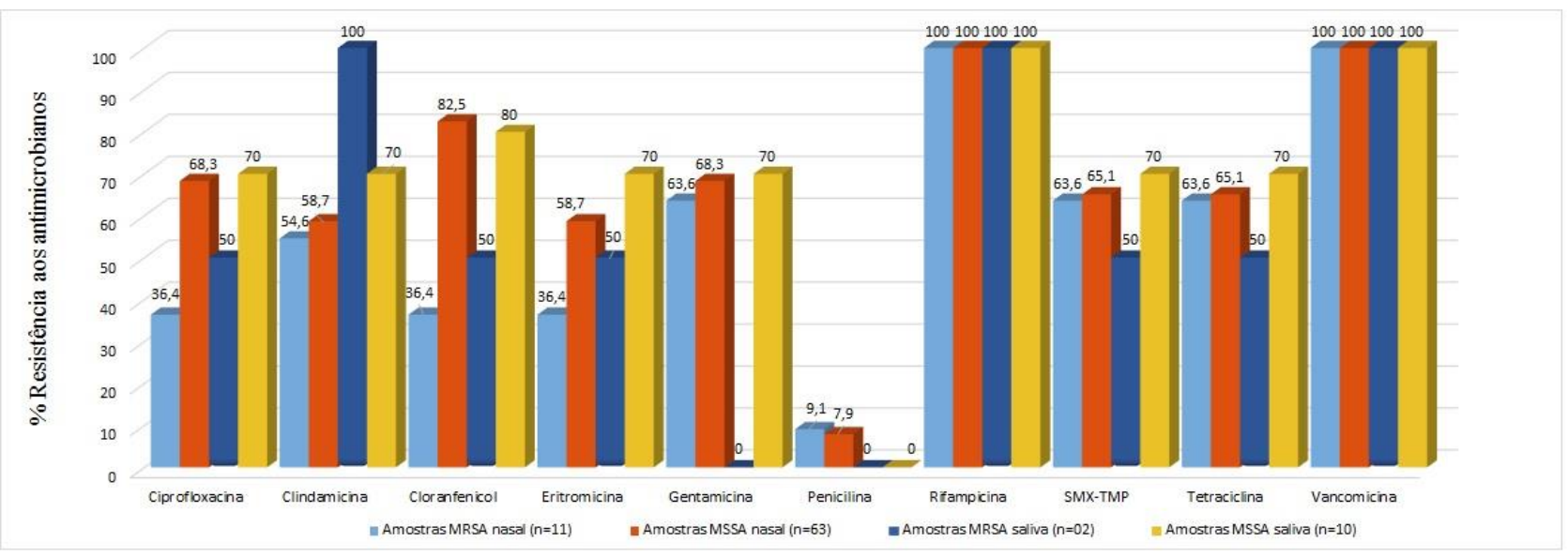

Gráfico 2 - Perfil de sensibilidade dos Staphylococcus aureus sensíveis e resistentes à oxacilina isolados na saliva e na secreção nasal dos profissionais de enfermagem aos antimicrobianos. Ribeirão Preto-SP, 2014-2015

Os 11 MRSA isolados na secreção nasal apresentaram-se sensíveis à rifampicina e à vancomicina; 63,6\%, à gentamicina, SMX-TMP, tetraciclina; 54,6\%, à clindamicina; 36,4\%, à ciprofloxacina, cloranfenicol e eritromicina; enquanto que apenas 9,1\% apresentou sensibilidade à penicilina. Os dois MRSA presentes na saliva dos profissionais apresentaram sensibilidade à clindamicina, à rifampicina e à vancomicina; enquanto que um deles foi sensível à ciprofloxacina, ao cloranfenicol, à eritromicina, ao SMX-TMP e à tetraciclina. 
Com relação aos 63 MSSA isolados na secreção nasal, todos foram sensíveis à rifampicina e à vancomicina; 82,5\%, ao cloranfenicol; 68,3\%, à ciprofloxacina e gentamicina; $65,1 \%$ ao SMX-TMP e tetraciclina, 58,7\%, à clindamicina e eritromicina; e apenas 7,9\% apresentaram sensibilidade à penicilina. Todas as 10 amostras positivas para MSSA na saliva dos profissionais apresentaram-se sensíveis à rifampicina e à vancomicina; sensibilidade de $80,0 \%$ foi observada ao cloranfenicol e $70,0 \%$ ao demais antimicrobianos apresentados no Gráfico 2; com exceção da penicilina que foi resistente $(100,0 \%)$.

\subsection{Descrição dos itens que compõem as escalas do modelo explicativo de adesão às precauções-padrão}

\subsubsection{Escala de Adesão às Precauções-Padrão}

Os 13 itens que compõem a Escala de Adesão às PP estão descritos na Tabela 7.

No item 1, 100,0\% dos profissionais colonizados e não colonizados por Staphylococcus aureus assinalaram as opções "sempre" ou "muitas vezes".

Para o item 2, 79,1\% dos colonizados e $75,4 \%$ dos não colonizados responderam "sempre" ou "muitas vezes".

Com relação ao item 3, $86 \%$ dos colonizados e $79 \%$ dos não colonizados responderam "sempre" ou "muitas vezes" como alternativa. Observa-se que 4,7\% dos profissionais colonizados assinalaram a opção "nunca" para esse item.

O item 4, relacionado à higienização das mãos após a retirada de luvas descartáveis, $97,7 \%$ e $98,3 \%$ do grupo de colonizados e não colonizados, assinalaram as opções "sempre" ou "muitas vezes", respectivamente.

Os itens 5, 6, 7 e 8 estão relacionados ao uso de EPI na possibilidade de respingos de sangue ou outras secreções. As opções "sempre" ou "muitas vezes" foram assinaladas por ambos os grupos, colonizados e não colonizados, e os resultados em percentual foram, respectivamente: item 5, 93,0\% e 87,8\%; item 6, $100,0 \%$ e $96,5 \%$; item $7,86,1 \%$ e $91,2 \%$; item $8,83,7 \%$ e $91,2 \%$. 
A frequência das respostas no item 9 foi de $92,3 \%$ e $87,7 \%$ nas alternativas "sempre" ou "muitas vezes" para o grupo de colonizados e não colonizados, respectivamente.

Com relação à manipulação de bisturis ou de outros objetos perfurocortantes (item 10), 100,0\% dos profissionais colonizados e $98,3 \%$ dos não colonizados informaram que "sempre" ou "muitas vezes" manipulam com cuidado esses objetos.

O item 11, relacionado ao reencape de agulhas usadas, apenas $72,1 \%$ dos colonizados e 73,7\% dos não colonizados responderam "nunca"; nota-se que 27,9\% dos colonizados e $26,3 \%$ dos não colonizados realizam essa prática em algum momento.

O item 12 sobre a utilização de luvas durante as punções venosas, um percentual de $100,0 \%$ e $91,2 \%$ dos profissionais colonizados e não colonizados, respectivamente, responderam as alternativas "sempre" ou "muitas vezes".

E o item 13, 93,1\% dos colonizados e 85,9\% dos não colonizados afirmaram que "sempre" ou "muitas vezes" consideram contaminados. 
Tabela 7 - Distribuição dos profissionais de enfermagem, segundo respostas atribuídas aos itens que compõem a Escala de Adesão às Precauções-Padrão e à condição de colonizado ou não colonizado por Staphylococcus aureus. Ribeirão Preto-SP, 2014-2015

\begin{tabular}{|c|c|c|c|c|c|c|c|c|c|c|}
\hline \multirow{3}{*}{$\begin{array}{l}\text { Itens da Escala de Adesão às Precauções- } \\
\text { Padrão* }\end{array}$} & \multicolumn{2}{|c|}{ Sempre } & \multicolumn{2}{|c|}{$\begin{array}{l}\text { Muitas } \\
\text { vezes }\end{array}$} & \multicolumn{2}{|c|}{ Às vezes } & \multicolumn{2}{|c|}{ Raramente } & \multicolumn{2}{|c|}{ Nunca } \\
\hline & $C^{\bullet}$ & $\mathrm{NC}^{+}$ & $\mathrm{C}^{\bullet}$ & $\mathrm{NC}$ & $C^{\bullet}$ & NC & $\mathrm{C}^{\bullet}$ & NC+ & $C^{\bullet}$ & NC \\
\hline & $\%$ & $\%$ & $\%$ & $\%$ & $\%$ & $\%$ & $\%$ & $\%$ & $\%$ & $\%$ \\
\hline $\begin{array}{l}\text { 1. Descarta objetos perfurocortantes em } \\
\text { recipientes próprios }\end{array}$ & 97,7 & 98,2 & 2,3 & 1,8 & 0 & 0 & 0 & 0 & 0 & 0 \\
\hline $\begin{array}{l}\text { 2. Trata todos os pacientes como se estivessem } \\
\text { contaminados pelo HIV }\end{array}$ & 60,5 & 59,6 & 18,6 & 15,8 & 7,0 & 14,0 & 2,3 & 0 & 11,6 & 10,5 \\
\hline $\begin{array}{l}\text { 3. Segue as precauções-padrão (PP) com todos } \\
\text { os pacientes seja qual for seu diagnóstico }\end{array}$ & 67,4 & 57,9 & 18,6 & 21,1 & 7,0 & 15,8 & 2,3 & 5,3 & 4,7 & 0 \\
\hline 4. Lava as mãos após retirar luvas descartáveis & 81,4 & 86,0 & 16,3 & 12,3 & 2,3 & 1,8 & 0 & 0 & 0 & 0 \\
\hline $\begin{array}{l}\text { 5. Usa avental protetor quando há possibilidade } \\
\text { de sujar as roupas com sangue ou outras } \\
\text { secreções }\end{array}$ & 76,7 & 63,2 & 16,3 & 24,6 & 7,0 & 12,3 & 0 & 0 & 0 & 0 \\
\hline $\begin{array}{l}\text { 6. Usa luvas descartáveis quando há } \\
\text { possibilidade de contato com sangue ou outras } \\
\text { secreções }\end{array}$ & 93,0 & 89,5 & 7,0 & 7,0 & 0 & 3,5 & 0 & 0 & 0 & 0 \\
\hline $\begin{array}{l}\text { 7. Usa óculos protetor quando há possibilidade } \\
\text { de respingar os olhos com sangue ou outras } \\
\text { secreções }\end{array}$ & 62,8 & 71,9 & 23,3 & 19,3 & 11,6 & 7,0 & 2,3 & 0 & 0 & 1,8 \\
\hline $\begin{array}{l}\text { 8. Usa máscara descartável quando há } \\
\text { possibilidade de respingar a boca com sangue } \\
\text { ou outras secreções }\end{array}$ & 62,8 & 71,9 & 20,9 & 19,3 & 16,3 & 7,0 & 0 & 0 & 0 & 1,8 \\
\hline $\begin{array}{l}\text { 9. Limpa imediatamente com desinfetante todo } \\
\text { derramamento de sangue ou de outras } \\
\text { secreções }\end{array}$ & 76,0 & 61,4 & 16,3 & 26,3 & 7,0 & 7,0 & 0 & 3,5 & 0 & 1,8 \\
\hline $\begin{array}{l}\text { 10. Manipula com cuidado bisturis ou outros } \\
\text { objetos perfurocortantes }\end{array}$ & 100,0 & 96,5 & 0 & 1,8 & 0 & 1,8 & 0 & 0 & 0 & 0 \\
\hline 11. Reencapa agulhas usadas & 0 & 0 & 0 & 1,8 & 16,3 & 12,3 & 11,6 & 12,3 & 72,1 & 73,7 \\
\hline 12. Usa luvas para puncionar veia de pacientes & 90,7 & 75,4 & 9,3 & 15,8 & 0 & 7,0 & 0 & 1,8 & 0 & 0 \\
\hline $\begin{array}{l}\text { 13. Considera contaminados todos os materiais } \\
\text { que estiveram em contato com saliva de } \\
\text { pacientes }\end{array}$ & 79,1 & 78,9 & 14,0 & 7,0 & 4,7 & 12,3 & 0 & 0 & 2,3 & 1,8 \\
\hline
\end{tabular}

\subsubsection{Escala de Personalidade de Risco}

Com relação aos quatro itens da Escala de Personalidade de Risco, descritos na Tabela 8, observa-se que a frequência das respostas foram mais diversificadas para ambos os grupos. 
No item 1,93,0\% dos colonizados e não colonizados assinalaram "discordo totalmente" ou "discordo" como opções.

Para o item 2, relacionado a assumir riscos na vida, 95,3\% dos profissionais colonizados e $96,5 \%$ dos não colonizados responderam "discordo totalmente" ou "discordo".

Tabela 8 - Distribuição dos profissionais de enfermagem, segundo respostas atribuídas aos itens que compõem a Escala de Personalidade de Risco e à condição de colonizado ou não colonizado por Staphylococcus aureus. Ribeirão Preto-SP, 2014-2015

\begin{tabular}{|c|c|c|c|c|c|c|c|c|c|c|}
\hline \multirow{3}{*}{$\begin{array}{l}\text { Itens da Escala de Personalidade de } \\
\text { Risco* }\end{array}$} & \multicolumn{2}{|c|}{$\begin{array}{l}\text { Concordo } \\
\text { totalmente }\end{array}$} & \multicolumn{2}{|c|}{ Concordo } & \multicolumn{2}{|c|}{ Indeciso } & \multicolumn{2}{|c|}{ Discordo } & \multicolumn{2}{|c|}{$\begin{array}{l}\text { Discordo } \\
\text { totalmente }\end{array}$} \\
\hline & $\mathbf{C}^{\bullet}$ & NC & $\mathbf{C}^{\bullet}$ & NC & $\mathbf{C}^{\bullet}$ & NC & $\mathbf{C}^{\bullet}$ & NC & $\mathbf{C}^{\bullet}$ & $N^{+}$ \\
\hline & $\%$ & $\%$ & $\%$ & $\%$ & $\%$ & $\%$ & $\%$ & $\%$ & $\%$ & $\%$ \\
\hline 1. Eu prefiro uma vida excitante e imprevisível & 0 & 0 & 0 & 1,8 & 7,0 & 5,3 & 44,2 & 49,1 & 48,8 & 43,9 \\
\hline 2. Eu gosto de assumir riscos em minha vida & 2,3 & 0 & 2,3 & 1,8 & 0 & 1,8 & 39,5 & 35,1 & 55,8 & 61,4 \\
\hline $\begin{array}{l}\text { 3. Às vezes, faço coisas perigosas só por } \\
\text { emoção }\end{array}$ & 0 & 0 & 2,3 & 1,8 & 2,3 & 3,5 & 20,9 & 26,3 & 74,4 & 68,4 \\
\hline $\begin{array}{l}\text { 4. Eu prefiro experiências novas e excitantes, } \\
\text { mesmo que elas sejam perigosas }\end{array}$ & 0 & 0 & 0 & 1,8 & 2,3 & 3,5 & 32,6 & 31,6 & 65,1 & 63,2 \\
\hline
\end{tabular}

\subsubsection{Escala de Eficácia da Prevenção}

Referentemente à descrição dos três itens que compõem a Escala de Eficácia da Prevenção (Tabela 9), no item 1, 79,0\% dos colonizados e 77,2\% dos não colonizados responderam "concordo totalmente" ou "concordo" com a afirmação.

O item 2 que discorre se o risco de contaminação com o HIV no trabalho pode ser diminuído se o profissional seguir as PP, 97,7\% dos colonizados e 94,8\% dos não colonizados afirmaram concordar totalmente ou concordar. Porém, tivemos um percentual $3,5 \%$ dos não colonizados que responderam discordar totalmente desse item.

No item 3, $90,7 \%$ e $87,7 \%$ dos colonizados e dos não colonizados assinalaram as opções "concordo totalmente" ou "concordo", respectivamente. 
Tabela 9 - Distribuição dos profissionais de enfermagem, segundo respostas atribuídas aos itens que compõem a Escala de Eficácia da Prevenção e à condição de colonizado ou não colonizado por Staphylococcus aureus. Ribeirão Preto-SP, 2014-2015

\begin{tabular}{|c|c|c|c|c|c|c|c|c|c|c|}
\hline \multirow{3}{*}{ Itens da Escala de Eficácia da Prevenção* } & \multicolumn{2}{|c|}{$\begin{array}{c}\text { Concordo } \\
\text { totalmente }\end{array}$} & \multicolumn{2}{|c|}{ Concordo } & \multicolumn{2}{|c|}{ Indeciso } & \multicolumn{2}{|c|}{ Discordo } & \multicolumn{2}{|c|}{$\begin{array}{c}\text { Discordo } \\
\text { totalmente }\end{array}$} \\
\hline & $\mathbf{C}^{\bullet}$ & NC & $\mathbf{C}^{\bullet}$ & NC & $C^{\bullet}$ & NC• & $C^{+}$ & NC• & C‘ & NC• \\
\hline & $\%$ & $\%$ & $\%$ & $\%$ & $\%$ & $\%$ & $\%$ & $\%$ & $\%$ & $\%$ \\
\hline $\begin{array}{l}\text { 1. Se eu usar luvas descartáveis, estarei me } \\
\text { protegendo da contaminação pelo HIV }\end{array}$ & 48,8 & 28,1 & 30,2 & 49,1 & 0 & 5,3 & 16,3 & 12,3 & 4,7 & 5,3 \\
\hline $\begin{array}{l}\text { 2. Eu posso diminuir o risco de me contaminar } \\
\text { com o HIV no trabalho se eu seguir as PP }\end{array}$ & 62,8 & 63,2 & 34,9 & 31,6 & 2,3 & 1,8 & 0 & 0 & 0 & 3,5 \\
\hline $\begin{array}{l}\text { 3. Se as PP forem seguidas com todos os } \\
\text { pacientes, meu risco de contrair HIV/AIDS é } \\
\text { muito baixo }\end{array}$ & 44,2 & 50,9 & 46,5 & 36,8 & 4,7 & 8,8 & 4,7 & 1,8 & 0 & 1,8 \\
\hline
\end{tabular}

\subsubsection{Escala Percepção de Risco}

Os três itens que compõem a Escala Percepção de Risco estão apresentados na Tabela 10.

No item 1, um percentual de $74,4 \%$ e $80,7 \%$ de colonizados e de não colonizados, respectivamente, mencionaram "concordo totalmente" ou "concordo".

Para o item 2, 79,1\% dos colonizados e 75,5\% dos não colonizados responderam "discordo totalmente" ou "discordo"

Com relação ao item 3, 86,1\% dos colonizados e $86,0 \%$ dos não colonizados assinalaram "concordo totalmente" ou "concordo" como opções. 
Tabela 10 - Distribuição dos profissionais de enfermagem, segundo respostas atribuídas aos itens que compõem a Escala de Percepção de Risco e à condição de colonizado ou não colonizado por Staphylococcus aureus. Ribeirão Preto-SP, 2014-2015

\begin{tabular}{|c|c|c|c|c|c|c|c|c|c|c|}
\hline \multirow{3}{*}{$\begin{array}{l}\text { Itens da Escala de Percepção de } \\
\text { Risco* }^{*}\end{array}$} & \multicolumn{2}{|c|}{$\begin{array}{l}\text { Concordo } \\
\text { totalmente }\end{array}$} & \multicolumn{2}{|c|}{ Concordo } & \multicolumn{2}{|c|}{ Indeciso } & \multicolumn{2}{|c|}{ Discordo } & \multicolumn{2}{|c|}{$\begin{array}{l}\text { Discordo } \\
\text { totalmente }\end{array}$} \\
\hline & $C^{\bullet}$ & $\mathrm{NC}^{+}$ & $C^{\bullet}$ & $\mathrm{NC}^{+}$ & $C^{\bullet}$ & NC• & $C^{4}$ & NC• & $C^{+}$ & NC• \\
\hline & $\%$ & $\%$ & $\%$ & $\%$ & $\%$ & $\%$ & $\%$ & $\%$ & $\%$ & $\%$ \\
\hline $\begin{array}{l}\text { 1. Existe alto risco de me picar com uma } \\
\text { agulha contaminada no trabalho }\end{array}$ & 39,5 & 42,1 & 34,9 & 38,6 & 7,0 & 0 & 16,3 & 12,3 & 2,3 & 7,0 \\
\hline $\begin{array}{l}\text { 2. O risco de me contaminar com o HIV } \\
\text { no trabalho é baixo }\end{array}$ & 0 & 3,5 & 11,6 & 17,5 & 9,3 & 3,5 & 46,5 & 35,1 & 32,6 & 40,4 \\
\hline $\begin{array}{l}\text { 3. No meu trabalho, estou exposto à } \\
\text { contaminação pelo HIV }\end{array}$ & 51,2 & 43,9 & 34,9 & 42,1 & 7,0 & 3,5 & 2,3 & 7,0 & 4,7 & 3,5 \\
\hline
\end{tabular}

\subsubsection{Escala de Conhecimento da Transmissão Ocupacional do HIV}

A Escala de Conhecimento da Transmissão Ocupacional do HIV composta por sete itens está apresentada na Tabela 11.

Quanto ao item 1, relacionado à realização de curativos em pessoas com HIV sem uso de luvas, $79,1 \%$ dos colonizados e $82,4 \%$ dos não colonizados responderam concordar totalmente ou concordar que o HIV pode ser transmitido aos profissionais de saúde, por meio dessa ação.

Com relação à possibilidade de transmissão do HIV ao respingar na boca ou nos olhos do profissional, sangue ou outras secreções de paciente portador do HIV (item 3 ), $88,4 \%$ dos colonizados e $84,2 \%$ dos não colonizados responderam a alternativa "concordo totalmente" ou "concordo", acreditando que possa ocorrer a transmissão. No entanto, verificou-se que $9,3 \%$ dos colonizados e $3,5 \%$ dos não colonizados discordaram totalmente dessa afirmação.

Os itens 5, 6 e 7 referentes à possibilidade de transmissão do HIV ao "Ter se espetado ou se cortado com objetos perfurocortantes contaminados com sangue ou outras secreções", "Fazer respiração boca-a-boca em paciente portador do HIV sem usar dispositivo protetor" e "Pressionar local de sangramento de paciente portador do HIV sem usar luvas", $88,3 \%$, 79,0\% e $81,4 \%$ dos colonizados e $93,0 \%, 85,9 \%$ e 
$89,4 \%$ dos não colonizados assinalaram as opções "concordo totalmente" ou "concordo" para os itens descritos, respectivamente.

Tabela 11 - Distribuição dos profissionais de enfermagem, segundo respostas atribuídas aos itens que compõem a Escala de Conhecimento da Transmissão Ocupacional do HIV e à condição de colonizado ou não colonizado por Staphylococcus aureus. Ribeirão Preto-SP, 2014-2015

\begin{tabular}{|c|c|c|c|c|c|c|c|c|c|c|}
\hline \multirow{3}{*}{$\begin{array}{l}\text { Itens da Escala de Conhecimento da } \\
\text { Transmissão Ocupacional do HIV* }\end{array}$} & \multicolumn{2}{|c|}{$\begin{array}{l}\text { Concordo } \\
\text { totalmente }\end{array}$} & \multicolumn{2}{|c|}{ Concordo } & \multicolumn{2}{|c|}{ Indeciso } & \multicolumn{2}{|c|}{ Discordo } & \multicolumn{2}{|c|}{$\begin{array}{l}\text { Discordo } \\
\text { totalmente }\end{array}$} \\
\hline & $C^{\bullet}$ & $\mathrm{NC}^{+}$ & $C^{\bullet}$ & $\mathrm{NC}$ & $C^{\bullet}$ & NC• & $C^{+}$ & NC• & $C^{+}$ & $\mathrm{NC}^{\bullet}$ \\
\hline & $\%$ & $\%$ & $\%$ & $\%$ & $\%$ & $\%$ & $\%$ & $\%$ & $\%$ & $\%$ \\
\hline $\begin{array}{l}\text { 1. Fazer curativos em pessoa portadora do HIV } \\
\text { sem utilizar luvas }\end{array}$ & 51,2 & 56,1 & 27,9 & 26,3 & 0 & 3,5 & 4,7 & 8,8 & 16,3 & 5,3 \\
\hline $\begin{array}{l}\text { 2. Puncionar veia de pessoa portadora do HIV } \\
\text { sem usar luvas }\end{array}$ & 53,5 & 59,6 & 30,2 & 22,8 & 0 & 5,3 & 4,7 & 8,8 & 11,6 & 3,5 \\
\hline $\begin{array}{l}\text { 3. Ter a boca ou os olhos respingados com } \\
\text { sangue ou outras secreções de paciente } \\
\text { portador do HIV }\end{array}$ & 55,8 & 54,4 & 32,6 & 29,8 & 0 & 7,0 & 2,3 & 5,3 & 9,3 & 3,5 \\
\hline $\begin{array}{l}\text { 4. Ter contato com sangue HIV positivo em } \\
\text { mãos ressecadas ou rachadas }\end{array}$ & 53,5 & 50,9 & 25,6 & 36,8 & 11,6 & 3,5 & 2,3 & 5,3 & 7,0 & 3,5 \\
\hline $\begin{array}{l}\text { 5. Ter se espetado ou se cortado com objetos } \\
\text { perfurocortantes contaminados com sangue ou } \\
\text { outras secreções }\end{array}$ & 58,1 & 61,4 & 30,2 & 31,6 & 2,3 & 0 & 2,3 & 1,8 & 7,0 & 5,3 \\
\hline $\begin{array}{l}\text { 6. Fazer respiração boca-a-boca em paciente } \\
\text { portador do HIV sem usar dispositivo protetor }\end{array}$ & 48,8 & 49,1 & 30,2 & 36,8 & 9,3 & 1,8 & 2,3 & 7,0 & 9,3 & 5,3 \\
\hline $\begin{array}{l}\text { 7. Pressionar local de sangramento de paciente } \\
\text { portador do HIV sem usar luvas }\end{array}$ & 48,8 & 56,1 & 32,6 & 33,3 & 7,0 & 1,8 & 2,3 & 1,8 & 9,3 & 7,0 \\
\hline
\end{tabular}

\subsubsection{Escala Obstáculos para Seguir as Precauções-Padrão}

$\mathrm{Na}$ Tabela 12, encontra-se a descrição dos seis itens que compõem a Escala de Obstáculos para Seguir as PP.

Quanto ao item $1,93,0 \%$ dos colonizados e $80,7 \%$ dos não colonizados responderam discordar totalmente ou discordar.

Sobre o item 3, um percentual de $72,1 \%$ dos colonizados e $63,2 \%$ dos não colonizados demarcaram as opções "discordo totalmente" ou "discordo". 
Para o item 4, um percentual de $97,6 \%$ dos colonizados e $93,0 \%$ dos não colonizados responderam "discordo totalmente" ou "discordo".

Com relação ao item $5,79,1 \%$ e $70,1 \%$ dos colonizados e dos não colonizados, respectivamente, declararam discordar totalmente ou discordar do item.

Tabela 12 - Distribuição dos profissionais de enfermagem, segundo respostas atribuídas aos itens que compõem a Escala de Obstáculos para Seguir as Precauções-Padrão e à condição de colonizado ou não colonizado por Staphylococcus aureus. Ribeirão Preto-SP, 2014-2015

\begin{tabular}{|c|c|c|c|c|c|c|c|c|c|c|}
\hline \multirow[t]{3}{*}{$\begin{array}{l}\text { Itens da Escala de Obstáculos para Seguir } \\
\text { as Precauções-Padrão* }\end{array}$} & \multicolumn{2}{|c|}{$\begin{array}{l}\text { Concordo } \\
\text { totalmente }\end{array}$} & \multicolumn{2}{|c|}{ Concordo } & \multicolumn{2}{|c|}{ Indeciso } & \multicolumn{2}{|c|}{ Discordo } & \multicolumn{2}{|c|}{$\begin{array}{l}\text { Discordo } \\
\text { totalmente }\end{array}$} \\
\hline & $C^{\bullet}$ & $\mathrm{NC}^{+}$ & $C^{\bullet}$ & $\mathrm{NC}^{+}$ & $C^{\bullet}$ & NC• & $C^{+}$ & $\mathrm{NC}^{\bullet}$ & $C^{4}$ & NC• \\
\hline & $\%$ & $\%$ & $\%$ & $\%$ & $\%$ & $\%$ & $\%$ & $\%$ & $\%$ & $\%$ \\
\hline $\begin{array}{l}\text { 1. Não consigo me acostumar com o uso de } \\
\text { equipamento de proteção na realização de } \\
\text { algumas tarefas }\end{array}$ & 2,3 & 1,8 & 4,7 & 14,0 & 0 & 3,5 & 53,5 & 35,1 & 39,5 & 45,6 \\
\hline $\begin{array}{l}\text { 2. As PP não permitem que eu faça meu } \\
\text { trabalho da melhor forma }\end{array}$ & 0 & 0 & 4,7 & 7,0 & 4,7 & 10,5 & 55,8 & 45,6 & 34,9 & 36,8 \\
\hline $\begin{array}{l}\text { 3. Com frequência, o acúmulo de atividades } \\
\text { diárias interfere na minha capacidade de seguir } \\
\text { as PP }\end{array}$ & 4,7 & 1,8 & 11,6 & 19,3 & 11,6 & 15,8 & 55,8 & 38,6 & 16,3 & 24,6 \\
\hline $\begin{array}{l}\text { 4. Nem sempre posso seguir as PP, pois as } \\
\text { necessidades de meus pacientes veem em } \\
\text { primeiro lugar }\end{array}$ & 0 & 1,8 & 0 & 1,8 & 2,3 & 3,5 & 58,1 & 49,1 & 39,5 & 43,9 \\
\hline $\begin{array}{l}\text { 5. Às vezes, não há tempo suficiente para usar } \\
\text { as PP }\end{array}$ & 2,3 & 1,8 & 14,0 & 14,0 & 4,7 & 14,0 & 55,8 & 36,8 & 23,3 & 33,3 \\
\hline $\begin{array}{l}\text { 6. Seguir as recomendações das PP torna meu } \\
\text { trabalho mais difícil }\end{array}$ & 2,3 & 0 & 2,3 & 3,5 & 4,7 & 8,8 & 65,1 & 59,6 & 25,6 & 28,1 \\
\hline
\end{tabular}

\subsubsection{Escala de Carga de Trabalho}

A Tabela 13 apresenta os três itens pertencentes à Escala de Carga de Trabalho.

No item 1, 72,1\% dos colonizados e 78,9\% dos não colonizados referiram que "sempre" ou "muitas vezes".

Um percentual de $69,7 \%$ dos colonizados e $80,7 \%$ dos não colonizados respondeu que "sempre" ou "muitas vezes" é exigido que trabalhe duro (item 2). 
No item 3, ao questionar a frequência com que existe muito trabalho a ser feito, $81,4 \%$ dos colonizados e $94,8 \%$ dos não colonizados disseram que "sempre" ou "muitas vezes" ocorre essa situação.

Tabela 13 - Distribuição dos profissionais de enfermagem, segundo respostas atribuídas aos itens que compõem a Escala de Carga de Trabalho e à condição de colonizado ou não colonizado por Staphylococcus aureus. Ribeirão Preto-SP, 20142015

\begin{tabular}{|c|c|c|c|c|c|c|c|c|c|c|}
\hline \multirow{3}{*}{ Itens da Escala de Carga de Trabalho* } & \multicolumn{2}{|c|}{ Sempre } & \multicolumn{2}{|c|}{$\begin{array}{l}\text { Muitas } \\
\text { vezes }\end{array}$} & \multicolumn{2}{|c|}{ Às vezes } & \multicolumn{2}{|c|}{ Raramente } & \multicolumn{2}{|c|}{ Nunca } \\
\hline & $C^{\bullet}$ & NC & $C^{\bullet}$ & NC & $C^{\bullet}$ & NC• & $C^{+}$ & NC• & $\mathbf{C}^{+}$ & NC• \\
\hline & $\%$ & $\%$ & $\%$ & $\%$ & $\%$ & $\%$ & $\%$ & $\%$ & $\%$ & $\%$ \\
\hline $\begin{array}{l}\text { 1. Com que frequência seu trabalho exige que } \\
\text { você seja rápido? }\end{array}$ & 27,9 & 29,8 & 44,2 & 49,1 & 23,3 & 19,3 & 4,7 & 1,8 & 0 & 0 \\
\hline $\begin{array}{l}\text { 2. Com que frequência é exigido que você } \\
\text { trabalhe duro? }\end{array}$ & 30,2 & 22,8 & 39,5 & 57,9 & 18,6 & 12,3 & 9,3 & 7,0 & 2,3 & 0 \\
\hline $\begin{array}{l}\text { 3. Com que frequência existe muito trabalho a } \\
\text { ser feito? }\end{array}$ & 41,9 & 47,4 & 39,5 & 47,4 & 18,6 & 3,5 & 0 & 1,8 & 0 & 0 \\
\hline
\end{tabular}

\subsubsection{Escala de Clima de Segurança}

Os 12 itens que compõem a Escala de Clima de Segurança estão descritos na Tabela 14.

No item $1,65,2 \%$ dos colonizados e $68,5 \%$ dos não colonizados responderam "concordo totalmente" ou "concordo".

Quanto ao item 2, 69,8\% dos colonizados e 61,4\% dos não colonizados relataram concordar totalmente ou concordar que os funcionários são comunicados quando não seguem as PP.

Para o item 3, um percentual de $97,6 \%$ e $82,4 \%$ dos colonizados e não colonizados, respectivamente, assinalaram as opções "concordo totalmente" ou "concordo".

Os profissionais, quando questionados se no hospital práticas inseguras de trabalho são corrigidas pelos supervisores (item 7) e se a alta gerência se envolve pessoalmente nas atividades de segurança (item 8 ), entre os colonizados $83,8 \%$ e 
41,9\% responderam "concordo totalmente" ou "concordo" para o item 7 e 8, respectivamente. Enquanto que, entre os não colonizados, o percentual que respondeu "concordo totalmente" ou "concordo" foi de 59,7\% para o item 7 e 35,1\%, para o item 8.

No item 11,79,0\% dos colonizados e 52,7\% dos não colonizados informaram concordar totalmente ou concordar com a afirmação.

Tabela 14 - Distribuição dos profissionais de enfermagem, segundo respostas atribuídas aos itens que compõem a Escala de Clima de Segurança e à condição de colonizado ou não colonizado por Staphylococcus aureus. Ribeirão Preto-SP, 20142015

\begin{tabular}{|c|c|c|c|c|c|c|c|c|c|c|}
\hline \multirow{3}{*}{ Itens da Escala de Clima de Segurança* } & \multicolumn{2}{|c|}{$\begin{array}{l}\text { Concordo } \\
\text { totalmente }\end{array}$} & \multicolumn{2}{|c|}{ Concordo } & \multicolumn{2}{|c|}{ Indeciso } & \multicolumn{2}{|c|}{ Discordo } & \multicolumn{2}{|c|}{$\begin{array}{l}\text { Discordo } \\
\text { totalmente }\end{array}$} \\
\hline & $\mathbf{C}^{\bullet}$ & NC+ & $C^{\bullet}$ & NC & $C^{\bullet}$ & NC• & $C^{4}$ & NC• & $C^{+}$ & NC• \\
\hline & $\%$ & $\%$ & $\%$ & $\%$ & $\%$ & $\%$ & $\%$ & $\%$ & $\%$ & $\%$ \\
\hline $\begin{array}{l}\text { 1. Na minha unidade de trabalho, a adesão de } \\
\text { funcionários às recomendações das PP faz } \\
\text { parte da avaliação de desempenho }\end{array}$ & 23,3 & 28,1 & 41,9 & 40,4 & 23,3 & 17,5 & 9,3 & 7,0 & 2,3 & 7,0 \\
\hline $\begin{array}{l}\text { 2. Os funcionários são comunicados quando } \\
\text { não seguem as PP }\end{array}$ & 7,0 & 14,0 & 62,8 & 47,4 & 9,3 & 24,6 & 20,9 & 12,3 & 0 & 1,8 \\
\hline 3. Meu supervisor me apoia no uso das PP & 48,8 & 49,1 & 48,8 & 33,3 & 2,3 & 8,8 & 0 & 3,5 & 0 & 5,3 \\
\hline $\begin{array}{l}\text { 4. Neste hospital, funcionários, supervisores e } \\
\text { gerentes agem em conjunto para garantir } \\
\text { condições mais seguras de trabalho }\end{array}$ & 20,9 & 17,5 & 67,4 & 50,9 & 7,0 & 15,8 & 4,7 & 12,3 & 0 & 3,5 \\
\hline $\begin{array}{l}\text { 5. A prevenção da exposição ocupacional ao } \\
\text { HIV é prioridade da gerência neste hospital }\end{array}$ & 11,6 & 10,5 & 46,5 & 31,6 & 23,3 & 24,6 & 18,6 & 28,1 & 0 & 5,3 \\
\hline $\begin{array}{l}\text { 6. Neste hospital, todas as medidas possíveis } \\
\text { são tomadas para reduzir tarefas e } \\
\text { procedimentos perigosos }\end{array}$ & 16,3 & 17,5 & 48,8 & 35,1 & 9,3 & 31,6 & 23,3 & 14,0 & 2,3 & 1,8 \\
\hline $\begin{array}{l}\text { 7. Neste hospital, práticas inseguras de trabalho } \\
\text { são corrigidas pelos supervisores }\end{array}$ & 23,3 & 21,1 & 60,5 & 38,6 & 11,6 & 33,3 & 4,7 & 5,3 & 0 & 1,8 \\
\hline $\begin{array}{l}\text { 8. Neste hospital, a alta gerência se envolve } \\
\text { pessoalmente nas atividades de segurança }\end{array}$ & 7,0 & 12,3 & 34,9 & 22,8 & 39,5 & 28,1 & 14,0 & 33,3 & 4,7 & 3,5 \\
\hline $\begin{array}{l}\text { 9. Neste hospital, existe um comitê de } \\
\text { segurança }\end{array}$ & 25,6 & 35,1 & 67,4 & 47,4 & 7,0 & 15,8 & 0 & 0 & 0 & 1,8 \\
\hline $\begin{array}{l}\text { 10. Sinto-me à vontade para notificar violações } \\
\text { das normas de segurança neste hospital }\end{array}$ & 9,3 & 14,0 & 44,2 & 40,4 & 32,6 & 28,1 & 11,6 & 12,3 & 2,3 & 5,3 \\
\hline $\begin{array}{l}\text { 11. Meu supervisor preocupa-se com minha } \\
\text { segurança no trabalho }\end{array}$ & 20,9 & 21,1 & 58,1 & 31,6 & 14,0 & 35,1 & 7,0 & 10,5 & 0 & 1,8 \\
\hline $\begin{array}{l}\text { 12. Neste hospital, práticas inseguras são } \\
\text { corrigidas pelos colegas }\end{array}$ & 14,0 & 12,3 & 55,8 & 36,8 & 16,3 & 33,3 & 11,6 & 14,0 & 2,3 & 3,5 \\
\hline
\end{tabular}




\subsubsection{Escala de Disponibilidade de Equipamento de Proteção Individual}

A Escala de Disponibilidade de EPI, composta por 2 itens, encontra-se descrita na Tabela 15.

No item 1, 95,3\% dos colonizados e $82,4 \%$ dos não colonizados assinalaram a alternativa "concordo totalmente" ou "concordo".

No item 2, o percentual de profissionais que responderam "concordo totalmente" ou "concordo" foi de $100,0 \%$ para os colonizados e $91,3 \%$, para os não colonizados.

Observa-se que no item 1 e 2 um percentual de 1,8\% dos não colonizados mencionaram discordar totalmente das afirmações.

Tabela 15 - Distribuição dos profissionais de enfermagem, segundo respostas atribuídas aos itens que compõem a Escala de Disponibilidade de Equipamento de Proteção Individual e à condição de colonizado ou não colonizado por Staphylococcus aureus. Ribeirão Preto-SP, 2014-2015

Itens da Escala de Disponibilidade de Equipamento de Proteção Individual*

\begin{tabular}{|c|c|c|c|c|c|c|c|c|c|}
\hline \multicolumn{2}{|c|}{$\begin{array}{c}\text { Concordo } \\
\text { totalmente }\end{array}$} & \multicolumn{2}{|c|}{ Concordo } & \multicolumn{2}{|c|}{ Indeciso } & \multicolumn{2}{|c|}{ Discordo } & \multicolumn{2}{|c|}{$\begin{array}{l}\text { Discordo } \\
\text { totalmente }\end{array}$} \\
\hline$C^{\bullet}$ & NC & $C^{\bullet}$ & NC & $\mathrm{C}^{\bullet}$ & NC• & C & NC• & $C^{+}$ & NC• \\
\hline$\%$ & $\%$ & $\%$ & $\%$ & $\%$ & $\%$ & $\%$ & $\%$ & $\%$ & $\%$ \\
\hline 39,5 & 29,8 & 55,8 & 52,6 & 4,7 & 8,8 & 0 & 7,0 & 0 & 1,8 \\
\hline 37,2 & 47,4 & 62,8 & 43,9 & 0 & 5,2 & 0 & 1,8 & 0 & 1,8 \\
\hline
\end{tabular}

1. Todos os equipamentos e materiais necessários para evitar meu contato com o HIV estão disponíveis e facilmente acessíveis

2. Minha unidade de trabalho possui todos os equipamentos e materiais necessários para eu me proteger da exposição ao HIV

C• - Colonizados; NC` - Não Colonizados

*Brevidelli e Cianciarullo (2009)

\subsubsection{Escala de Treinamento em Prevenção da Exposição Ocupacional ao HIV}

A Tabela 16 descreve os quatro itens que compõem a Escala de Treinamento em Prevenção da Exposição Ocupacional ao HIV. 
Quanto ao item 1, 79,1\% dos colonizados e $63,2 \%$ dos não colonizados responderam "concordo totalmente" ou "concordo".

Para o item 2, um percentual de $95,3 \%$ dos colonizados e $87,7 \%$ dos não colonizados relataram concordar totalmente ou concordar com a afirmação.

Com relação ao item 3 , apenas $83,7 \%$ dos colonizados e $66,7 \%$ dos não colonizados mencionaram concordar totalmente ou concordar que na unidade as chefias incentivam os funcionários a assistir palestras sobre segurança.

Tabela 16 - Distribuição dos profissionais de enfermagem, segundo respostas atribuídas aos itens que compõem a Escala de Treinamento em Prevenção da Exposição Ocupacional ao HIV e à condição de colonizado ou não colonizado por Staphylococcus aureus. Ribeirão Preto-SP, 2014-2015

\begin{tabular}{|c|c|c|c|c|c|c|c|c|c|c|}
\hline \multirow{3}{*}{$\begin{array}{l}\text { Itens da Escala de Treinamento em } \\
\text { Prevenção da Exposição Ocupacional ao } \\
\text { HIV }^{*}\end{array}$} & \multicolumn{2}{|c|}{$\begin{array}{l}\text { Concordo } \\
\text { totalmente }\end{array}$} & \multicolumn{2}{|c|}{ Concordo } & \multicolumn{2}{|c|}{ Indeciso } & \multicolumn{2}{|c|}{ Discordo } & \multicolumn{2}{|c|}{$\begin{array}{l}\text { Discordo } \\
\text { totalmente }\end{array}$} \\
\hline & C• & NC+ & $C^{\bullet}$ & NC & $c^{\bullet}$ & NC• & $\mathrm{C}^{+}$ & NC• & C. & NC' \\
\hline & $\%$ & $\%$ & $\%$ & $\%$ & $\%$ & $\%$ & $\%$ & $\%$ & $\%$ & $\%$ \\
\hline $\begin{array}{l}\text { 1. Meu hospital oferece treinamento específico } \\
\text { sobre infecções transmitidas por via sanguínea }\end{array}$ & 18,6 & 15,8 & 60,5 & 47,4 & 9,3 & 26,3 & 11,6 & 7,0 & 0 & 3,5 \\
\hline $\begin{array}{l}\text { 2. Eu tive oportunidade de ser treinado } \\
\text { adequadamente no uso de equipamentos de } \\
\text { proteção individual para me proteger da } \\
\text { exposição ao HIV }\end{array}$ & 27,9 & 35,1 & 67,4 & 52,6 & 2,3 & 8,8 & 2,3 & 1,8 & 0 & 1,8 \\
\hline $\begin{array}{l}\text { 3. Na minha unidade, os chefes incentivam os } \\
\text { funcionários a assistir palestras sobre } \\
\text { segurança }\end{array}$ & 18,6 & 21,1 & 65,1 & 45,6 & 14,0 & 21,1 & 2,3 & 8,8 & 0 & 3,5 \\
\hline $\begin{array}{l}\text { 4. Os funcionários são ensinados a estarem } \\
\text { alertas e reconhecerem riscos potenciais à } \\
\text { saúde no trabalho }\end{array}$ & 25,6 & 21,1 & 60,5 & 49,1 & 9,3 & 21,1 & 4,7 & 7,0 & 0 & 1,8 \\
\hline
\end{tabular}

$\mathrm{C}^{\bullet}$ - Colonizados; NC^ - Não Colonizados

*Brevidelli e Cianciarullo (2009)

\subsection{Comparação dos escores médios das escalas do modelo explicativo de adesão às precauções-padrão}

Ao testar a confiabilidade das escalas por meio do coeficiente alfa de Cronbach ( $\alpha$ ), obteve-se, para a Escala de Adesão às PP, $\alpha=0,744$; Escala de Personalidade de Risco, $\alpha=0,745$; Escala de Eficácia da Prevenção, $\alpha=0,624$; Escala de Percepção de Risco, $\alpha=0,546$; Escala de Treinamento em Prevenção da 
Exposição Ocupacional ao HIV, $\alpha=0,791$; Escala de Obstáculos para Seguir as PP, $\alpha=0,799$; Escala de Conhecimento da Transmissão Ocupacional do HIV, $\alpha=0,959$; Escala de Clima de Segurança, $\alpha=0,850$; Escala de Disponibilidade de EPI, $\alpha=0,796$ e para a Escala de Carga de Trabalho, $\alpha=0,799$.

Os escores médios obtidos para cada uma das escalas do modelo explicativo de adesão às PP entre os grupos de profissionais colonizados e não colonizados por Staphylococcus aureus estão apresentados na Tabela 17.

Tabela 17 - Escore médio e desvio padrão das escalas que compõem o modelo explicativo de adesão às precauções-padrão entre o grupo de profissionais de enfermagem colonizados $(n=43)$ e não colonizados $(n=57)$ por Staphylococcus aureus. Ribeirão Preto-SP, 2014-2015

\begin{tabular}{lcccc}
\hline \multirow{2}{*}{ ESCALAS $^{*}$} & \multicolumn{2}{c}{ ESCORE MÉDıO } & \multicolumn{2}{c}{ DESVIO PADRÃo } \\
\cline { 2 - 5 } & Colonizados & $\begin{array}{c}\text { Não } \\
\text { Colonizados }\end{array}$ & Colonizados & $\begin{array}{c}\text { Não } \\
\text { Colonizados }\end{array}$ \\
\hline Escala de Adesão às PP & 4,67 & 4,60 & 0,28 & 0,41 \\
Escala de Personalidade de Risco & 4,54 & 4,52 & 0,45 & 0,52 \\
Escala de Eficácia da Prevenção & 4,31 & 4,22 & 0,64 & 0,75 \\
Escala de Percepção de Risco & 4,06 & 4,01 & 0,69 & 0,88 \\
Escala de Treinamento em Prevenção & 4,03 & 3,83 & 0,54 & 0,73 \\
da Exposição Ocupacional ao HIV & & & & 0,51 \\
Escala de Obstáculos para Seguir as & 4,06 & 4,02 & 0,72 \\
PP & 4,12 & 4,26 & 1,10 & 0,99 \\
Escala de Conhecimento da & 3,78 & 3,60 & 0,46 & 0,65 \\
Transmissão Ocupacional do HIV & 4,36 & 4,17 & 0,47 & 0,79 \\
Escala de Clima de Segurança & 4,01 & 4,14 & 0,76 & 0,60 \\
Escala de Disponibilidade de EPI & & & & \\
Escala de Carga de Trabalho & & & & \\
\hline *Brevidelli Cianciarullo (2009) & & & & \\
\end{tabular}

${ }^{*}$ Brevidelli e Cianciarullo (2009)

Tanto o grupo de profissionais colonizados, como o grupo de não colonizados por Staphylococcus aureus apresentaram escores médios alto para a Escala de Adesão às PP e para a Escala de Personalidade de Risco (escore acima de 4,5), e escores médios classificados como intermediários para as demais escalas aplicadas. Em ambos os grupos, não foram obtidos escores médio baixos, pois todos os valores foram superiores a 3,5.

O teste Levene mostrou que as variâncias dos escores foram diferentes entre os dois grupos para a Escala de Treinamento em Prevenção da Exposição 
Ocupacional ao HIV $(F=5,10 ; p=0,02)$ e a para a Escala de Obstáculos para Seguir as $P P(F=7,39 ; p=0,008)$. Para a Escala de Adesão às $P P$, as variâncias foram iguais em ambos os grupos ( $F=1,56 ; p=0,21)$.

A comparação das médias dos escores da Escala de Adesão às PP entre os profissionais colonizados e não colonizados não apresentou diferença estatisticamente significante entre os dois grupos $(t=-0,91$; e $p=0,36)$. Resultado semelhante foi obtido com as demais escalas (Tabela 18).

Tabela 18 - Comparação das médias dos escores das dez escalas que compõem o modelo explicativo de adesão às precauções-padrão entre os grupos de profissionais de enfermagem colonizados $(n=43)$ e não colonizados $(n=57)$ por Staphylococcus aureus. Ribeirão Preto-SP, 2014-2015

\begin{tabular}{lcc}
\hline ESCALAS* & t & p \\
\hline Escala de Adesão às PP & $-0,91$ & 0,36 \\
Escala de Personalidade de Risco & $-0,18$ & 0,85 \\
Escala de Eficácia da Prevenção & $-0,61$ & 0,54 \\
Escala de Percepção de Risco & $-0,30$ & 0,75 \\
Escala de Treinamento em Prevenção da Exposição Ocupacional ao & $-1,53$ & 0,12 \\
HIV & & \\
Escala de Obstáculos para Seguir as PP & $-0,34$ & 0,72 \\
Escala de Conhecimento da Transmissão Ocupacional do HIV & 0,67 & 0,50 \\
Escala de Clima de Segurança & $-1,52$ & 0,13 \\
Escala de Disponibilidade de EPI & $-1,35$ & 0,17 \\
Escala de Carga de Trabalho & 0,95 & 0,34 \\
\hline${ }^{*}$ Brevidelli e Cianciarullo (2009) & &
\end{tabular}

Observou-se maior média dos escores com relação à Escala de Adesão às PP entre os profissionais colonizados da categoria profissional enfermeiro, sexo feminino, idade de 20 a 29 anos e maior ou igual a 50 anos, pós-graduação completa, regime de rodízio de turnos, tempo na função inferior a cinco anos, carga horária semanal de 30 a 36 horas e entre aqueles que possuíam um único vínculo empregatício. Entretanto, não houve diferença estatisticamente significante na comparação das médias dos escores da Escala de Adesão às PP entre os profissionais colonizados com essas variáveis demográficas e profissionais (Tabela 19). 
Tabela 19 - Comparação das médias dos escores da escala de adesão às precauções-padrão entre os profissionais de enfermagem colonizados por Staphylococcus aureus e as variáveis demográficas e profissionais. Ribeirão PretoSP, 2014-2015

\begin{tabular}{|c|c|c|c|c|c|}
\hline \multicolumn{6}{|c|}{$\begin{array}{c}\text { Colonizados } \\
n=43\end{array}$} \\
\hline Variáveis & $f(\%)$ & $\begin{array}{l}\text { Escore } \\
\text { médio }\end{array}$ & $\begin{array}{l}\text { Desvio } \\
\text { padrão }\end{array}$ & F ou $t$ & $p$ \\
\hline \multicolumn{6}{|l|}{ Categoria Profissional } \\
\hline $\begin{array}{l}\text { Enfermeiro } \\
\text { Técnico de Enfermagem } \\
\text { Auxiliar de Enfermagem }\end{array}$ & $\begin{array}{l}09(20,9) \\
11(25,6) \\
23(53,5)\end{array}$ & $\begin{array}{l}4,82 \\
4,71 \\
4,58\end{array}$ & $\begin{array}{l}0,13 \\
0,23 \\
0,33\end{array}$ & $2,59^{*}$ & 0,08 \\
\hline $\begin{array}{l}\text { Idade (anos) } \\
20 \text { a } 29 \\
30 \text { a } 39 \\
40 \text { a } 49\end{array}$ & $\begin{array}{l}08(18,6) \\
15(34,9) \\
11(25,6)\end{array}$ & $\begin{array}{l}4,71 \\
4,69 \\
4,57\end{array}$ & $\begin{array}{l}0,21 \\
0,26 \\
0,31\end{array}$ & $0,56^{*}$ & 0,64 \\
\hline$\geq 50$ & $09(20,9)$ & 4,71 & 0,36 & & \\
\hline $\begin{array}{l}\text { Escolaridade } \\
\text { Ensino médio completo } \\
\text { Superior completo } \\
\text { Pós-graduação completa }\end{array}$ & $\begin{array}{l}26(60,5) \\
12(27,9) \\
05(11,6)\end{array}$ & $\begin{array}{l}4,65 \\
4,60 \\
4,89\end{array}$ & $\begin{array}{l}0,31 \\
0,23 \\
0,11\end{array}$ & $1,85^{*}$ & 0,16 \\
\hline $\begin{array}{l}\text { Turno de trabalho } \\
\text { Diurno } \\
\text { Noturno } \\
\text { Rodízio }\end{array}$ & $\begin{array}{l}21(48,8) \\
06(14,0) \\
16(37,2)\end{array}$ & $\begin{array}{l}4,69 \\
4,44 \\
4,71\end{array}$ & $\begin{array}{l}0,28 \\
0,35 \\
0,24\end{array}$ & $2,21^{*}$ & 0,12 \\
\hline $\begin{array}{l}\text { Tempo na função (anos) } \\
<05 \\
05 \text { a } 14 \\
\geq 15\end{array}$ & $\begin{array}{l}08(18,6) \\
16(37,2) \\
19(44,2)\end{array}$ & $\begin{array}{l}4,77 \\
4,74 \\
4,56\end{array}$ & $\begin{array}{l}0,17 \\
0,29 \\
0,29\end{array}$ & $2,42^{*}$ & 0,10 \\
\hline $\begin{array}{l}\text { Sexo } \\
\text { Feminino } \\
\text { Masculino }\end{array}$ & $\begin{array}{l}33(76,7) \\
10(23,3)\end{array}$ & $\begin{array}{l}4,69 \\
4,58\end{array}$ & $\begin{array}{l}0,29 \\
0,27\end{array}$ & $1,08^{* *}$ & 0,28 \\
\hline $\begin{array}{l}\text { Trabalha em outra } \\
\text { instituição } \\
\text { Sim } \\
\text { Não }\end{array}$ & $\begin{array}{l}07(14,0) \\
36(86,0)\end{array}$ & $\begin{array}{l}4,51 \\
4,70\end{array}$ & $\begin{array}{l}0,27 \\
0,28\end{array}$ & $-1,57^{* *}$ & 0,12 \\
\hline $\begin{array}{l}\text { Carga horária semanal } \\
\text { (horas) } \\
30 \text { a } 36 \\
>36 \\
\end{array}$ & $\begin{array}{l}22(51,2) \\
21(48,8)\end{array}$ & $\begin{array}{l}4,73 \\
4,60 \\
\end{array}$ & $\begin{array}{l}0,28 \\
0,28\end{array}$ & $1,41^{* *}$ & 0,16 \\
\hline
\end{tabular}

Com relação à média dos escores da Escala de Adesão às PP entre os profissionais de enfermagem colonizados, o enfermeiro foi a categoria com maior escore de adesão às PP (Figura 2). 


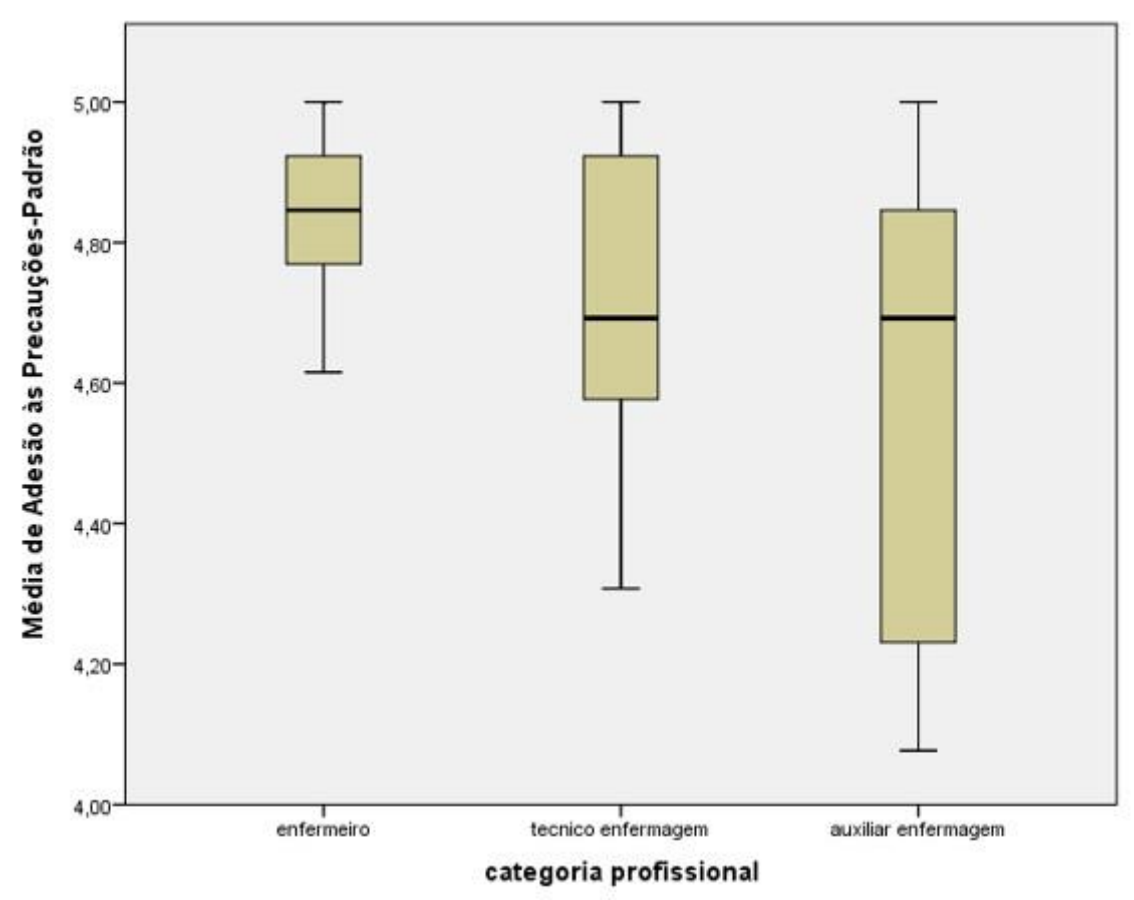

Figura 2 - Média dos escores entre o grupo de profissionais colonizados por Staphylococcus aureus e as categorias de enfermagem

Observa-se que, à medida que aumenta os anos em tempo de exercício profissional na enfermagem, decresce a média dos escores da Escala de Adesão às PP entre os profissionais de enfermagem colonizados.

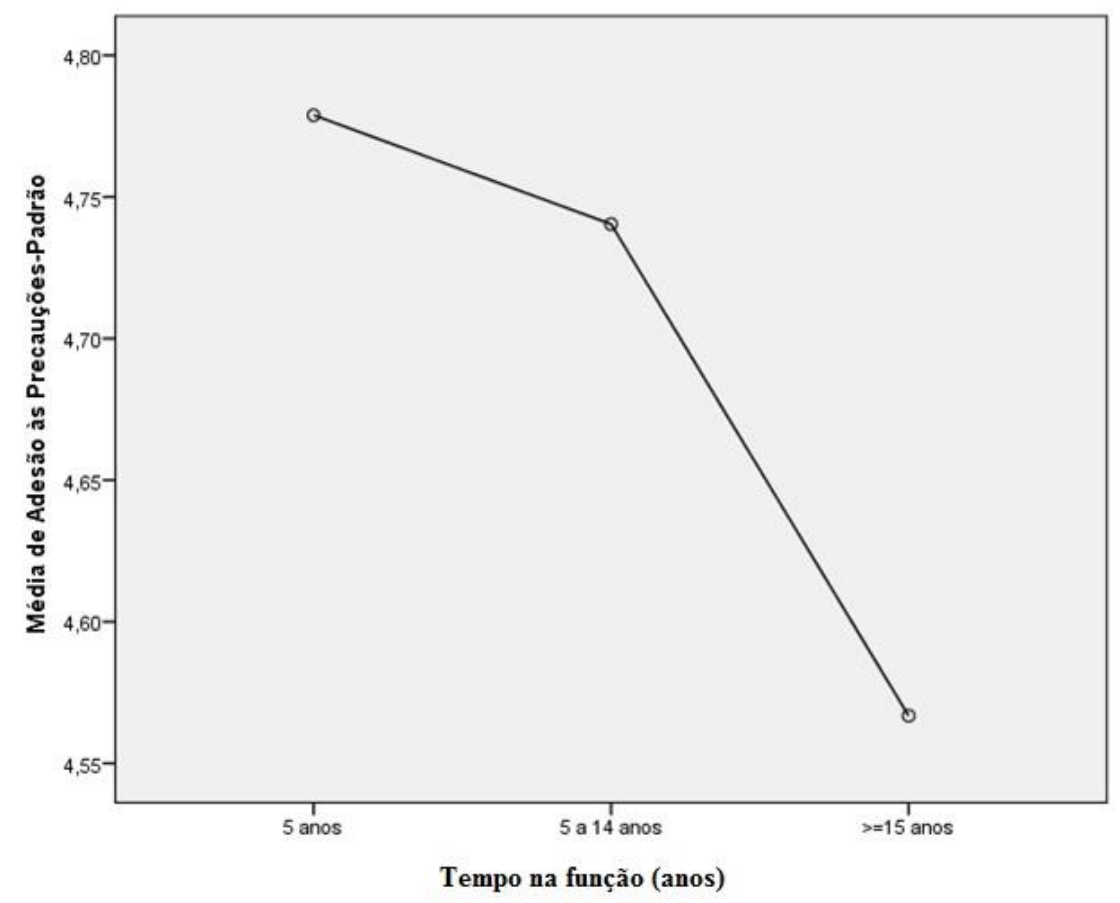

Figura 3 - Média dos escores entre o grupo de profissionais colonizados por Staphylococcus aureus e o tempo de função na enfermagem 
Neste estudo, um fator associado ao risco para a colonização por Staphylococcus aureus foi o armazenamento da escova dental no banheiro em compartimento fechado/protegido. Enquanto que, o conhecimento sobre as PP e o relato de participação em treinamento sobre as PP apresentaram-se como fatores associados à proteção para a não colonização (Tabela 20). 
Tabela 20 - Medidas de associação entre características demográficas, profissionais e individuais com a colonização por Staphylococcus aureus em profissionais de enfermagem, Ribeirão Preto-SP, 2014-2015

\begin{tabular}{|c|c|c|c|c|c|}
\hline \multirow[t]{2}{*}{ Variáveis } & \multicolumn{2}{|c|}{$\begin{array}{c}\text { Não } \\
\text { Colonizados } \\
(n=57)\end{array}$} & \multicolumn{2}{|c|}{$\begin{array}{c}\text { Colonizados } \\
(n=43)\end{array}$} & \multirow[t]{2}{*}{ RP (IC95\%) } \\
\hline & $f$ & $\%$ & $\mathbf{f}$ & $\%$ & \\
\hline \multicolumn{6}{|l|}{ Categoria Profissional } \\
\hline Enfermeiro & 10 & 17,5 & 09 & 20,9 & $0,90(0,57-1,44)$ \\
\hline Não enfermeiro & 47 & 82,5 & 34 & 79,1 & 1 \\
\hline \multicolumn{6}{|l|}{ Sexo } \\
\hline Feminino & 46 & 80,7 & 33 & 76,7 & $1,11(0,71-1,74)$ \\
\hline Masculino & 11 & 19,3 & 10 & 23,3 & 1 \\
\hline \multicolumn{6}{|l|}{ Idade (anos) } \\
\hline 20 a 39 & 22 & 38,6 & 23 & 53,5 & $0,76(0,54-1,10)$ \\
\hline$\geq 40$ & 35 & 61,4 & 20 & 46,5 & 1 \\
\hline \multicolumn{6}{|l|}{ Escolaridade } \\
\hline Ensino médio completo & 42 & 73,7 & 26 & 60,5 & $1,31(0,87-1,99)$ \\
\hline Superior completo & 15 & 26,3 & 17 & 39,5 & 1 \\
\hline \multicolumn{6}{|l|}{ Rodízio de turno } \\
\hline Sim & 19 & 33,3 & 16 & 37,2 & $1,07(0,64-1,34)$ \\
\hline Não & 38 & 66,7 & 27 & 62,8 & 1 \\
\hline \multicolumn{6}{|l|}{ Tempo na função (anos) } \\
\hline$\leq 09$ & 17 & 29,8 & 19 & 44,2 & $1,32(0,51-1,12)$ \\
\hline$\geq 10$ & 40 & 70,2 & 24 & 55,8 & 1 \\
\hline \multicolumn{6}{|l|}{ Trabalha em outra instituição } \\
\hline Sim & 08 & 14,0 & 06 & 14,0 & $1,00(0,61-1,64)$ \\
\hline Não & 49 & 86,0 & 37 & 86,0 & 1 \\
\hline \multicolumn{6}{|l|}{ Carga horária semanal (horas) } \\
\hline 30 a 36 & 21 & 36,8 & 22 & 51,2 & $0,77(0,54-1,11)$ \\
\hline$>36$ & 36 & 63,2 & 21 & 48,8 & 1 \\
\hline \multicolumn{6}{|l|}{ Uso de antimicrobiano } \\
\hline Sim & 05 & 8,8 & 03 & 7,0 & $0,90(0,63-1,95)$ \\
\hline Não & 52 & 91,2 & 40 & 93,0 & 1 \\
\hline \multicolumn{6}{|l|}{ Uso de tabaco } \\
\hline Sim & 09 & 15,8 & 04 & 9,3 & $1,25(0,83-1,89)$ \\
\hline Não & 48 & 84,2 & 39 & 90,7 & 1 \\
\hline \multicolumn{6}{|l|}{ Uso de prótese dentária } \\
\hline Sim & 06 & 10,5 & 04 & 9,3 & $1,05(0,62-1,81)$ \\
\hline Não & 51 & 89,5 & 39 & 90,7 & 1 \\
\hline \multicolumn{6}{|l|}{ Uso de aparelho ortodôntico } \\
\hline Sim & 06 & 10,5 & 02 & 4,7 & $1,35(0,87-2,10)$ \\
\hline Não & 51 & 89,5 & 41 & 95,3 & 1 \\
\hline \multicolumn{6}{|l|}{$\begin{array}{l}\text { Local de armazenamento da } \\
\text { escova dental }\end{array}$} \\
\hline Compartimento protegido & 50 & 87,7 & 28 & 65,1 & $2,07(1,07-3,80)^{\star *}$ \\
\hline Compartimento desprotegido & 07 & 12,3 & 15 & 34,9 & 1 \\
\hline \multicolumn{6}{|l|}{ Conhecimento sobre PP* } \\
\hline Sim & 49 & 86,0 & 43 & 100,0 & $0,53(0,44-0,64)^{\star *}$ \\
\hline Não & 08 & 14,0 & 0 & 0 & 1 \\
\hline \multicolumn{6}{|l|}{$\begin{array}{l}\text { Participação em treinamento } \\
\text { sobre } \text { PP }^{\star}\end{array}$} \\
\hline Sim & 48 & 84,2 & 43 & 100,0 & $0,52(0,43-0,64)^{\star *}$ \\
\hline Não & 09 & 15,8 & 0 & 0 & 1 \\
\hline
\end{tabular}




\section{DISCUSSÃO}

O presente estudo avaliou a prevalência de Staphylococcus aureus e a adesão às PP em profissionais de enfermagem que prestam cuidados a pessoas com HIV/aids. Amostras foram obtidas da saliva e da secreção nasal de 100 profissionais de enfermagem. Além disso, swab da superfície externa do telefone celular dos profissionais que possuíam o equipamento também foram coletadas. A coleta de dados ocorreu em três momentos, nos meses zero, quatro e oito.

Entre os 100 participantes, o predomínio foi do sexo feminino $(79,0 \%)$ e os auxiliares de enfermagem foram a categoria profissional em maior número, com $59,0 \%$ da população. Estudos realizados na mesma instituição e com profissionais de enfermagem relataram que as mulheres, assim como os auxiliares de enfermagem, representam a maioria nessa classe profissional (CANINI et al., 2008; MOURA et al., 2011; PEREIRA et al., 2013).

Com relação ao tempo de atuação profissional, este variou de 08 meses a 36 anos, com média de 12,9 anos. Estudo de Felix et al. (2013) apontou resultado semelhante, em que o tempo mediano de atuação dos profissionais de enfermagem foi de 11 anos, variando de 1,5 a 40 anos.

Neste estudo, apenas $08(8,0 \%)$ profissionais mencionaram não conhecer as PP. Entre os que possuíam o conhecimento, a maioria referiu que o conhecimento foi obtido na própria instituição de trabalho. Além disso, 91,0\% dos profissionais afirmaram ter participado de treinamento sobre PP em algum momento de sua formação profissional. Esses resultados foram semelhantes aos descritos na literatura, pois estes apontam que mais de $90,0 \%$ dos profissionais de enfermagem apresentam o conhecimento acerca desta temática (AIRES et al., 2010; PEREIRA et al., 2013).

Estudos associam a adesão às PP ao grau de conhecimento do profissional sobre o assunto (FELIX et al., 2013; SAX et al., 2005). Investigação realizada por Malaguti et al. (2008) mostrou que menos de 50,0\% dos enfermeiros com cargo de chefia relataram ter recebido treinamento específico sobre PP. Esse dado é preocupante, visto que esses profissionais são referências em seus setores e suas atitudes podem influenciar as ações dos demais membros da equipe. 
No Brasil, a segurança e a saúde do trabalhador dos serviços de saúde são estabelecidas pela Norma Regulamentadora 32 (NR 32), a qual visa medidas de proteção no ambiente de trabalho. De acordo com a NR 32, a instituição deve assegurar capacitação aos trabalhadores, por meio de treinamentos, não apenas antes do início das atividades, mas também de forma contínua e regular (BRASIL, 2011).

Segundo a Portaria no 2616, de 12 de maio de 1998, as CClHs devem cooperar com os setores de treinamento ou até mesmo, se responsabilizarem pelos treinamentos, com o objetivo de obter uma melhor capacitação do quadro de funcionários e profissionais, com relação ao controle de infecções hospitalares (BRASIL, 1998).

Brevidelli e Cianciarullo (2009), em estudo realizado com profissionais de saúde, apontaram que o recebimento de treinamento específico sobre PP na instituição influencia positivamente a adesão ao uso de EPI.

No presente estudo, o conhecimento sobre as PP e a participação em treinamento sobre as PP apresentaram-se como fatores associados à proteção para a não colonização dos profissionais de enfermagem.

Em relação aos aspectos individuais dos participantes do estudo, a minoria dos indivíduos referiu que estava em uso de antimicrobiano, ou que o utilizou nos últimos 30 dias que antecederam a coleta.

O uso abusivo de antibióticos pode promover o aparecimento de resistência bacteriana (BUSATO; GABARDO; LEÃO, 2006). Estudos internacionais apontaram o uso prévio de antibióticos como fator de risco para a colonização por MRSA em pacientes e em indivíduos da comunidade (ELLIS et al., 2004; HIDRON et al., 2005; TACCONELLI et al., 2008).

A cavidade bucal, em virtude da alimentação, da fala, e do contato com objetos pode abrigar uma variedade de microrganismos, muitas vezes potencialmente patogênicos (ANKOLA; HEBBAL; ESHWAR, 2009). Escovas dentais podem ser contaminadas por bactérias, por vírus e por fungos após a primeira utilização (SARAVIA et al., 2008). Esses microrganismos, provenientes da boca e do meio ambiente, podem permanecer vivos nas cerdas por um período de 24 horas até sete dias. Após higienizar a escova apenas com água, as bactérias permanecem ativas, principalmente se a escova for armazenada em local fechado e úmido, como estojos plásticos e armários de banheiro (GONÇALO; MIALHE, 2009). 
A pia do banheiro, não é um local recomendado para armazenar a escova dental. Estudos apontam a presença de coliformes fecais alojados em escovas, devido à proximidade da pia com o vaso sanitário (COUTINHO et al., 2007; MOREIRA; CAVALCANTE, 2008).

No presente estudo, a maioria do profissionais (78,0\%) referiram armazenar a escova dental em compartimento fechado/protegido. Essa atitude foi apontada como um fator associado ao risco para a colonização por Staphylococcus aureus $(\mathrm{RP}=2,07 ; \mathrm{IC} 95 \%=1,07-3,80)$.

Pessoas suscetíveis a infecções devem ter cuidados redobrados para não serem expostas aos microrganismos durante a escovação. Por isso, a desinfecção da escova dental, após cada uso, é fundamental e deve se tornar um hábito. Um método seguro e eficaz para a desinfecção da escova dental é a utilização de solução de clorexidina a $0,12 \%$, em forma de spray, nas cerdas. Com essa ação, a escova pode ser armazenada no armário ou em compartimentos fechados sem preocupação, pois a proliferação dos microrganismos estará controlada (CHAVES et al., 2007; NELSON FILHO et al., 2000).

A literatura aponta que os telefones celulares de profissionais de saúde podem estar contaminados por agentes patogênicos capazes de sobreviver por meses em superfícies secas e serem considerados veículos de transmissão de microrganismos do âmbito hospitalar para a comunidade (BRADY et al., 2009; USTUN; CIHANGIROGLU, 2012).

Pesquisa realizada em hospital no Estado de Minas Gerais, com o objetivo de verificar se o telefone celular é responsável por veiculação de microrganismos e se há compatibilidade com as bactérias encontradas nas cavidades bucais e nasais de profissionais de saúde, mostrou que 40,0\% dos profissionais de enfermagem estavam colonizados por Staphylococcus aureus e 6,7\% apresentaram essa bactéria no telefone celular (STUCHI et al., 2013).

Ustun e Cihangiroglu (2012) apontaram em seu estudo que mais de 90,0\% do telefones celulares de profissionais de saúde apresentaram contaminação bacteriana. Entre os microrganismos isolados, estavam: Staphylococcus aureus (MRSA e MSSA), estafilococos coagulase-negativa, Escherichia coli, Klebsiella spp. e Enterococcus spp.

Contudo, os resultados do presente estudo não corroboram com o descrito na literatura, pois amostras coletadas e analisadas de 94 telefones celulares de 
profissionais de enfermagem não apresentaram crescimento de Staphylococcus aureus. Ressalta-se que, no momento em que ocorreu a coleta do swab na superfície do telefone celular, não foi observado ou questionado se o profissional fez uso do equipamento naquele dia.

Recomendações como higienização das mãos, antes e após a utilização do telefone celular, além de sua descontaminação diária com álcool a 70\%, podem reduzir o risco de contaminação cruzada entre profissionais, pacientes e comunidade (BRADY et al., 2009).

Neste estudo, 72,2\% dos profissionais de enfermagem relataram utilizar o telefone celular no ambiente de trabalho, 42,3\% disseram que compartilham 0 equipamento com membros da família e aproximadamente $65,0 \%$ não possuem o hábito de higienizar o telefone celular.

A prevalência de Staphylococcus aureus foi de 43,0\% nas amostras coletadas de saliva e de secreção nasal dos profissionais de enfermagem, sendo que a prevalência de MSSA foi de 36,0\% (36/100) e de MRSA, 7,0\% (7/100). Essa prevalência foi semelhante à descrita no estudo de Moura et al. (2011), em que $41,0 \%$ dos profissionais de enfermagem apresentaram colonização pelo microrganismo, 29,6\%, eram MSSA e 7,1\%, MRSA.

Em um hospital no Estado do Paraná, a prevalência de Staphylococcus aureus nas mãos e nos vestíbulos nasais da equipe de enfermagem foi de 59,0\% (MOREIRA; SANTOS; BEDENDO, 2013).

Carvalho, M. et al. (2009), ao investigar a colonização por Staphylococcus aureus na saliva de profissionais de saúde, mostrou que $47,2 \%$ dos profissionais estavam colonizados, e 92,6\% eram da equipe de enfermagem. No estudo, a prevalência de MSSA foi de $43,5 \%$ e de MRSA, de $4,1 \%$.

Estudo epidemiológico realizado em um hospital de Curitiba apontou que $60,9 \%$ dos trabalhadores de saúde apresentaram colonização por Staphylococcus aureus na saliva. Prevalência elevada de MRSA (12,7\%) foi relatada pelos autores, enquanto que de MSSA foi de 48,1\% (CRUZ et al., 2011).

Rabelo et al. (2014), ao coletar amostras biológicas da cavidade nasal de 120 profissionais de saúde, identificaram que 22,5\% (27/120) estavam colonizados por MRSA e $74,1 \%$ eram da equipe de enfermagem.

Investigação para identificar a presença de microrganismos nas narinas dos profissionais de enfermagem de unidades especializadas em HIV/aids apontou que 
seis tipos de microrganismos foram isolados nas amostras de secreção nasal dos profissionais, entre eles, Staphylococcus aureus, Staphylococcus lugdunensis, Pseudomonas aeruginosa, Klebsiella pneumoniae, Enterobacter aerogenes e Proteus mirabilis. O Staphylococcus aureus foi o mais prevalente e representou 23,0\% das culturas positivas, sendo que 6,6\% eram MRSA (REINATO et al., 2015).

Em Portugal, estudo realizado para determinar a percepção e atitudes dos enfermeiros em relação ao risco de exposição ao MRSA apontou que $71,9 \%$ dos enfermeiros concordaram que podem estar em risco de colonização por MRSA no ambiente de trabalho. Muitos desses enfermeiros acreditam que a adoção de medidas preventivas como higienização das mãos e uso de EPI são capazes de reduzir o risco pessoal de colonização (PEDRO; SOUSA-UVA; PINA, 2014).

Revisão de literatura evidencia que equipe de enfermagem é mais suscetível à colonização por MRSA; a prevalência média de MRSA entre os profissionais de saúde foi de $4,6 \%$ e, entre os profissionais de enfermagem, 7,4\% (ALBRICH; HARBARTH, 2008).

Embora existam outros sítios potenciais de colonização por Staphylococcus aureus, no presente estudo foi investigada apenas a colonização nasal e de saliva. Estudos consideram a cavidade nasal como um importante sítio de investigação para a colonização por esse microrganismo, assim como a cavidade bucal, devido à dispersão de gotículas produzidas na fala, na tosse e no espirro. Além disso, por meio desses sítios, há a possibilidade de disseminação do microrganismo para outras regiões do organismo (BISAGA et al. 2008; CRUZ et al., 2011; KLUYTMANS; VAN BELKUM; VERBRUGH, 1997; WENZEL et al., 1998).

Identificou-se que $32,0 \%$ dos profissionais de enfermagem apresentaram colonização nasal por Staphylococcus aureus; $1,0 \%$ na saliva e $10,0 \%$ nasal e na saliva, simultaneamente. Nos três momentos da coleta (nos meses zero, quatro e oito), a prevalência do microrganismo foi semelhante; a de MSSA, variou de 21,0 a $23,0 \%$ e de MRSA foi de 4,0\% em cada etapa.

Apesar de a literatura (CRUZ et al., 2011; KLUYTMANS; VAN BELKUM; VERBRUGH, 1997; MOURA et al., 2011) apontar a cavidade bucal como um potencial reservatório e fonte de disseminação de Staphylococcus aureus por meio da dispersão de gotículas, as narinas são consideradas o principal sítio de colonização, sendo o mais eficiente e indicado para avaliar a colonização. 
No presente estudo, evidenciou-se a preferência do microrganismo em colonizar a cavidade nasal, pois a prevalência de Staphylococcus aureus na cavidade nasal dos profissionais de enfermagem foi de $42,0 \%$, enquanto que na cavidade oral foi apenas de 11,0\%. Além disso, se a identificação de Staphylococcus aureus fosse somente por meio das culturas de saliva, não seriam detectados $32,0 \%$ dos casos.

Auxiliares de enfermagem representaram 59,0\% dos participantes, porém destacamos maior prevalência de colonização por Staphylococcus aureus na categoria de técnicos de enfermagem $(50,0 \%)$ e de enfermeiros $(47,4 \%)$. Além disso, a prevalência foi mais elevada no sexo masculino (47,6\%); em indivíduos com idade de 20 a 29 anos (88,9\%); turno de trabalho diurno $(56,8 \%)$ e com menos de cinco anos de atividade profissional (53,3\%). Corroborando os achados neste estudo, Rabelo et al. (2014) relataram maior prevalência de MRSA entre os técnicos de enfermagem (48,1\%); a pesquisa apontou também que o grupo de indivíduos mais colonizados foram os com idade entre 20 e 28 anos e com menos de cinco anos de experiência profissional.

Estudo conduzido por Moghadam, Pourmand e Davoodabad (2015) apontou que a colonização por MRSA além de ser mais frequente em enfermeiros $(70,6 \%)$, foi maior em indivíduos do sexo masculino (64,7\%).

Silva et al. (2008), ao avaliar o perfil epidemiológico e de suscetibilidade dos Staphylococcus aureus isolados em profissionais da saúde, identificou que 25,7\% estavam colonizados; um dos fatores de risco associado à colonização foi a faixa etária. Com relação à faixa etária, observou-se no estudo que indivíduos com idade de 20 a 28 anos (grupo com maior prevalência de colonização) apresentou 3,5 vezes mais chance de ser colonizados (IC 95\% 1,25-10,20) quando comparado com o grupo de indivíduos com faixa etária de menor prevalência de colonização (33 a 44 anos).

Pesquisas (CARVALHO, M. et al., 2009; CRUZ et al., 2011; RABELO et al., 2014; SILVA et al., 2008) relacionadas à colonização por Staphylococcus aureus em profissionais de saúde mostraram que o turno de trabalho diurno foi predominante entre os colonizados, corroborando com os resultados identificados no presente estudo.

Observa-se no estudo de Rabelo et al. (2014) que um percentual próximo de $46,4 \%$ dos profissionais colonizados por MRSA possuía menos de cinco anos de 
experiência profissional. Além disso, o estudo aponta que essa população menos experiente profissionalmente pode apresentar algumas deficiências relacionadas à prática profissional, ocasionando uma maior suscetibilidade à colonização por microrganismos.

Embora se espere que uma jornada de trabalho elevada favoreça maior exposição no ambiente hospitalar considerado insalubre, neste estudo, profissionais que realizavam uma carga horária semanal de 30 a 36 horas apresentaram maior prevalência de colonização comparativamente àqueles com uma carga horária superior a 36 horas semanais.

Estudo de Palos (2006) mostrou que a colonização por Staphylococcus aureus predominou em profissionais de saúde que exerciam uma carga horária de 30 horas semanais, pois $69,4 \%$ dos colonizados referiram trabalhar essa carga horária.

Com relação aos sítios de colonização, 50,0\% dos profissionais foram classificados como carreadores persistentes nas amostras coletadas de secreção nasal, e os demais foram carreadores transitórios. Observou-se que um profissional foi colonizado apenas na amostra de saliva; entre os colonizados nas amostras de saliva e de secreção nasal, a maioria $(70,0 \%)$ foi considerada carreador persistente nasal e transitório na saliva.

Dos sete profissionais colonizados por MRSA, 100,0\% apresentaram colonização nasal; e 57,1\% foram considerados carreadores persistentes e 42,9\%, transitórios.

Vale ressaltar que, no estudo, carreadores persistentes foram aqueles que, das três culturas processadas e analisadas, apresentaram duas ou três positivas para o microrganismo, enquanto que os carreadores transitórios tiveram apenas uma cultura positiva.

Para Moura (2009), é importante que se avalie a persistência ou a transitoriedade da colonização por MRSA. Embora o conhecimento do estado de portador seja relevante, essa colonização, quando identificada como persistente, é preocupante. O conhecimento do estado de portador pelo profissional permite que medidas de isolamento sejam tomadas, evitando-se, com isso, a disseminação desses microrganismos nos serviços de saúde.

$\mathrm{Na}$ instituição em estudo, a descolonização por MRSA é realizada por meio de aplicação tópica de sulfadiazina de prata 1\% nas fossas nasais de 12 em 12 
horas, associada ao banho de clorexidina degermante 2\% (uma vez a dia), por um período de cinco dias. Para os indivíduos com colonização oral, adiciona-se ao protocolo de descolonização o uso de clorexidina $0,12 \%$ na forma de bochecho (três vezes ao dia) por cinco dias consecutivos. Embora a literatura recomende o uso de mupirocina tópica para descolonização de MRSA, a instituição não dispõe desse antimicrobiano na prática clínica.

Para Peres et al. (2014), a descolonização de profissionais de saúde deve ser indicada apenas em casos de suspeita ou de confirmação de colonização persistente associada à transmissão cruzada; sendo aconselhável o acompanhamento dos casos pela equipe de CCIH. Além disso, se a descolonização não for eficaz no primeiro momento, o protocolo poderá ser repetido, porém não se recomenda mais que duas aplicações.

Um dos objetivos da pesquisa foi identificar o perfil de suscetibilidade aos antimicrobianos das amostras de Staphylococcus aureus isoladas na saliva e na secreção nasal dos profissionais de enfermagem. Com relação às amostras de MRSA e MSSA isoladas na secreção nasal, 90,9\% e 92,1\%, respectivamente, apresentaram resistência à penicilina; $63,6 \%$ e $41,3 \%$, à eritromicina, 45,5\% e $41,3 \%$, à clindamicina, 27,3\% e 1,6\%, à ciprofloxacina. Resistência de 3,2\% ao SMX-TMP e 4,8\% à tetraciclina foram identificadas apenas nas amostras de MSSA. Apenas nas amostras de MRSA observou-se resistência ao cloranfenicol (36,4\%).

Nas amostras de MRSA e de MSSA, isoladas na saliva dos profissionais, observou-se resistência de $50,0 \%$ e $30,0 \%$ à eritromicina.

O estudo mostrou que as amostras de MRSA e MSSA, isoladas na secreção nasal e na saliva dos profissionais, não apresentaram resistência à gentamicina, à rifampicina e à vancomicina.

Observou-se no estudo que amostras de MRSA, isoladas na saliva ou secreção nasal, apresentaram resistência a cinco antimicrobianos entre os 10 avaliados.

Estudos (CARVALHO, M. et al., 2009; MOREIRA; SANTOS; BEDENDO, 2013; SILVA, E. et al., 2012) evidenciaram elevada taxa de resistência à penicilina e à eritromicina, em geral taxa superior a 90,0\%. Essa pesquisa corrobora os resultados deste estudo, pois os antibióticos com elevada resistência foram penicilina e eritromicina. 
Moghadam, Pourmand e Davoodabad (2015), ao investigar o perfil de suscetibilidade aos antimicrobianos nas amostras de secreção nasal dos profissionais de saúde, não identificaram resistência à rifampicina nos MSSA, conforme identificado no presente estudo.

Para a análise das escalas, considerou-se o escore médio para medir a intensidade das respostas obtidas pelos profissionais. Tanto o grupo de profissionais colonizados, como o grupo de não colonizados por Staphylococcus aureus apresentaram escores médios alto para a Escala de Adesão às PP e Escala de Personalidade de Risco (escore acima de 4,5), e escores médios classificados como intermediários para as demais escalas aplicadas. Em ambos os grupos, não foram obtidos escore médio baixo, pois todos os valores foram superiores a 3,5.

Assim, com relação à compreensão dos fatores individuais, a Escala que avaliou a Adesão às PP entre o grupo de profissionais de enfermagem colonizados e não colonizados apresentou escores, respectivamente, de 4,67 e 4,60. Observa-se, portanto, maior grau de adesão às PP como recomendado.

Em relação à adesão as medidas de PP, estudo realizado no Estado do Rio de Janeiro concluiu que a maioria dos profissionais reconhece e adota as medidas de precauções, no entanto uma parcela pequena, porém significativa, adota de forma insuficiente ou não adota tais medidas (SILVA, G. et al., 2012).

$\mathrm{Na}$ Escala de Adesão às $\mathrm{PP}$, o item acerca do reencape de agulhas usadas apontou que $27,9 \%$ dos colonizados e $26,3 \%$ dos não colonizados reencapam agulhas com alguma frequência. Embora, o reencape de agulha não seja preditor para a colonização por microrganismo, constitui-se risco para acidentes ocupacionais.

A NR 32 estabelece as diretrizes básicas para que os estabelecimentos de saúde possam implementar medidas de proteção à segurança e à saúde dos profissionais de saúde que visem à diminuição dos acidentes ocupacionais (BRASIL, 2011). Verifica-se que, apesar de a NR 32 vedar o reencape e a desconexão manual de agulhas, ainda há uma parcela importante de profissionais que executa este procedimento.

Nesse sentido, estudo realizado com objetivo de avaliar a adesão dos profissionais às medidas PP observou nas respostas a persistência de práticas não recomendadas como o reencape de agulhas usadas (MALAGUTI et al., 2008). Vale destacar que essa prática é um importante preditor para acidentes percutâneos 
entre profissionais de enfermagem em instituições hospitalares (CANINI et al., 2008; MOURA; GIR; CANINI, 2006).

Quanto à Escala de Personalidade de Risco, o escore médio entre o grupo de profissionais de enfermagem colonizados e não colonizados apresentou os seguintes escores, 4,54 e 4,52, ou seja, um escore alto. Portanto, quanto maior o escore, menor a personalidade de risco adotada pelo profissional.

A personalidade de risco pode influenciar na adesão às PP de acordo com estudo realizado por Pereira et al. (2013) no qual a Escala de Personalidade de Risco apresentou correlação estatisticamente significativa quando comparada com a adesão às PP.

Pesquisa realizada sobre os fatores determinantes para a adesão aos EPI identificou que a exposição ocupacional pode estar associada ao comportamento individual e pessoal e que estas podem ser determinadas pelas crenças em saúde (NEVES et al., 2011). Assim, a avaliação dos aspectos relacionados ao comportamento é de suma importância, uma vez que o conhecimento, em si, não garante a adoção de práticas seguras no trabalho e que a inclusão desses aspectos relacionados à mudança de comportamento e ao estímulo a autopromoção da saúde podem contribuir para mudar esse panorama (BONINI et al., 2009).

Em relação à Escala de Eficácia da Prevenção e a Escala Percepção de Risco, o escore médio foi intermediário. Para a Escala de Eficácia da Prevenção, o escore médio entre o grupo de profissionais de enfermagem colonizados e não colonizados foi de 4,31 e 4,22, respectivamente, o que denota percepção intermediária em relação à eficácia da utilização desses equipamentos. Para a Escala Percepção de Risco, o escore médio entre o grupo de profissionais de enfermagem colonizados e não colonizados foi de 4,06 e 4,01, respectivamente, o que denota percepção ao risco de exposição no trabalho.

Um estudo sobre o conhecimento do trabalhador de saúde sobre os riscos à saúde de seu trabalho identificou que os profissionais possuem conhecimentos sobre os riscos de forma genérica e que esse conhecimento não se transforma em uma ação segura de prevenção (OLIVEIRA; MUROFUSE, 2001). Portanto, perceber o risco que o procedimento oferece em sua execução pode colaborar para a adoção de uma postura correta o que implica utilizar as medidas preconizadas (PEREIRA, 2011). 
Em relação às bactérias resistentes a múltiplas drogas (BRMD), o conhecimento da situação de risco implica diretamente a percepção de suscetibilidade do profissional de contrair ou de disseminar as BRMD. Assim, quanto maior o conhecimento do profissional, maior sua percepção e, portanto, maior possibilidade de adesão às medidas preventivas (MOURA; GIR, 2007).

A Escala de Conhecimento da Transmissão Ocupacional do HIV apresentou um escore médio entre o grupo de profissionais de enfermagem colonizados e não colonizados, respectivamente, de 4,12 e 4,26. Identifica-se uma menor percepção sobre o conhecimento referente à transmissão ocupacional do HIV. Vale destacar que a adesão às medidas de PP está associada ao grau de conhecimento do profissional (SAX et al., 2005).

Para os fatores relacionados ao trabalho, a Escala Obstáculos para Seguir as PP apresentou escore médio entre o grupo de profissionais de enfermagem colonizados e não colonizados, respectivamente, de 4,06 e 4,02, ou seja, houve uma percepção intermediária em relação à dificuldade na utilização dos EPI e na realização das tarefas. Nesse sentido, no item "Com frequência, o acúmulo de atividades diárias interfere na minha capacidade de seguir as PP”, a maioria dos profissionais demarcou a opção "discordo" e "discordo totalmente". No entanto, observa-se que $16,3 \%$ e $21,1 \%$ do grupo de colonizados e não colonizados, respectivamente, informaram concordar totalmente ou concordar com a afirmação.

Assim, um estudo identificou que os obstáculos encontrados no dia-a-dia de trabalho para a adesão às medidas preventivas à exposição ocupacional são: a falta de informação sobre os riscos, o número inadequado de profissionais e a sobrecarga de trabalho (MALAGUTI et al., 2008).

A Escala de Carga de Trabalho aborda aspectos referentes à percepção sobre a sobrecarga de trabalho e a rapidez. Essa Escala apresentou um escore médio entre o grupo de profissionais de enfermagem colonizados e não colonizados, respectivamente, de 4,01 e 4,14, ou seja, uma carga intermediária de trabalho. Esse resultado corrobora estudo de Pereira (2011) em que o escore da Escala de Carga de Trabalho foi de 4,24.

Contudo, a literatura evidencia que um fator que ocasiona a sobrecarga de trabalho do profissional deve-se à escassez de recursos humanos que altera o ritmo de trabalho (GALLAS; FONTANA, 2010). 
Com relação aos fatores organizacionais, o Escala de Clima de Segurança apresentou escore médio entre o grupo de profissionais de enfermagem colonizados e não colonizados, respectivamente, de 3,78 e 3,60, ou seja, classificado como intermediário.

O clima de segurança organizacional refere-se à percepção do valor atribuído à segurança no trabalho compartilhada pelos profissionais (DEJOY et al., 1996). Assim, a segurança organizacional pode influenciar a adesão às PP (BREVIDELLI; CIANCIARULLO, 2009). Portanto, quanto maior a percepção de segurança, maior a adesão às PP (DEJOY et al., 2000; GERSHON et al., 1995).

A Escala de Disponibilidade de Equipamento de Proteção Individual apresentou escore médio entre o grupo de profissionais de enfermagem colonizados e não colonizados, respectivamente, de 4,36 e 4,17, classificado como intermediário, ou seja, embora ocorra a adesão intermediária, a disponibilidade e a acessibilidade aos EPI são reduzidas. Vale destacar que a NR 32 assegura que as instituições forneçam os EPI, descartáveis ou não, em número suficiente nos postos de trabalho, de forma que seja garantido o imediato fornecimento ou reposição (BRASIL, 2011). É importante salientar que na instituição do estudo é oferecido na admissão do profissional um EPI individual.

Para a Escala de Treinamento em Prevenção da Exposição Ocupacional ao HIV, o escore médio entre o grupo de profissionais de enfermagem colonizados e não colonizados foi, respectivamente, de 4,03 e 3,83. Identifica-se uma menor percepção, ou seja, uma deficiência em relação aos treinamentos.

Além de fornecer os EPI e monitorar sua utilização, o treinamento é imprescindível (TIMILSHINA; ANSARI; DAYAL, 2011). Assim, é necessário que as instituições de saúde enfatizem a formação sobre a temática (BELLO et al., 2011).

Estratégias adotadas para a prevenção e para o controle de infecções por MRSA incluem: uso criterioso de antimicrobianos; educação e treinamento dos profissionais de saúde; incentivo e regulamentação de protocolos de higienização das mãos; sistema de vigilância ativa para identificação precoce e isolamento de indivíduos colonizados por MRSA, e incentivo à adesão às precauções-padrão e de contato preconizadas pelos Serviços de Controle de Infecção Hospitalar (BRASIL, 2007; TACCONELLI, 2009).

Estudo de Silva et al. (2010) apontou que os fatores mais citados pelos profissionais de enfermagem como facilitadores na adesão às medidas preventivas 
na assistência a pacientes colonizados por MRSA foram: disponibilidade de EPI; quantidade adequada de recursos humanos; trabalho em equipe; treinamento e orientação, além de identificação precoce do microrganismo e sinalização do isolamento.

Ressalta-se a importância de vestir e retirar de forma correta os EPI para evitar a contaminação e disseminação de microrganismos dentro do hospital. A retirada dos EPI deverá obedecer a seguinte sequência: luvas; óculos protetor; máscara e avental (SIEGEL et al., 2007b).

As mãos dos profissionais de saúde, se não higienizadas adequadamente, podem se tornar o principal veículo de transmissão de microrganismos resistentes no ambiente de trabalho. Dessa forma, visando diminuir o risco de transmissão desses microrganismos a OMS propôs "Os 5 momentos para a higienização das mãos": 1- antes do contato com o paciente; 2- antes da realização de procedimento asséptico; 3- após risco de exposição a fluidos corporais; 4- após contato com paciente e 5- após contato com as áreas próximas aos pacientes (WHO, 2009b).

Programas de cultura de vigilância ativa são uma importante estratégia para detectar a colonização assintomática. Estudo demonstra que, se a identificação de MRSA fosse apenas por meio de solicitação de culturas por razões clínicas, apenas $17,8 \%$ dos casos seriam identificados (ROBICSEK et al., 2008). Porém a decisão na implantação desta estratégia deve ser avaliada conforme o perfil epidemiológico da instituição. Para isso, alguns aspectos devem ser considerados: necessidade de apoio e de envolvimento de toda equipe para que a implementação seja bem sucedida, decisão da população alvo ou de risco e definição do tempo ótimo e do intervalo da coleta (MARTINS et al., 2013).

Investigação que propôs aplicar uma estratégia multimodal para controle de MRSA em um hospital em Portugal revelou que houve um decréscimo da proporção de MRSA de $66,0 \%$ para $57,0 \%$ e uma redução significativa de 1,80 para 0,68 casos por mil dias de internamento em um período de cinco anos (PERES et al., 2014).

Profissionais de enfermagem, por exercerem atividades que envolvem contato direto na assistência aos pacientes, apresentam um papel fundamental na prevenção e no controle de microrganismos nos serviços de saúde e a adesão aos protocolos existentes nas instituições pode minimizar a colonização e a transmissão de BRMD (LOPES et al., 2015). 
Os resultados apresentados permitiram confirmar as duas primeiras hipóteses deste estudo: a prevalência de Staphylococcus aureus pode ser influenciada por fatores relacionados as características demográficas, profissionais e individuais; profissionais de enfermagem que prestam cuidados a pacientes com HIV/aids podem apresentar colonização na saliva e narina anterior por Staphylococcus aureus em seu ambiente de trabalho. Porém, as outras duas hipóteses não foram confirmadas: objetos de uso pessoal dos profissionais como telefone celular podem estar contaminados por Staphylococcus aureus; os escores médios das escalas que compõem o modelo explicativo de adesão às PP entre os profissionais de enfermagem não colonizados são maiores com relação ao grupo de profissionais colonizados por Staphylococcus aureus.

Os resultados obtidos não identificaram a presença de Staphylococcus aureus nos telefones celulares dos profissionais de enfermagem e, não houve diferença estatisticamente significante na comparação das médias dos escores das escalas que compõem o modelo explicativo de adesão às $\mathrm{PP}$, entre os grupos de colonizados e não colonizados. 


\section{CONCLUSÃO}

> A prevalência de colonização por Staphylococcus aureus em profissionais de enfermagem nas amostras de saliva e/ou de secreção nasal foi de $43,0 \%$, nos três períodos da coleta; sendo $36,0 \%$, MSSA e 7,0\%, MRSA.

> Nas amostras coletadas de secreção nasal dos profissionais de enfermagem, a prevalência foi de $32,0 \%$, na saliva $1,0 \%$, enquanto que nas amostras de secreção nasal e saliva foi de $10,0 \%$.

> A prevalência de colonização por MSSA na amostras de saliva e/ou na secreção nasal, nos meses zero, quatro e oito, foi $23,0 \%, 22,0 \%$ e $21,0 \%$, respectivamente. Considerando-se os MRSA, a prevalência foi de $4,0 \%$ em cada um dos três períodos.

> Observou-se que a prevalência de Staphylococcus aureus foi maior nos profissionais: técnicos de enfermagem $(50,0 \%)$; sexo masculino $(47,6 \%)$; faixa etária de 20 a 29 anos (88,9\%); ensino superior completo (54,5\%); turno de trabalho diurno (56,8\%); tempo na função inferior a cinco anos $(53,3 \%)$; apenas um vínculo empregatício $(43,0 \%)$ e com carga horária semanal de 30 a 36 horas $(51,2 \%)$.

> Dos colonizados na secreção nasal, 50,0\% foram carreadores persistentes e $50,0 \%$, carreadores transitórios. O único colonizado exclusivamente na amostra de saliva foi carreador transitório. Entre os colonizados nas amostras de saliva e de secreção nasal, $70,0 \%$ foram carreadores persistentes na secreção nasal e transitórios na saliva; 20,0\%, carreadores transitórios na secreção nasal e na saliva e $10,0 \%$, carreadores persistentes na saliva e transitórios na secreção nasal.

> Das 74 amostras de secreção nasal com Staphylococcus aureus, 14,9\% (11/74) foram resistentes à oxacilina; enquanto que nas 12 amostras de saliva a resistência foi de $16,7 \%(2 / 12)$.

> Os Staphylococcus aureus isolados na secreção nasal e na saliva dos profissionais apresentaram maior resistência à penicilina $(93,0 \%)$, à eritromicina $(43,0 \%)$ e à clindamicina $(39,5 \%)$.

> Os grupos de profissionais colonizados e não colonizados, respectivamente, apresentaram escores médios alto para a Escala de Adesão às PP (4,67 e 
4,60) e Escala de Personalidade de Risco (4,54 e 4,52). As demais escalas apresentaram escores médios intermediários para ambos os grupos.

$>$ Não houve diferença estatisticamente significante na comparação das médias dos escores das dez escalas que compõem o modelo explicativo de adesão às $\mathrm{PP}$, entre os grupos de profissionais colonizados e não colonizados.

$>$ Armazenamento da escova dental em compartimento fechado/protegido $(\mathrm{RP}=2,07 ; \quad \mathrm{IC} 95 \%=1,07-3,80)$ foi um fator associado ao risco para a colonização por Staphylococcus aureus.

> Conhecimento sobre as PP ( $R P=0,53$; IC95\%=0,44-0,64) e participação em treinamento sobre as PP (RP=0,52; IC95\%=0,43-0,64) apresentaram-se como fatores associados à proteção para a não colonização por Staphylococcus aureus. 


\section{CONSIDERAÇÕES FINAIS}

A problemática das infecções relacionadas à assistência à saúde, com a propagação de microrganismos multirresistentes tem sido motivo de inúmeras preocupações. Dentre os agentes responsáveis por tais infecções, estão os Staphylococcus aureus, microrganismos de extrema relevância para a saúde pública e conhecidos por sua virulência e capacidade de desenvolver resistência a uma variedade de antimicrobianos. Infecções causadas por MRSA são preocupantes, pois, além de elevar as taxas de morbidade e mortalidade, podem ser difíceis de serem controladas.

Profissionais de saúde são potenciais carreadores e disseminadores de MRSA no ambiente de trabalho. Objetos pessoais, materiais e equipamentos utilizados na assistência e o ambiente também podem atuar como fontes de microrganismos. A disseminação de microrganismos frequentemente ocorre pelas mãos dos profissionais, ocasionando contaminação cruzada.

A adoção de medidas de prevenção e de controle de microrganismos patogênicos são essenciais para a prática da enfermagem e de segurança do paciente.

Um dos fatores determinantes para a adesão às medidas de prevenção e de controle de microrganismos resistentes é a percepção de suscetibilidade do profissional de contrair ou de disseminar esses microrganismos. No entanto, é importante que esse profissional obtenha o conhecimento de sua condição de portador, pois se acredita que esse conhecimento possa contribuir para uma reflexão e uma mudança de atitude na prática profissional.

Capacitação em biossegurança e participação em treinamentos são fatores facilitadores para a adesão às medidas preventivas, mas não o suficiente para a mudança de comportamento dos profissionais.

Além das ações educativas, o incentivo às medidas de vigilância para identificação precoce dos indivíduos colonizados, o isolamento dos colonizados em quartos privativos, a racionalização no uso de antimicrobianos e a higienização das mãos são estratégias que, ao serem adotadas, minimizam a disseminação de MRSA no ambiente hospitalar. 
Uma das limitações desta pesquisa refere-se ao local do estudo e à população. O estudo foi realizado em um hospital de ensino de grande porte com alta complexidade e com a população composta apenas pela equipe de enfermagem, o que pode limitar a generalização dos resultados para as demais instituições e categorias profissionais. A segunda limitação refere-se ao fato de não ter sido possível padronizar os horários de coleta do swab do telefone celular dos profissionais. Acredita-se que resultados diferentes poderiam ter sido obtidos se a coleta tivesse sido realizada no final do turno de trabalho. Porém, por questões relacionadas à organização da unidade, à passagem de plantão ou mesmo à dependência de transporte coletivo por alguns profissionais, tornou-se inviável realizar a padronização desses horários. 


\section{REFERÊNCIAS}

AIRES, S.; CARVALHO, A.; AIRES, E.; CALADO, E.; ARAGÃO, I.; OLIVEIRA J.; POLÓNIA, A.; VASCONCELOS, C. Avaliação dos conhecimentos e atitudes sobre Precauções padrão. Acta Médica Portuguesa, v. 23, n. 2, p. 191-202, mar./abr. 2010.

ALBRICH, W. C.; HARBARTH, S. Health-care workers: source, vector, or victim of MRSA? The Lancet Infectious Diseases, v. 8, n. 5, p. 289-301, May 2008.

ANKOLA, A.V.; HEBBAL, M.; ESHWAR, S. How clean is the toothbrush that cleans your tooth? International Journal of Dental Hygiene, v. 7, n. 4, p. 237-240, 2009.

APPELBAUM, P. C. The emergence of vancomycin-intermediate and vancomycinresistant Staphylococcus aureus. Clinical Microbiology and Infection, v. 12, p. 1623, Mar. 2006. Supplement 1.

BELLO, A.; ASIEDU, E. N.; ADEGOKE, B. O. A.; QUARTEY, J. N. A.; APPIAH-KUBI, K. O.; OWUSU-ANSAH, B. Nosocomial infections: knowledge and source of information among clinical health care students in Ghana. International Journal of General Medicine, v. 4, p. 571-574, Aug. 2011.

BISAGA, A.; PAQUETTE, K.; SABATINI, L.; LOVELL, E. O. A prevalence study of methicillin-resistant Staphylococcus aureus colonization in emergency department health care workers. Annals of Emergency Medicine, v. 52, n. 5, p. 525-528, Apr. 2008.

BONINI, A. M.; ZEVIANI, C. P.; FACCHIN, L. T.; GIR, E.; CANINI, S. R. M. S. Exposição ocupacional dos profissionais de enfermagem de uma unidade de terapia intensiva a material biológico. Revista Eletrônica de Enfermagem, v. 11, n. 3, p. 658-664, 2009.

BOUCHER, H. W.; TALBOT, G. H.; BRADLEY, J. S.; EDWARDS, J. E.; GILBERT D.; RICE, L. B.; SCHELD, M.; SPELLBERG, B.; BARTLETT, J. Bad bugs, no drugs: no ESKAPE! An update from the Infectious Diseases Society of America. Clinical Infectious Diseases, v. 48, n. 1, p. 1-12, Jan. 2009.

BOYCE, J. M.; PITTET, D. Guideline for hand hygiene in health-care settings: recommendations of the healthcare infection control practices advisory committee and the HICPAC/SHEA/APIC/IDSA hand hygiene task force. Infection Control and Hospital Epidemiology, v. 23, n. 12, p. S3-40, Dec. 2002. Supplement. 
BRADY, R. R.; VERRAN, J.; DAMANI, N. N.; GIBB, A. P. Review of mobile communication devices as potential reservoirs of nosocomial pathogens. The Journal of Hospital Infection, v. 71, n. 4, p. 295-300, Apr. 2009.

BRASIL. Agência Nacional de Vigilância Sanitária. Investigação e controle de bactérias multirresistentes. Brasília, DF, 2007. 21 p.

BRASIL. Ministério da Saúde. Portaria n².616, de 12 de maio de 1998. Estabelece normas para controle de infecção hospitalar. Diário Oficial da União, Brasília, DF, 13 maio 1998. Seção 1, p. 133.

BRASIL. Ministério do Trabalho e Emprego. Secretaria de Inspeção do Trabalho. NR 32: Norma Regulamentadora de Segurança e Saúde no Trabalho em Estabelecimentos de Saúde. Aprovada pela Portaria GM № 1.748, de 30 de agosto de 2011. Diário Oficial da União, Brasília, DF, 31 ago. 2011. Seção 1, p. 143.

BREVIDELLI, M. M. Modelo Explicativo de Adesão às Precauções-padrão: construção e aplicação. 2003. 211 f. Tese (Doutorado) - Escola de Enfermagem Universidade de São Paulo, São Paulo, 2003.

BREVIDELLI, M. M.; CIANCIARULLO, T. I. Fatores psicossociais e organizacionais na adesão às precauções-padrão. Revista de Saúde Pública, v. 43, n. 6, p. 907916, dez. 2009.

BROOKS, G. F.; CARROL, K. C.; BUTEL, J. S.; MORSE, S. A.; MIETZNER, T. A. Microbiologia médica de Jawetz, Melnick \& Adelberg. 26. ed. Porto Alegre: AMGH, 2014. 872 p.

BUEHLMANN, M.; FREI, R.; FENNER, L.; DANGEL, M.; FLUCKIGER, U.; WIDMER, A. F. Highly effective regimen for decolonization of methicillin-resistant Staphylococcus aureus carriers. Infection Control and Hospital Epidemiology, v. 29 , n. 6, p. 510-516, Jun. 2008.

BUSATO, C. R.; GABARDO, J.; LEÃO, M. T. C. The Evolution of the resistance of Staphylococcus aureus found on healthcare workers correlated with local consumption of antibiotics. The Brazilian Journal Infectious Diseases, v. 10, n. 3, p. 185-190, Jun. 2006.

CANINI, S. R. M. S.; MORAES, S. A.; GIR. E.; FREITAS, I. C. M. Fatores associados a acidentes percutâneos na equipe de enfermagem de um hospital universitário de nível terciário. Revista Latino-Americana de Enfermagem, v. 16, n. 5, p. 818-823, set./out. 2008 
CARVALHO, C. M. R. S.; MADEIRA, M. Z. A.; TAPETY, F. I.; ALVES, E. L. M.; MARTINS, M. C. C.; BRITO, J. N. P. O. Aspectos de biossegurança relacionados ao uso do jaleco pelos profissionais de saúde: uma revisão da literatura. Texto \& Contexto Enfermagem, v. 18, n. 2, p. 355-360, abr./jun. 2009.

CARVALHO, M. J.; PIMENTA, F. C.; HAYASHIDA, M.; GIR, E.; SILVA, A. M.; BARBOSA, C. P.; CANINI, S. R.; SANTIAGO, S. Prevalence of methicillin-resistant and methicillin-susceptible $S$. aureus in the saliva of health professionals. Clinics, v. 64, n. 4, p. 295-302, Apr. 2009.

CENIZAL, M. J.; HARDY, R. D.; ANDERSON, M.; KATZ, K.; SKIEST, D. J. Prevalence of and risk factors for methicillin-resistant Staphylococcus aureus (MRSA) nasal colonization in HIV-infected ambulatory patients. Journal of Acquired Immune Deficiency Syndromes, v. 48, n. 5, p. 567-571, Aug. 2008.

CENTERS FOR DISEASE CONTROL AND PREVENTION (CDC). Four pediatric deaths from community-acquired methicillinresistant Staphylococcus aureus Minesota and North Dakota, 1997-1999. MMWR, v. 48, n. 32, p. 707-710, Aug. 1999.

CENTERS FOR DISEASE CONTROL AND PREVENTION (CDC). Staphylococcus aureus resistant to vancomycin-United States 2002. MMWR, v. 51, n. 26, p. 565-567, Jul. 2002.

CENTERS FOR DISEASE CONTROL AND PREVENTION (CDC). Active bacterial core surveillance (ABCs) report emerging infections program network methicillin-resistant Staphylococcus aureus. 2011. Disponível em: <http://www.cdc.gov/abcs/reports-findings/survreports/mrsa11.pdf>. Acesso em: 08 jun. 2015.

CHACKO, J.; KURUVILA, M.; BHAT, G. K. Factors affecting the nasal carriage of methicillin-resistant Staphylococcus aureus in human immunodeficiency virusinfected patients. Indian Journal of Medical Microbiology, v. 27, n. 2, p. 146-148, Apr./Jun. 2009.

CHAVES, R. A. C.; RIBEIRO, D. M. L.; ZAIA, J. E.; ALVES, E. G.; SOUZA, M. G. M.; MARTINS, C. H. G.; MESTRINER, S. F. Avaliação de soluções antibacterianas na descontaminação de escovas dentais de pré-escolares. Revista de Odontologia da UNESP, v. 36, n. 1, p. 29-33. 2007.

CLINICAL LABORATORY STANDARDS INSTITUTE (CLSI). Performance Standards for Antimicrobial Susceptibility Testing; Twenty-Fourth Informational Supplement. M100-S24, v. 34, n. 1, p. 1-226, Jan. 2014. 
COUTINHO, P. G.; BITTAR, P.; DITTERICH, R. G.; RASTELLI, M. C.; ROMANELLI, M. C. M. O. V.; WAMBIER, D. S. Análise do acondicionamento e condições de escovas dentais utilizadas por pré-escolares. Revista Odonto Ciência, v. 22, n. 58, p. 335-339, out./dez. 2007.

CRUZ, E. D. A.; PIMENTA, F. C.; PALOS, M. A. P.; CANINI, S. R. M. S.; GIR, E. Higienização de mãos: 20 anos de divergências entre a prática e 0 idealizado. Ciencia y Enfermería, v. 15, n. 1, p. 33-38, abr. 2009.

CRUZ, E. D. A.; PIMENTA, F. C.; PALAZZO, I. C. V.; DARINI, A. L. C.; GIR, E. Prevalência de Staphylococcus aureus na saliva de trabalhadores de saúde. Colombia Médica, v. 42, n. 2, p. 10-16, abr./jun. 2011.

DEJOY, D. M.; MURPHY, L. R.; GERSHON, R. M. The influence of employee, job/task, and organizational factors on adherence to universal precautions among nurses. International Journal of Industrial Ergonomics, v. 16, n. 1, p. 43-55, Jul. 1995.

DEJOY, D. M.; GERSHON, R. R.; MURPHY, L. R.; WILSON, M. G. A work-systems analysis of compliance with universal precautions among health care workers. Health Education Quarterly, v. 23, n. 2, p. 159-174, May 1996.

DEJOY, D. M.; SEARCY, C. A.; MURPHY, L. R.; GERSHON, R. R. Behavioraldiagnostic analysis of compliance with universal precautions among nurses. Journal of Occupational Health Psychology, v. 5, n. 1, p. 127-141, Jan. 2000.

ELIE-TURENNE, M. C.; FERNANDES, H.; MEDIAVILLA, J. R.; ROSENTHAL, M.; MATHEMA, B.; SINGH, A.; COHEN, T. R.; PAWAR, K. A.; SHAHIDI, H.; KREISWIRTH, B. N.; DEITCH, E. A. Prevalence and characteristics of Staphylococcus aureus colonization among healthcare professionals in an urban teaching hospital. Infection Control and Hospital Epidemiology, v. 31, n. 6, p. 574580, Jun. 2010.

ELLIS, M. W.; HOSPENTHAL, D. R.; DOOLEY, D. P.; GRAY, P. J.; MURRAY, C. K. Natural history of community-acquired methicillin-resistant Staphylococcus aureus colonization and infection in soldiers. Clinical Infectious Diseases, v. 39, n. 7, p. 971-979, Oct. 2004.

EUROPEAN CENTRE FOR DISEASE PREVENTION AND CONTROL. Multidrugresistant, extensively drug-resistant and pandrug-resistant bacteria: an international expert proposal for interim standard definitions for acquired resistance. 2011. Disponível em: <http://ecdc.europa.eu/en/activities/diseaseprogrammes/ ARHAl/Documents/table-1_Clinical_Microbiology_and_Infection.pdf>. Acesso em: 29 jul. 2015. 
FARLEY, J. E.; HAYAT, M. J.; SACAMANO, P. L.; ROSS, T.; CARROLL, K. Prevalence and risk factors for methicillin-resistant Staphylococcus aureus in an HIVpositive cohort. American Journal of Infection Control, v. 43, n. 4, p. 329-335, Apr. 2015.

FELIX, A. M. S.; VICTOR, E.; TOFFANO-MALAGUTI, S. E.; GIR, E. Fatores individuais, laborais e organizacionais associados à adesão às precauções padrão. Journal of Infection Control, v. 2, n. 2, p. 106-111, 2013.

FONTANA, R. T. As infecções hospitalares e a evolução histórica das infecções. Revista Brasileira de Enfermagem, v. 59, n. 5, p. 703-706, set./out. 2006.

FRIDKIN, S. K. Vancomycin-intermediate and -resistant Staphylococcus aureus: what the infectious disease specialist needs to know. Clinical Infectious Diseases, v. 32, n. 1, p. 108-115, Nov./Dec. 2001.

GALES, A. C.; SADER, H. S.; RIBEIRO, J.; ZOCCOLI, C.; BARTH, A.; PIGNATARI, A. C. Antimicrobial susceptibility of gram-positive bacteria isolated in Brazilian hospitals participating in the SENTRY program (2005-2008). The Brazilian Journal of Infectious Diseases, v. 13, n. 2, p. 90-98, Apr. 2009.

GALLAS, S. R.; FONTANA, R. T. Biossegurança e a enfermagem nos cuidados clínicos: contribuições para a saúde do trabalhador. Revista Brasileira de Enfermagem, v. 63, n. 5, p. 786-792, out. 2010.

GEBREYESUS, A.; GEBRE-SELASSIE, S.; MIHERT, A. Nasal and hand carriage rate of methicillin resistant Staphylococcus aureus (MRSA) among health care workers in Mekelle Hospital, North Ethiopia. Ethiopian medical journal, v. 51, n. 1, p. 41-47, Jan. 2013.

GERSHON, R. R.; VLAHOV, D.; FELKNOR, S. A.; VESLEY, D., JOHNSON, P. C.; DELCLOS, G. L.; MURPHY, L. R. Compliance with universal precautions among health care workers at three regional hospitals. American Journal of Infection Control, v. 23, n. 4, p. 225-236, Aug. 1995.

GOLDBLATT, J. G.; KRIEF, I.; KLONSKY, T.; HALLER, D.; MILLOUL, V.; SIXSMITH, D. M.; SRUGO, I.; POTASMAN, I. Use of cellular telephones and transmission of pathogens by medical staff in New York and Israel. Infection Control and Hospital Epidemiology, v. 28, n. 4, p. 500-503, Apr. 2007.

GONÇALO, C. S.; MIALHE, F. L. Contaminação das escovas dentais: uma revisão crítica da literatura. Revista Periodontia, v. 19, n. 3, p. 56-63, set. 2009. 
HIDRON, A. I.; KOURBATOVA, E. V.; HALVOSA, J. S.; TERRELL, B. J.; MCDOUGAL, L. K.; TENOVER, F. C.; BLUMBERG, H. M.; KING, M. D. Risk factors for colonization with methicillin-resistant Staphylococcus aureus (MRSA) in patients admitted to an urban hospital: emergence of community-associated MRSA nasal carriage. Clinical Infectious Diseases, v. 41, n. 2, p. 159-166, Jul. 2005.

HIDRON, A. I.; MOANNA, A.; RIMLAND, D. The rise and fall of methicillin-resistant Staphylococcus aureusinfections in HIV patients. AIDS, v. 25, n. 7, p. 1001-1003, Apr. 2011.

HIGGINSON, R. Taking uniforms home: why it just doesn't wash. British Journal of Nursing, v. 20, n. 13, p. 781, Jul. 2011.

HIRAMATSU, K.; HANAKI, H.; INO, T.; YABUTA, K.; OGURI, T.; TENOVER, F. C. Methicillin-resistant Staphylococcus aureus clinical strain with reduced vancomycin susceptibility. Journal of Antimicrobial Chemotherapy, v. 40, n. 1, p. 135-136, Jul. 1997.

HOSPITAL DAS CLÍNICAS DA FACULDADE DE MEDICINA DE RIBEIRÃO PRETO DA UNIVERSIDADE DE SÃO PAULO (HCFMRP-USP). Relatório de atividades 2012. Disponível em: <http://www.hcrp.fmrp.usp.br/sitehc/upload\%5CRelatoriode Atividades_HCRP_2012.pdf>. Acesso em: 13 jun. 2015.

JEVONS, P. M. "Celbenin" - resistant staphylococci. British Medical Journal, v. 1, n. 5219, p. 124-125, Jan. 1961.

JORGE, A. O. C. Microbiologia: atividades práticas. 2. ed. São Paulo: Editora Santos, 2001. $146 \mathrm{p}$.

KIM, M. N.; PAI, C. H.; WOO, J. H.; RYU, J. S.; HIRAMATSU, K. Vancomycinintermediate Staphylococcus aureus in Korea. Journal of Clinical Microbiology, v. 38, n. 10, p. 3879-3891, Oct. 2000.

KLUYTMANS, J.; VAN BELKUM, A.; VERBRUGH, $H$. Nasal carriage of Staphylococcus aureus: epidemiology, underlying mechanisms, and associated risks. Clinical Microbiology Reviews, v. 10, n. 3, p. 505-520, Jul. 1997.

KRAMER, A.; SCHWEBKE, I.; KAMPF, G. How long do nosocomial pathogens persist on inanimate surfaces? A systematic review. BMC Infectious Diseases, v. 6, p. 130, Aug. 2006.

LICITRA, G. Etymologia: Staphylococcus. Emerging Infectious Diseases, v. 19, n. 9, p. 1553, Sep. 2013. 
LONGTIN, Y.; SCHNEIDER, A.; TSCHOPP, A.; RENZI, G.; GAYET-AGERON, A.; SCHRENZE, J.; PITTET, D. Contamination of stethoscopes and physicians' hands following a physical examination. Mayo Clinic Proceedings, v. 89, n. 3, p. 291-299, Mar. 2014.

LOPES, A. E. R.; CANINI, S. R. M. S.; REINATO, L. A. F.; LOPES, L. P. GIR, E. Prevalência de bactérias gram-negativas em portadores de HIV internados em serviço especializado. Acta Paulista de Enfermagem, v. 28, n. 3, p. 281-286, maio/jun. 2015.

LOPES, H. V. CA-MRSA: um novo problema para o infectologista. Revista Panamericana de Infectologia, v. 7, n. 3, p. 34-36, jul./set. 2005.

LOWY, F. D. Antimicrobial resistance: the example of Staphylococcus aureus. The Journal of Clinical Investigation, v. 111, n. 9, p. 1265-1273, May 2003.

MACKENZIE, F. M.; LOPEZ-LOZANO, J. M.; MONNET, D. L.; STUART, D.; BEYAERT, A.; WILSON, R.; GOULD, I. M. Temporal relationship between prevalence of meticillin-resistant Staphylococcus aureus (MRSA) in one hospital and prevalence of MRSA in the surrounding community: a time-series analysis. The Journal of Hospital Infection, v. 67, n. 3, p. 225-231, Nov. 2007.

MALAGUTI, S. E.; HAYASHIDA, M.; CANINI, S. R. M. S.; GIR, E. Enfermeiros com cargos de chefia e medidas preventivas à exposição ocupacional: facilidades e barreiras. Revista da Escola de Enfermagem da USP, v. 42, n. 3, p. 496-503, set. 2008.

MANDELL, G.; BENNET, J.; DOLIN, R. Mandell, Douglas e Benett's principles and practice of infectious diseases. 7th ed. Philadelphia: Churchill Livingstone, 2010. 4320 p.

MARGARIDO, C. A.; BOAS, T. M. V.; MOTA, V. S.; SILVA, C. K. M.; POVEDA, V. B. Contaminação microbiana de punhos de jalecos durante a assistência à saúde. Revista Brasileira de Enfermagem, v. 67, n. 1, p. 127-132, jan./fev. 2014.

MARRA, A. R.; ALMEIDA, S. M.; CORREA, L.; SILVA, M. Jr.; MARTINO, M. D.; SILVA, C. V.; CAL, R. G.; EDMOND, M. B.; SANTOS, O. F. The effect of limiting antimicrobial therapy duration on antimicrobial resistance in the critical care setting.

American Journal of Infection Control, v. 37, n. 3, p. 204-209, Apr. 2009.

MARTINS, A. F.; PRATES, C. G.; LOPES, F. S.; PRATES, J.; SILIPRAND, E. M. O.; BEATRIZ; SARAIVA, N.; BATISTA, S. R. O.; LONDERO, F.; SCHWANCK, J. L. B.; HAUSCHILD, J. A.; METZ, M.; OPPERMANN, C. M.; VIANA, K. S.; DIAS, L. C.; DALAROSA, M.; FERREIRA, R. L. T.; KUPLICH, N.; DOSSA, A. W.; SEVERINI, M. 
H. A. Manual de controle e monitoramento de microrganismos multirresistentes. Journal of Infection Control, v. 2, n. 4, p. 153-175, 2013.

MOELLERING, R. C., JR. MRSA: the first half century. The Journal of Antimicrobial Chemotherapy, v. 67, n. 1, p. 4-11, Oct. 2012.

MOGHADAM S. O.; POURMAND M. R.; DAVOODABADI A. The detection of mupirocin resistance and nasal carriage of methicillin resistant Staphylococcus aureus among healthcare workers at University Hospitals of Tehran, Iran. Iranian Journal of Public Health, v. 44, n. 3, p. 361-368, Mar. 2015.

MOREIRA, A. C. M. G.; SANTOS, R. R.; BEDENDO, J. Prevalência e perfil de sensibilidade de Staphylococcus aureus isolados em pacientes e equipe de enfermagem. Ciência, Cuidado e Saúde, v. 12, n. 3, p. 572-579, jul./set. 2013.

MOREIRA, A. C. S.; CAVALCANTE, G. M. Influência da higienização na contaminação de escovas dentais. Arquivos de Ciências da Saúde da Unipar, v. 12, n. 1, p. 99-103, maio/ago. 2008.

MORETTI, M. L.; PEDRO, R. J. Estafilococcias. In: FOCACCIA, R.; VERONESI, R. Tratado de infectologia. 4. ed. São Paulo: Atheneu, 2009. p. 963-978.

MOTA, E. C.; BARBOSA, D. A.; SILVEIRA, B. R. M.; RABELO, T. A.; SILVA, N. M.; SILVA, P. L. N.; RIBEIRO, J. L.; SILVA, C. S. O.; GONÇALVES, R. P. F. Higienização das mãos: uma avaliação da adesão e da prática dos profissionais de saúde no controle das infecções hospitalares. Revista de Epidemiologia e Controle de Infecção, v. 4, n. 1, p. 12-17, jan./mar. 2014.

MOURA, J. P. A colonização dos profissionais de enfermagem por Staphylococcus aureus: problemática e desafios. 2009. 113 f. Tese (Doutorado) Escola de Enfermagem de Ribeirão Preto, Universidade de São Paulo, Ribeirão Preto, 2009.

MOURA, J. P.; GIR, E. Conhecimento dos profissionais de enfermagem referente à resistência bacteriana a múltiplas drogas. Acta Paulista de Enfermagem, v. 20, n. 3, p. 351-356, jul./set. 2007.

MOURA, J. P.; GIR, E.; CANINI, S. R. M. S. Acidentes ocupacionais com material perfurocortante em um hospital regional de Minas Gerais, Brasil. Ciencia y Enfermería, v. 12, n. 1, p. 29-37, jun. 2006.

MOURA, J. P.; GIR, E.; ROSA, J. O.; BELÍSSIMO-RODRIGUES, F.; CRUZ, E. D. A.; OLIVEIRA, A. C. A.; PIMENTA, F. C. Resistência à mupirocina entre isolados de 
Staphylococcus aureus de profissionais de enfermagem. Acta Paulista de Enfermagem, v. 23, n. 3, p. 399-403, mar./abr. 2010.

MOURA, J. P.; PIMENTA, F. C.; HAYASHIDA, M.; CRUZ, E. D. A.; CANINI, S. R. M. S. A colonização dos profissionais de enfermagem por Staphylococcus aureus. Revista Latino-Americana de Enfermagem, v. 19, n. 2, p. 325-331, mar./abr. 2011.

MURRAY, P. R.; ROSENTHAL, K. S.; PFALlER, M. A. Microbiologia médica. 7. ed. Rio de Janeiro: Elsevier, 2014. 888 p.

NELSON FILHO, P.; MACARI, S.; FARIA, G.; ASSED, S.; ITO, I. Y. Microbial contamination of toothbrushes and their decontamination. Pediatric Dentistry, v. 22, n. 5, p. 381-384, Sep./Oct. 2000.

NEVES, H. C. C.; SOUZA, A. C. S.; MEDEIROS, M.; MUNARI, D. B.; RIBEIRO, L. C. M.; TIPPLE, A. F. V. Segurança dos trabalhadores de enfermagem e fatores determinantes para adesão aos equipamentos de proteção individual. Revista Latino- Americana de Enfermagem, v. 19, n. 2, p. 1-8, mar./abr. 2011.

NEVES, Z. C. P.; TIPPLE, A. F. V.; SOUZA, A. C. S.; PEREIRA, M. S.; MELO, D. S.; FERREIRA, L. R. Higienização das mãos: o impacto de estratégias de incentivo à adesão entre profissionais de saúde de uma unidade de terapia intensiva neonatal. Revista Latino-Americana de Enfermagem, v. 14, n. 4, p. 546-552, jul./ago. 2006.

NILSSON, P.; RIPA, T. Staphylococcus aureus throat colonization is more frequent than colonization in the anterior nares. Journal of Clinical Microbiology, v. 44, n. 9, p. 3334-3339, Sep. 2006.

OGSTON, A. Report upon microorganisms in surgical diseases. The British Medical Journal, v. 1, p. 369-375, Mar. 1881.

OLIVA, A.; LICHTNER, M.; MASCELLINO, M. T.; IANNETTA, M.; IALUNGO, A. M.; TADADJEU-MEWAMBA, S.; PAVONE, P.; MENGONI, F.; MASTROIANNI, C. M.; VULLO, V. Study of methicillin-resistant Staphylococcus aureus (MRSA) carriage in a population of HIV-negative migrants and HIV-infected patients attending an outpatient clinic in Rome. Annali di Igiene: Medicina Preventiva e di Comunità, v. 25, n. 2, p. 99-107, Mar./Apr. 2013.

OLIVEIRA, A. C.; PAULA, A. O. Fatores relacionados à baixa adesão à higienização das mãos na área da saúde: uma reflexão. Ciência, Cuidado e Saúde, v. 13, n. 1, p. 185-190, jan./mar. 2014. 
OLIVEIRA, B. R G.; MUROFUSE, N. T. Acidentes de trabalho e doença ocupacional: estudo sobre o conhecimento do trabalhador hospitalar dos riscos à saúde de seu trabalho. Revista Latino-Americana de Enfermagem, v. 9, n. 1, p. 109-115, jan. 2001.

OLIVEIRA, G. A.; DELL'AQUILA, A. M.; MASIERO, R. L.; LEVY, C. E.; GOMES, M. S.; CUI, L.; HIRAMATSU, K.; MAMIZUKA, E. M. Isolation in Brazil of nosocomial Staphylococcus aureus with reduced susceptibility to vancomycin. Infectious Control Hospital Epidemiology, v. 22, n. 7, p. 443-448, Jul. 2001.

OTTER, J. A.; FRENCH, G. L. Community-associated meticillin-resistant Staphylococcus aureus strains as a cause of healthcare-associated infection. The Journal of Hospital Infection, v. 79, n. 3, p. 189-193, Nov. 2011.

PALOS, M. A. P. Staphylococcus aureus e Staphylococcus aureus meticilina resistentes (MRSA) em profissionais de saúde $e$ as interfaces com as infecções nosocomiais. 2006. 188 f. Tese (Doutorado) - Escola de Enfermagem de Ribeirão Preto, Universidade de São Paulo, Ribeirão Preto, 2006.

PANDEY, A.; ASTHANA, A. K.; TIWARI, R.; KUMAR, L.; DAS, A.; MADAN, M. Physician accessories: doctor, what you carry is every patient's worry? Indian Journal of Pathology \& Microbiology, v. 53, n. 4, p. 711-713, Oct./Dec. 2010.

PEDRO, A. L.; SOUSA-UVA, A.; PINA, E. Endemic methicillin-resistant Staphylococcus aureus: Nurses' risk perceptions and attitudes. American Journal of Infection Control, v. 42, n. 10, p. 1118-1120, Oct. 2014.

PEREIRA, F. M. V. Adesão às precauções-padrão por profissionais de enfermagem que atuam em terapia intensiva em um hospital universitário do interior paulista. 2011. 86 f. Dissertação (Mestrado) - Escola de Enfermagem de Ribeirão Preto, Universidade de São Paulo, Ribeirão Preto, 2011.

PEREIRA, F. M. V.; MALAGUTI-TOFFANO, S. E.; SILVA, A. M. S.; CANINI, S. R. M. S.; GIR, E. Adesão às precauções-padrão por profissionais de enfermagem que atuam em terapia intensiva em um hospital universitário. Revista da Escola de Enfermagem da USP, v. 47, n. 3, p. 686-693, jun. 2013.

PERES, D.; NEVES, I.; VIEIRA, F.; DEVESA, I. Estratégia para controlar o Staphylococcus aureus resistente à meticilina: a experiência de cinco anos de um hospital. Acta Médica Portuguesa, v. 27, n. 1, p. 67-72, jan./fev. 2014.

PITTET, D. Improving compliance with hand hygiene in hospitals. Infection Control and Hospital Epidemiology, v. 21, n. 6, p. 381-386, Jun. 2000. 
PITTET, D.; ALLEGRANZI, B.; SAX, H.; DHARAN, S.; PESSOA-SILVA, C. L.; DONALDSON, L.; BOYCE, J. M. Evidence-based model for hand transmission during patient care and the role of improved practices. The Lancet Infectious Diseases, v. 6, n. 10, p. 641-652, Oct. 2006.

PLOY, M. C.; GRÉLAUD, C.; MARTIN, C.; LUMLEY, L.; DENIS, F. First clinical isolate of vancomycin-intermediate Staphylococcus aureus in a French hospital. The Lancet, v. 351, p. 1212, Apr. 1998.

PRADO, M. F.; HARTMANN, T. P. S.; TEIXEIRA FILHO, L. A. Acessibilidade da estrutura física hospitalar para a prática da higienização das mãos. Escola Anna Nery, v. 17, n. 2, p. 220-226, abr./jun. 2013.

PRIMO, M. G. B.; RIBEIRO, L. C. M.; FIGUEIREDO, L. F. S.; SIRICO, S. C. A.; SOUZA, M. A. Adesão à prática de higienização das mãos por profissionais de saúde de um Hospital Universitário. Revista Eletrônica de Enfermagem, v. 12, n. 2, p. 266-271, abr./jun. 2010.

RABELO, M. A.; BEZERRA NETO, A. M.; LOIBMAN, S. O.; LIMA, J. L.; FERREIRA, E. L.; LEAL, N. C.; MACIEL, M. A. The occurrence and dissemination of methicillin and vancomycin-resistant Staphylococcus in samples from patients and health professionals of a university hospital in Recife, State of Pernambuco, Brazil. Revista da Sociedade Brasileira de Medicina Tropical, v. 47, n. 4, p. 437-446, Jul. 2014.

RAMSETTY, S. K.; STUART, L. L.; BLAKE, R.T.; PARSONS, C. H.; SALGADO, C. D. Risks for methicillin-resistant Staphylococcus aureus colonization or infection among patients with HIV infection. HIV Medicine, v. 11, n. 6, p. 389-394, Jul. 2010.

REINATO, L. A. F.; PEREIRA, F. M. V.; LOPES, L. P.; PIO, D. P. M.; GIR, E. Colonização nasal em profissionais de enfermagem de unidades especializadas em HIV/aids. Revista Brasileira de Enfermagem, v. 68, n. 2, p. 320-324, mar./abr. 2015.

REINATO, L. A. F.; PIO, D. P. M.; LOPES, L. P.; PEREIRA, F. M. V.; LOPES, A. E. R.; GIR, E. Colonização nasal por Staphylococcus aureus em indivíduos com HIV/Aids atendidos em um hospital-escola brasileiro. Revista Latino-Americana de Enfermagem, v. 21, n. 6, p. 1235-1239, nov./dez. 2013.

RICE, L. B. Federal funding for the study of antimicrobial resistance in nosocomial pathogens: no ESKAPE. The Journal of Infectious Diseases, v. 197, n. 8, p.10791081, Apr. 2008.

ROBICSEK, A.; BEAUMONT, J. L.; PAULE, S. M.; HACEK, D. M.; THOMSON JUNIOR, R. B.; KAUL, K. L.; KING, P.; PETERSON, L. R. Universal surveillance for 
methicillin-resistant Staphylococcus aureus in 3 affiliated hospitals. Annals of Internal Medicine, v. 148, n. 6, p.409-418, Mar. 2008.

ROSSINI, F. P.; BELÍSSIMO-RODRIGUES, F.; FERREIRA, M. V. F.; SILVA, M. F. I.; RESUTO, T. J. O.; SILVA, M. H. A.; GASPAR, G. G.; MELO, L.; ROCHA, L. S. O.; PAZIN-FILHO, A.; COSTA, J. C. Protocolo para descolonização de pacientes colonizados ou infectados por Staphylococcus spp multidrogaresistentes (MDR). Revista Qualidade HC, v. 1, n. 1, p. 41-44, dez. 2009.

SAEED, N. K.; FARID, E.; JAMSHEER, A. E. Prevalence of opportunistic infections in HIV-positive patients in Bahrain: a four-year review (2009-2013). Journal of Infections in Developing Countries, v. 9, n. 1, p. 60-69, Jan. 2015.

SANTOS, A. L.; SANTOS, D. O.; FREITAS, C. C.; FERREIRA, B. L. A.; AFONSO, I. F.; RODRIGUES, C. R.; CASTRO, H. C. Staphylococcus aureus: visitando uma cepa de importância hospitalar. Jornal Brasileiro de Patologia e Medicina Laboratorial, v. 43, n. 6, p. 413-423, dez. 2007.

SANTOS, B. M. O. Monitoramento da colonização pelo Staphylococcus aureus em alunos de um curso de auxiliar de enfermagem durante a formação profissional. Revista Latino-Americana de Enfermagem, v. 8, n. 1, p. 67-73, jan. 2000.

SANTOS, H. G. S.; SANTOS, C. I. L.; LOPES, D. F. M.; BELEI, R. A. Multirresistência bacteriana: a vivência de pacientes internados em hospital-escola do município de Londrina - PR. Ciência, Cuidado e Saúde, v. 9, n. 1, p. 74-80, jan./mar. 2010.

SANTOS, N. Q. A resistência bacteriana no contexto da infecção hospitalar. Texto \& Contexto Enfermagem, v. 13, p. 64-70, 2004. Número Especial.

SÃO PAULO (Estado). Lei $n^{\circ} 14.466$, de 8 de junho de 2011. Proíbe o uso, por profissionais da área da saúde, de equipamentos de proteção individual fora do ambiente de trabalho. Diário Oficial do Estado de São Paulo, São Paulo, 09 jun. 2011. Seção 1, p. 01.

SARAVIA, M. E.; NELSON-FILHO, P.; SILVA, R. A.; FARIA, G.; ROSSI, M. A.; ITO, I. Y. Viability of Streptococcus mutans toothbrush bristles. Journal of Dentistry for Children, v. 75, n. 1, p. 29-32, Jan./Apr. 2008.

SAX, H.; PERNEGER, T.; HUGONNET, S.; HERRAULT, P.; CHRAÏTI, M. N.; PITTET, D. Knowledge of standard and isolation precautions in a large teaching hospital. Infectious Control Hospital Epidemiology, v. 26, n. 3, p. 298-304, Mar. 2005. 
SCHITO, G. C. The importance of the development of antibiotic resistance in Staphylococcus aureus. Clinical Microbiology and Infection, v. 12, p. 3-8, Mar. 2006. Supplement 1.

SIEGEL, J. D.; RHINEHART, E.; JACKSON, M.; CHIARELLO, L. Management of Multidrug-Resistant Organisms in Healthcare Settings, 2006. American Journal of Infection Control, v. 35, n. 10, p. S165-S193, Dec. 2007a.

SIEGEL, J. D.; RHINEHART, E.; JACKSON, M.; CHIARELLO, L. 2007 Guideline for isolation precautions: preventing transmission of infectious agents in health care settings, American Journal of Infection Control, v. 35, n. 10, p. S65-S164, Dec. 2007b.

SILVA, A. M.; CARVALHO, M. J.; CANINI, S. R. M. S.; CRUZ, E. D. A.; SIMÕES, C. L. A. P.; GIR, E. Staphylococcus aureus resistente à meticilina: conhecimento e fatores associados à adesão da equipe de enfermagem às medidas preventivas. Revista Latino-Americana de Enfermagem, v. 18, n. 3, p. 346-351, maio/jun. 2010.

SILVA, E. C. B. F.; ANTAS, M. G. C.; NETO, A. M. B.; RABELO, M. A.; MELO, F. L.; MACIEL, M. A. V. Prevalence and risk factors for Staphylococcus aureus in health care workers at a University Hospital of Recife-PE. The Brazilian Journal Infectious Diseases, v. 12, n. 6, p. 504-508, Dec. 2008.

SILVA, E. C. B. F.; SAMICO, T. M.; CARDOSO, R. R.; RABELO, M. A.; BEZERRA NETO, A. M.; MELO, F. L.; LOPES, A. C. S.; ACA, I. S.; MACIEL, M. A. V. Colonização pelo Staphylococcus aureus em profissionais de enfermagem de um hospital escola de Pernambuco. Revista da Escola de Enfermagem da USP, v. 46, n. 1, p. 132-137, fev. 2012.

SILVA, G. S.; ALMEIDA, A. J.; PAULA, V. S.; VILLAR, L. M. Conhecimento e utilização de medidas de precaução-padrão por profissionais de saúde. Escola Anna Nery, v. 16, n. 1, p. 103-110, mar. 2012.

SIMOR, A. E. Containing methicillin-resistant S aureus. Surveillance, control, and treatment methods. Postgraduate Medicine, v. 110, n. 4, p. 43-48, Oct. 2001.

SIMOR, A. E. Staphylococcal decolonisation: an effective strategy for prevention of infection? The Lancet Infectious Diseases, v. 11, n. 12, p. 952-962, Dec. 2011.

SIVARAMAN, K.; VENKATARAMAN, N.; COLE, A. M. Staphylococcus aureus Nasal Carriage and its Contributing Factors. Future Microbiology, v. 4, n. 8, p. 999-1008, Oct. 2009. 
TACCONELLI, E.; DE ANGELIS G.; CATALDO, M. A.; POZZI, E.; CAUDA, R. Does antibiotic exposure increase the risk of methicillin-resistant Staphylococcus aureus (MRSA) isolation? A systematic review and meta-analysis. The Journal of Antimicrobial Chemotherapy, v. 61, n. 1, p. 26-38, Jan. 2008.

TACCONELLI, E. Methicillin-resistant Staphylococcus aureus: source control and surveillance organization. Clinical Microbiology and Infection, v. 15, p. 31-38, Dec. 2009. Supplement 7.

TRABULSI, L. R.; ALTERTHUM, F. Microbiologia. 5. ed. São Paulo: Atheneu, 2008. $780 \mathrm{p}$.

STUCHI, R. A. G.; OlIVEIRA, C. H. A. S.; SOARES, B. M.; ARREGUY-SENA, C. Contaminação bacteriana e fúngica dos telefones celulares da equipe de saúde num hospital em Minas Gerais. Ciência, Cuidado e Saúde, v. 12, n. 4, p. 760-767, out./dez. 2013.

TIMILSHINA, N.; ANSARI, M. A.; DAYAL, V. Risk of infection among primary health workers in the Western Development Region, Nepal: knowledge and compliance. Journal of Infection in Developing Countries, v. 5, n.1, p. 18-22, Feb. 2011.

TREAKLE, A. M.; THOM, K. A.; FURUNO, J. P.; STRAUSS, S. M.; HARRIS, A. D.; PERENCEVICH, E. N. Bacterial contamination of health care workers' white coats. American Journal of Infection Control, v. 37, n. 2, p. 101-105, Mar. 2009.

TUMBARELLO, M.; DONATI, K. G.; TACCONELLI, E.; CITTON, R.; SPANU, T.; LEONE, F.; FADDA, G.; CAUDA, R. Risk factors and predictors of mortality of methicillin-resistant Staphylococcus aureus (MRSA) bacteraemia in HIV-infected patients. Journal Antimicrobial Chemotherapy, v. 50, n. 3, p. 375-382, Sep. 2002.

TURLEJ, A.; HRYNIEWICZ, W.; EMPEL, J. Staphylococcal cassette chromosome mec (SCCmec) classification and typing methods: an overview. Polish Journal of Microbiology, v. 60, n. 2, p. 95-103, 2011.

USTUN, C.; CIHANGIROGLU, M. Health care workers' mobile phones: a potential cause of microbial cross-contamination between hospitals and community. Journal of Occupational and Environmental Hygiene, v. 9, n. 9, p. 538-542, 2012.

VILARINHO, L. M.; VILARINHO, M. L. C. M.; SILVA, F. L.; GUIMARÃES, M. S. O.; LEAL, A. C. A. M. Isolamento de Staphylococcus aureus em mãos de profissionais de Unidades de Terapia Intensiva. Revista Prevenção de Infecção e Saúde, v. 1, n. 1, p. 10-18, mar. 2015. 
XAVIER, M. S.; UENO, M. Contaminação bacteriana de estetoscópios das unidades de pediatria em um hospital universitário. Revista da Sociedade Brasileira de Medicina Tropical, v. 42, n. 2, p. 217-218, mar./abr. 2009.

WILLEMSEN, I.; BOGAERS-HOFMAN, D.; WINTERS, M.; KLUYTMANS, J. Correlation between antibiotic use and resistance in a hospital: temporary and wardspecific observations. Infection, v. 37, n. 5, p. 432-437, Oct. 2009.

WEINKE, T.; ROHDE, I.; SCHILLER, R.; FEHRENBACH, F. J.; POHLE, H. D. Staphylococcus aureus carriage rate and frequency of staphylococcal bacteremia in HIV-infected patients. International Aids Society, n. 7, p. 242, Jun. 1991.

WENZEL, R. P.; REAGAN D. R.; BERTINO, J. S. J.; BARON, E. J., ARIAS, K. Methicillin-resistant Staphylococcus aureus outbreak: a consensus panel's definition and management guidelines. American Journal of Infection Control, v. 26, n. 2, p. 102-110, Apr. 1998.

WORLD HEALTH ORGANIZATION (WHO). A guide to the implementation of the WHO multimodal hand hygiene improvement strategy. 2009b. p. 1-47. Disponível em: <http://www.who.int/gpsc/5may/Guide_to_Implementation.pdf>. Acesso em: 10 jul. 2015.

WORLD HEALTH ORGANIZATION (WHO). Global strategy for containment of antimicrobial resistence. 2001. p. 1-99. Disponível em: <http://www.who.int/csr/ resources/publications/drugresist/en/EGlobal_Strat.pdf>. Acesso em: 22 maio 2015.

WORLD HEALTH ORGANIZATION (WHO). WHO guidelines on hand hygiene in health care. First global patient safety challenge: clean care is safe care. 2009a. p. 1-270. Disponível em: <http://whqlibdoc.who.int/publications/2009/ 9789241597906_eng.pdf>. Acesso em: 08 jun. 2015. 


\section{APÊNDICES}

\section{APÊNDICE A \\ TERMO DE CONSENTIMENTO LIVRE E ESCLARECIDO}

\section{Título da Pesquisa: Staphylococcus aureus em profissionais de enfermagem e as interfaces com a adesão às precauções-padrão}

Pesquisador Responsável: Letícia Pimenta Lopes

Você está sendo convidado(a) a participar, como voluntário, em uma pesquisa com o objetivo de analisar a prevalência de colonização de Staphylococcus aureus em profissionais de enfermagem e as interfaces com a adesão às precauções-padrão.

Para isto, precisamos de sua colaboração em responder dois instrumentos; um com questões abertas e fechadas abordando informações para a caracterização demográfica e profissional do participante (sexo, idade, categoria profissional, turno e setor de trabalho, tempo de exercício profissional, carga horária semanal de trabalho, hábitos ou características de saúde, conhecimento sobre precauções-padrão). E o segundo é uma escala para a avaliação da adesão dos profissionais às precauções-padrão. Para isso, solicitamos que assinale com um círculo apenas uma opção que corresponde a sua resposta. As informações serão coletadas no próprio serviço, em sala privativa. O tempo estimado para responder os instrumentos é de 20 minutos. Além disso, necessitamos que você cuspa cerca de 3 a $5 \mathrm{ml}$ de saliva num tubo estéril e colete um swab de secreção nasal de ambas as narinas. Caso possua um telefone celular, coletaremos também um swab da superfície externa e posterior da base de seu equipamento. Após quatro e oito meses, repetiremos a coleta de saliva, secreção nasal e o swab do telefone celular. Esses materiais serão analisados no Laboratório de Microbiologia deste hospital.

Informamos que:

- Os resultados dessa pesquisa poderão ser divulgados em eventos científicos, na mídia, ou similares, mantendo o anonimato do participante.

- O participante poderá sentir certo desconforto passageiro ao cuspir no frasco coletor e ou coletar a secreção nasal; isto pode ser amenizado se a coleta for realizada pelo próprio participante, em sala privativa. Caso necessário, podemos ocluir o frasco coletor do material para evitar a exposição do material coletado.

- Não há benefícios pessoais decorrentes da participação na pesquisa, a participação ajudará na comprovação da hipótese estabelecida.

- A participação dos sujeitos será apenas nas coletas e no preenchimento dos instrumentos, sendo que suas informações e identificação serão mantidas em completo sigilo.

- Não há previsão de gastos e/ou ressarcimento de despesas pelos participantes deste estudo. Em casos de danos, comprovadamente decorrentes da participação na pesquisa é garantido indenização, conforme a Resolução no 466/2012.

- Enquanto sujeito desta pesquisa, garantimos o direito e a sua liberdade de retirar o consentimento a qualquer momento. Além disso, serão oferecidos esclarecimentos, antes e durante o desenvolvimento da pesquisa.

- Caso seja isolado algum microrganismo multirresistente em sua saliva ou secreção nasal você será informado, e mediante sua concordância, encaminhado à Comissão de Controle de Infecção Hospitalar do HCFMRP-USP, para avaliação e conduta. 
Após ser esclarecido(a) sobre as informações, no caso de aceitar fazer parte do estudo, solicitamos que assine no verso, este documento, que está em duas vias. Sendo que uma das vias é sua e a outra é do pesquisador responsável. Em caso de recusa você não será penalizado de forma alguma.

(Verso do TCLE)

Caso ainda queira esclarecer quaisquer dúvidas sobre os aspectos éticos desta pesquisa, você poderá entrar em contato com o Comitê de Ética em Pesquisa da Escola de Enfermagem de Ribeirão Preto, designado para defender os interesses dos sujeitos da pesquisa em sua integridade e dignidade e contribuir no desenvolvimento da pesquisa dentro de padrões ético-científicos.

Telefone: (16) 3602-3386 - Horário de Funcionamento de segunda à sexta, das $8 \mathrm{~h}$ às $17 \mathrm{~h}$ Avenida dos Bandeirantes, 3900, Campus Universitário - Bairro Monte Alegre CEP: 14040-902 - Ribeirão Preto - SP.

Agradecemos sua participação.

Letícia Pimenta Lopes

Pesquisadora Responsável

Email: letylopes@yahoo.com.br

Telefone: (16)8145-9085

\section{Elucir Gir}

Orientadora

Docente da Escola de Enfermagem de Ribeirão Preto-USP Telefone: (16) 3602-3414; Email: egir@ eerp.usp.br

Endereço: Av. Bandeirantes, 3900, Sala 64 Ribeirão Preto-SP

\section{CONSENTIMENTO: A SER PREENCHIDO PELO PARTICIPANTE}

Fui devidamente informado(a) e esclarecido(a) pelo pesquisador sobre os propósitos da pesquisa Staphylococcus aureus em profissionais de enfermagem e as interfaces com a adesão às precauções-padrão, assim como dos procedimentos a serem realizados e a garantia de confiabilidade. Foi-me garantido o direito de retirar meu consentimento a qualquer momento, sem que isto leve a qualquer penalidade. Diante disto, eu concordo e aceito participar desta pesquisa.

NOME:

RG:

DATA:

ASSINATURA: 


\section{APÊNDICE B}

\section{Dados demográficos, profissionais e individuais da equipe de enfermagem}

Data: 1

No.

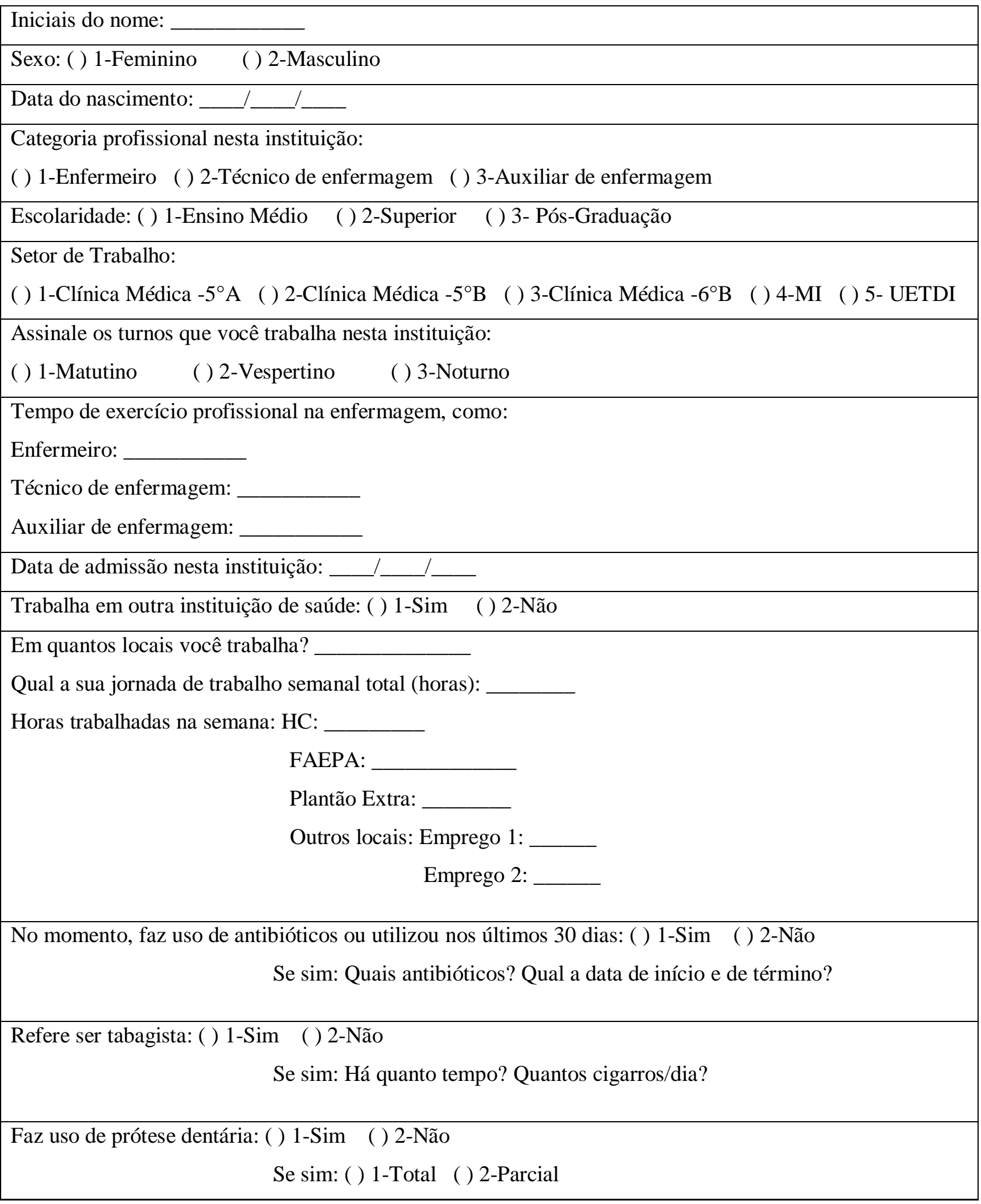




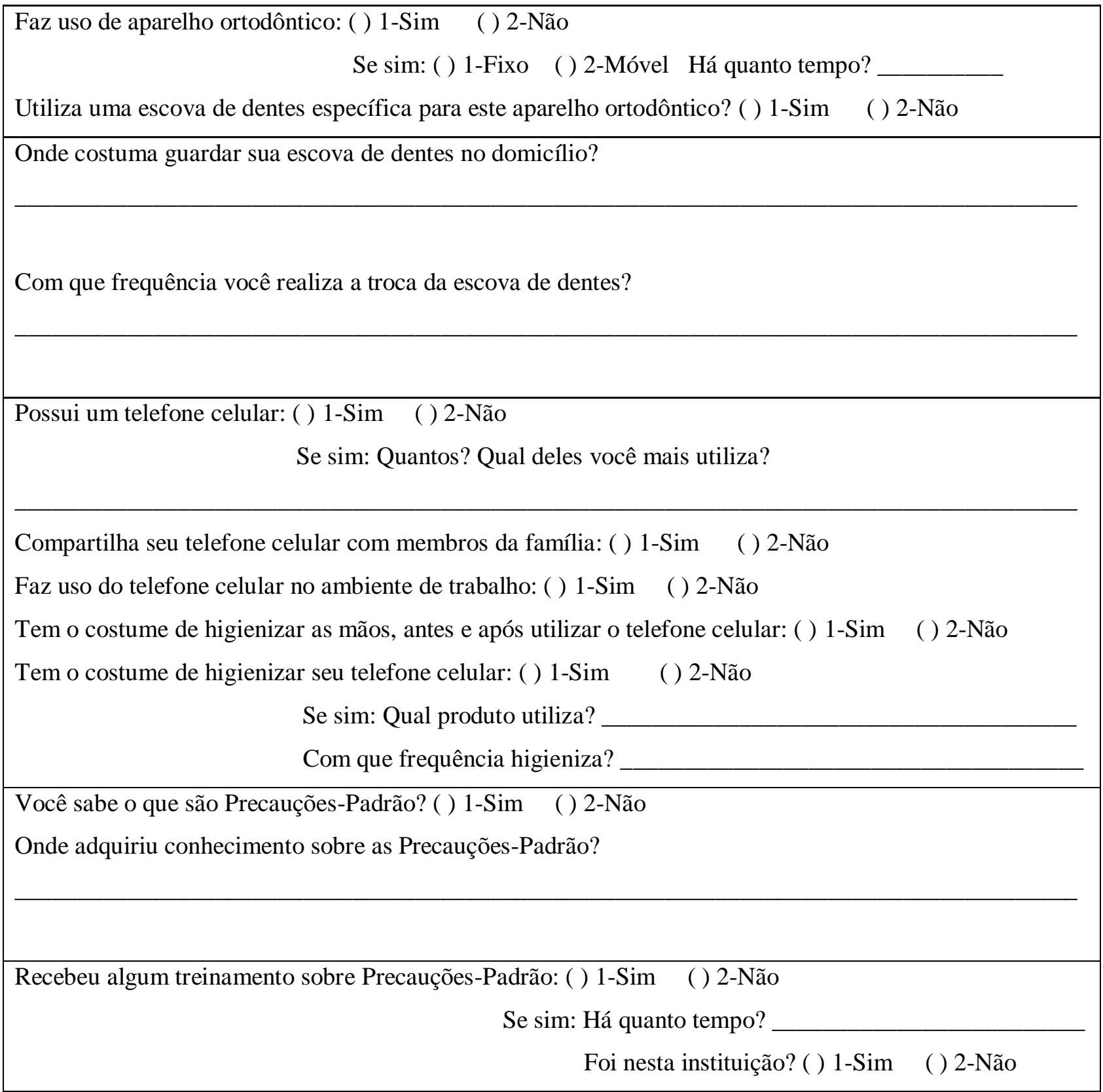


ANEXOS 


\section{ANEXOS}

\section{ANEXO A \\ Aprovação do Comitê de Ética em Pesquisa}

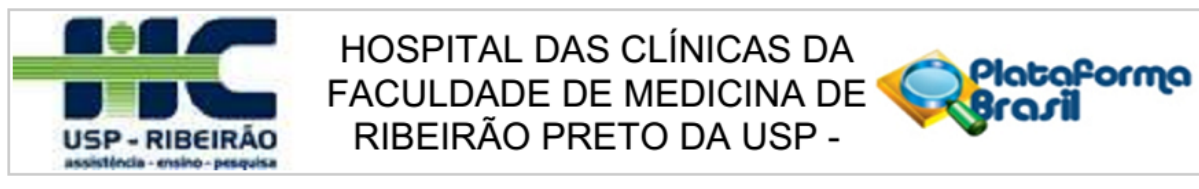

\section{PARECER CONSUBSTANCIADO DO CEP}

Elaborado pela Instituição Coparticipante

\section{DADOS DO PROJETO DE PESQUISA}

Título da Pesquisa: STAPHYLOCOCCUS AUREUS EM PROFISSIONAIS DE ENFERMAGEM E AS INTERFACES COM A ADESÃO ÀS PRECAUÇÕES-PADRÃO

Pesquisador: Letícia Pimenta Lopes

Área Temática:

Versão: 2

CAAE: 20111213.3.3001.5440

Instituição Proponente: Escola de Enfermagem de Ribeirão Preto - USP

Patrocinador Principal: Financiamento Próprio

\section{DADOS DO PARECER}

Número do Parecer: 603.228-0

Data da Relatoria: 06/11/2013

\section{Apresentação do Projeto:}

De acordo com o Parecer da Instituição Proponente.

Objetivo da Pesquisa:

De acordo com o Parecer da Instituição Proponente.

Avaliação dos Riscos e Benefícios:

De acordo com o Parecer da Instituição Proponente.

Comentários e Considerações sobre a Pesquisa:

De acordo com o Parecer da Instituição Proponente.

Considerações sobre os Termos de apresentação obrigatória:

De acordo com o Parecer da Instituição Proponente.

Recomendações:

Não há.

Conclusões ou Pendências e Lista de Inadequações:

O CEP tomou ciência e concorda com o parecer da Instituição Proponente.

Situação do Parecer:

Aprovado

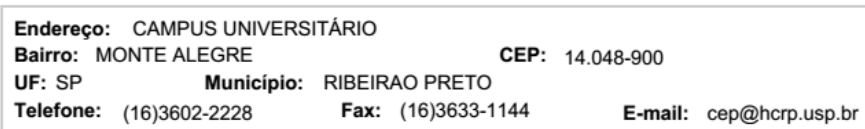




\section{HOSPITAL DAS CLÍNICAS DA \\ FACULDADE DE MEDICINA DE RIBEIRÃO PRETO DA USP -}

Continuação do Parecer: 603.228-0

Necessita Apreciação da CONEP:

Não

Considerações Finais a critério do CEP:

Projeto Aprovado: Tendo em vista a legislação vigente, devem ser encaminhados ao CEP, relatórios parciais anuais referentes ao andamento da pesquisa e relatório final ao término do trabalho. Qualquer modificação do projeto original deve ser apresentada a este CEP em nova versão, de forma objetiva e com justificativas, para nova apreciação.

RIBEIRAO PRETO, 12 de Abril de 2014

Assinador por:

MARCIA GUIMARÃES VILLANOVA

(Coordenador)

Este parecer reemitido substitui o parecer número 603228 gerado na data 22/11/2013 14:34:25, onde o número CAAE foi alterado de 20111213.3.0000.5393 para 20111213.3.3001.5440.

Endereço: CAMPUS UNIVERSITÁRIO

Bairro: MONTE ALEGRE

CEP: $14.048-900$

UF: SP Municipio: RIBEIRAO PRETO

Telefone: (16)3602-2228 Fax: (16)3633-1144 E-mail: cep@hcrp.usp.br 
Projeto de pesquisa: "STAPHYLOCOCCUS AUREUS EM PROFISSIONAIS DE ENFERMAGEM E AS INTERFACES COM A ADESÃO ÃS PREUCAÇŌES-PADRÃO.”

Pesquisador responsável: Leticia Pimenta Lopes e Profa. Dra. Elucir Gir

Instituição Proponente: Escola de Enfermagem de Ribeirão Preto USP

"O CEP do HC e da FMRP-USP concorda com o parecer ético emitido pelo CEP da Instituição Proponente, que cumpre as Resoluções Éticas Brasileiras, em especial a Resolução CNS 466/12. Diante disso, o HCFMRP-USP, como instituição co-participante do referido projeto de pesquisa, está ciente de suas co-responsabilidades e de seu compromisso no resguardo da segurança e bemestar dos sujeitos desta pesquisa, dispondo de infra-estrutura necessária para a garantia de tal segurança e bem-estar.

Ciente e de acordo:

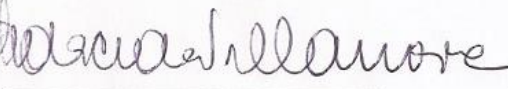
$\mathrm{Dr}^{\mathrm{a}}$ Marcia Guimarães Villanova

Coordenadora do Comitê de Ética em Pesquisa - HCFMRP USP
Prof. Dr. José Alexandre de Souza Crippa

Coordenador Técnico Científico da Unidade de Pesquisa Clínica HCFMRP-USP

\begin{tabular}{lr}
\hline Campus Universitário - Monte Alegre & Comitê de Ética em Pesquisa do HCRP e FMRP-USP \\
14048-900 Ribeirão Preto SP & FWA-00002733; IRB-00002186e \\
Registro Plataforma Brasil/CONEP n० 5440 \\
(016) $3602-2228$ \\
cep@hcrp.usp.br
\end{tabular}

www.hcrp.usp.br 


\section{ANEXO B}

\section{Autorização da Divisão de Enfermagem}

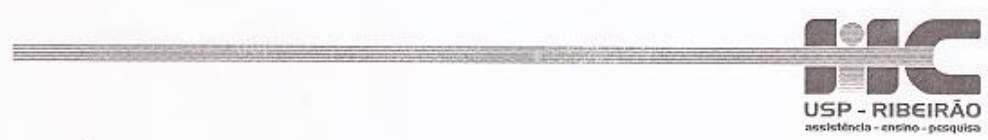

Ribeirão Preto, 15 de julho de 2013

Prezada Professora,

Acusamos o recebimento do projeto de pesquisa intitulado "Staphylococcus aureus em profissionais de enfermagem e as interfaces com a adesão às precauções-padrão", projeto desenvolvido pela doutoranda Leticia Pimenta Lopes, sob orientação da Profa. Dra. Elucir Gir, do Departamento de Enfermagem Geral e Especializada da Escola de Enfermagem de Ribeirão Preto - USP.

Informamos que esta Divisão não vê óbice na realização do referido projeto desde que o funcionário concorde em participar e que não interfira com suas atividades diárias no Setor.

Atenciosamente,

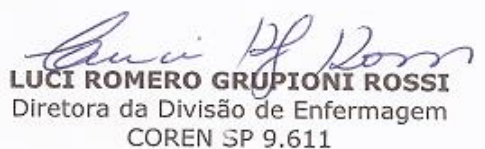

Ilustríssima Senhora

Profa. Dra. Claudia Benedita dos Santos

MD. Coordenadora do Comitê de Ética em Pesquisa da EERP-USP 


\section{ANEXO C}

Escalas traduzidas e validadas por Brevidelli e Cianciarullo (2009)

\section{Secção II}

Indique com que freqüência você realiza as seguintes ações em seu trabalho. Por favor, circule sua resposta.

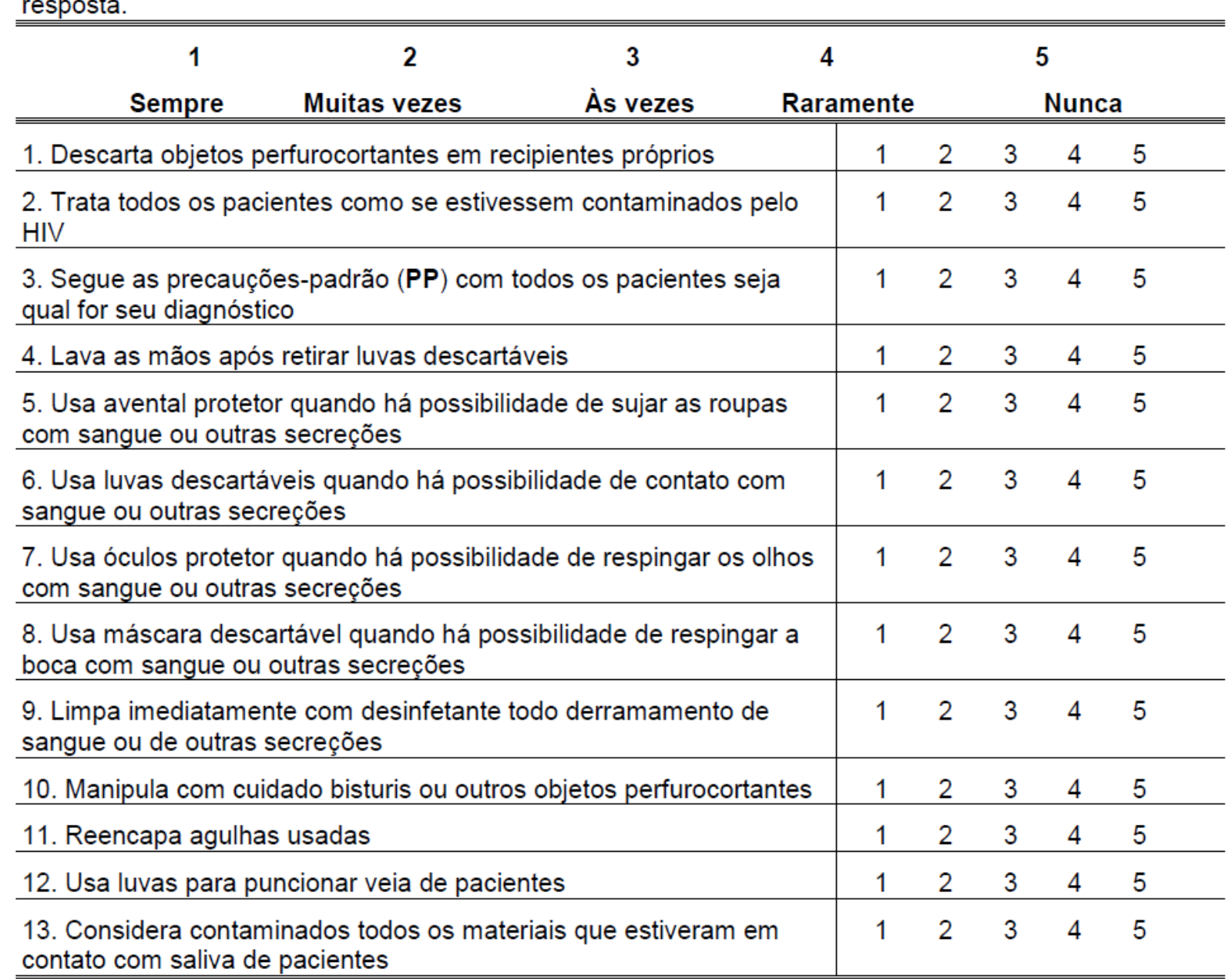

Por favor, indique o grau com que você concorda ou discorda das afirmações seguintes. Circule sua resposta

$\begin{array}{ccccc}1 & 2 & 3 & 4 & 5 \\ \text { Concordo totalmente } & \text { Concordo } & \text { Indeciso } & \text { Discordo } & \text { Discordo totalmente }\end{array}$

1. Eu prefiro uma vida excitante, imprevisível

2. Eu gosto de assumir riscos em minha vida

$\begin{array}{lllll}1 & 2 & 3 & 4 & 5 \\ 1 & 2 & 3 & 4 & 5 \\ 1 & 2 & 3 & 4 & 5 \\ 1 & 2 & 3 & 4 & 5\end{array}$

3 Às vezes, faço coisas perigosas só por emoção

4. Eu prefiro experiências novas e excitantes, mesmo que elas sejam $\quad \begin{array}{lllllll}1 & 2 & 3 & 4 & \end{array}$ perigosas 


\section{Secção III}

Por favor, responda as seguintes questões sobre precauções-padrão (PP) no seu local de trabalho. Circule sua resposta

$\begin{array}{lllll}1 & 2 & 3 & 4 & 5\end{array}$

Concordo totalmente Concordo Indeciso Discordo Discordo totalmente

1. Não consigo me acostumar com o uso de equipamento de proteção na $\quad \begin{array}{lllll}1 & 2 & 3 & 4 & 5\end{array}$ realização de algumas tarefas

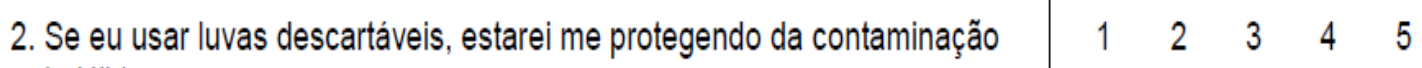
pelo HIV

3. Existe alto risco de me picar com uma agulha contaminada no trabalho

4. As PP não permitem que eu faça meu trabalho da melhor forma

5. Com freqüência, 0 acúmulo de atividades diárias interfere na minha capacidade de seguir as PP

6. Na minha unidade de trabalho, a adesão de funcionários às recomendações das PP faz parte da avaliação de desempenho

7. Eu posso diminuir o risco de me contaminar com o HIV no trabalho se eu seguir as PP

8. Nem sempre posso seguir as PP, pois as necessidades de meus pacientes vêem em primeiro lugar

9. O risco de me contaminar com o HIV no trabalho é baixo

10. Ás vezes, não há tempo suficiente para usar as PP

11. Os funcionários são comunicados quando não seguem as PP

12. Seguir as recomendações das PP torna meu trabalho mais dificil

13. No meu trabalho, estou exposto à contaminação pelo HIV

14. Meu supervisor me apóia no uso das PP

15. Se as PP forem seguidas com todos os pacientes, meu risco de contrair HIVIAIDS é muito baixo 


\section{Secção IV}

Por favor, responda as seguintes questões sobre seu local de trabalho. Circule sua resposta

$\begin{array}{lllll}1 & 2 & 3 & 4 & 5\end{array}$

Concordo totalmente Concordo Indeciso Discordo Discordo totalmente

1. Neste hospital, funcionários, supervisores e gerentes agem em conjunto $\quad \begin{array}{llllll}1 & 2 & 3 & 4 & 5\end{array}$ para garantir condições mais seguras de trabalho

2. A prevenção da exposição ocupacional ao HIV é prioridade da gerência neste hospital

3. Meu hospital oferece treinamento especifico sobre infecções transmitidas por via sanguínea

4. Todos os equipamentos e materiais necessários para evitar meu contato com o HIV estão disponiveis e facilmente acessiveis

5. Neste hospital, todas as medidas possíveis são tomadas para reduzir tarefas e procedimentos perigosos

6. Eu tive oportunidade de ser treinado adequadamente no uso de equipamentos de proteção individual para me proteger da exposição ao HIV

7. Neste hospital, práticas inseguras de trabalho são corrigidas pelos supervisores

8. Neste hospital, a alta gerência se envolve pessoalmente nas atividades de segurança

9. Neste hospital, existe um comitê de segurança

10. Sinto-me à vontade para notificar violações das normas de segurança neste hospital

\section{Meu supervisor preocupa-se com minha segurança no trabalho}

123. Na minha unidade, os chefes incentivam os funcionários a assistir palestras sobre segurança

13. Neste hospital, práticas inseguras são corrigidas pelos colegas

14. Minha unidade de trabalho possui todos os equipamentos e materiais necessários para eu me proteger da exposição ao HIV

15. Os funcionários são ensinados a estarem alertas e reconhecerem riscos potenciais à saúde no trabalho 


\section{Secção V}

O HIV pode ser transmitido a profissionais de saúde ao....

$$
\begin{array}{lllll}
1 & 2 & 3 & 4 & 5
\end{array}
$$

Concordo totalmente Concordo Indeciso Discordo Discordo totalmente

$\begin{array}{llllll}\text { 1. Fazer curativos em pessoa portadora do HIV sem utilizar luvas } & 1 & 2 & 3 & 4 & 5 \\ \text { 2. Puncionar veia de pessoa portadora do HIV sem usar luvas } & 1 & 2 & 3 & 4 & 5 \\ \text { 3. Ter a boca ou os olhos respingados com sangue ou outras secreções de } & 1 & 2 & 3 & 4 & 5\end{array}$
paciente portador do HIV

4. Ter contato com sangue HIV positivo em mãos ressecadas ou rachadas $\begin{array}{llllll}1 & 2 & 3 & 4 & 5\end{array}$

5. Ter se espetado ou se cortado com objetos perfurocortantes $\quad \begin{array}{llllll}1 & 2 & 3 & 4 & 5\end{array}$ contaminados com sangue ou outras secreções

6. Fazer respiração boca-a-boca em paciente portador do HIV sem usar $\quad \begin{array}{lllllll}1 & 2 & 3 & 4 & 5\end{array}$ dispositivo protetor

7. Pressionar local de sangramento de paciente portador do HIV sem usar $\begin{array}{lllllll}1 & 2 & 3 & 4 & 5\end{array}$ luvas

Por favor, indique com que freqüência os seguintes aspectos são exigidos no seu trabalho

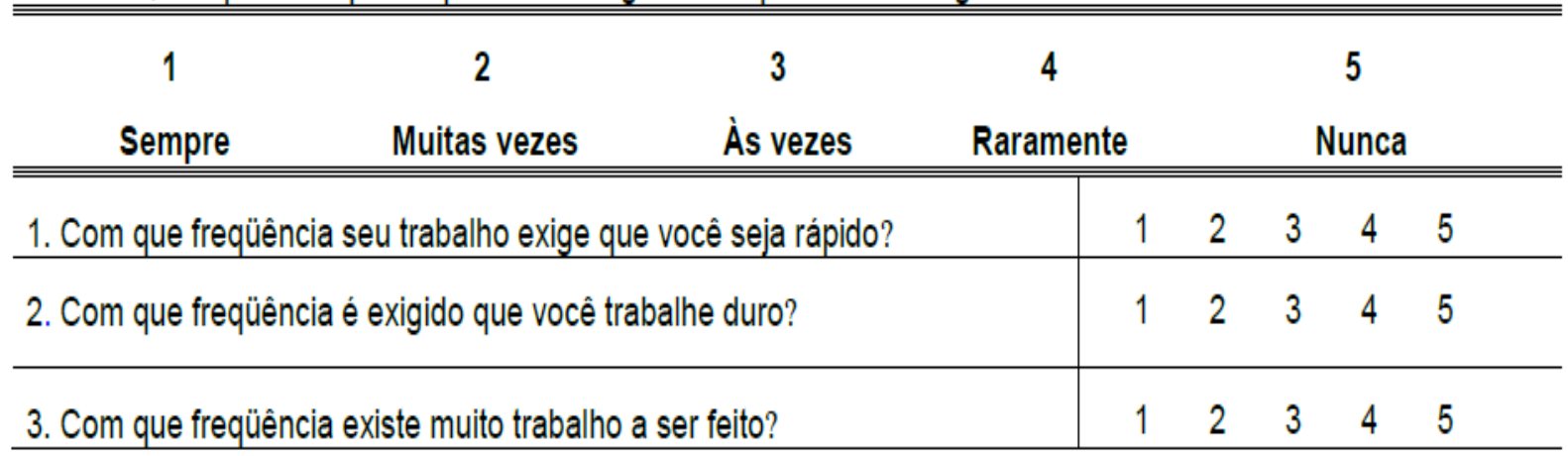




\section{ANEXO D \\ Autorização para utilização das escalas}

De meimei@usp.or

Para Leticia Lopes

Leticia, fique a vontade para usar as escalas em seu trabalho. Fico muito feliz ao ver meu trabalho sendo util.

Profa. Dra. Maria Meimei Brevidelli

Profa. Titular do Curso de Graduação em Enfermagem

Universidade Paulista - UNIP São Paulo

Tel. 11-982782266

De: "Leticia Lopes" <letylopes@yahoo.com.br>

Para: meimei@usp.br

Enviadas: Quinta-feira, 16 de Maio de 2013 14:52:40

Assunto: Autorização para uso das Escalas PP

Prezada Prof Dr² Maria Meimei Brevidelli,

Meu nome é Letícia, sou enfermeira, aluna de doutorado da EERP - USP sob a orientação da Prof Drª Elucir Gir.

Meu projeto de pesquisa tem como objetivo analisar a colonização de Staphylococcus aureus em profissionais de enfermagem $e$ a adesão às

precauções-padrão.

Gostaria de solicitar a autorização para utilizar as Escalas Psicométricas de Gershon et al e DeJoy et al, traduzidas e validadas para o Brasil pela senhora.

Atenciosamente,

Leticia Pimenta Lopes

Doutoranda do Programa de Enfermagem Fundamental da EERP-USP

\footnotetext{
- Re: Permission to use the scale

De Gershon, Robyn R. *

Para Letícia Lopes

cC Robyn Gershon Qi Zhi +
}

Yes of course-when I am back in my office next week I will send - as I am on travel this week Best

Robyn Gershon

On May 16, 2013, at 1:59 PM, "Leticia Lopes" <letylopes@yahoo.com.br> wrote:

Robyn Gershon, MHS, DrPH

My name is Letícia Lopes. I'm a nurse, a doctoral student at the University São Paulo and I'm working in the research group directed by Gir, Elucir, MHS, PhD.

I am writing this message to express my interest in working with the instrument published in the article "Compliance with Universal Precautions among health care workers at three Regional Hospitals" in my study.

My research project aims to analyze the colonization of Staphylococcus aureus in nursing staff and adherence to standard precautions.

I would ask your permission to use the instrument mentioned in my research.

Thank you for your attention, and looking forward to an answer, my best regards.

Letícia Pimenta Lopes, MS 